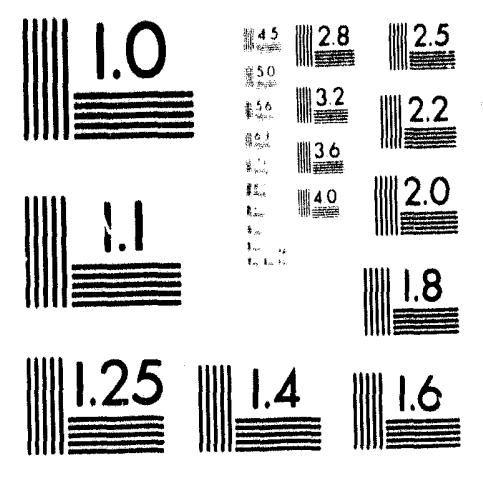



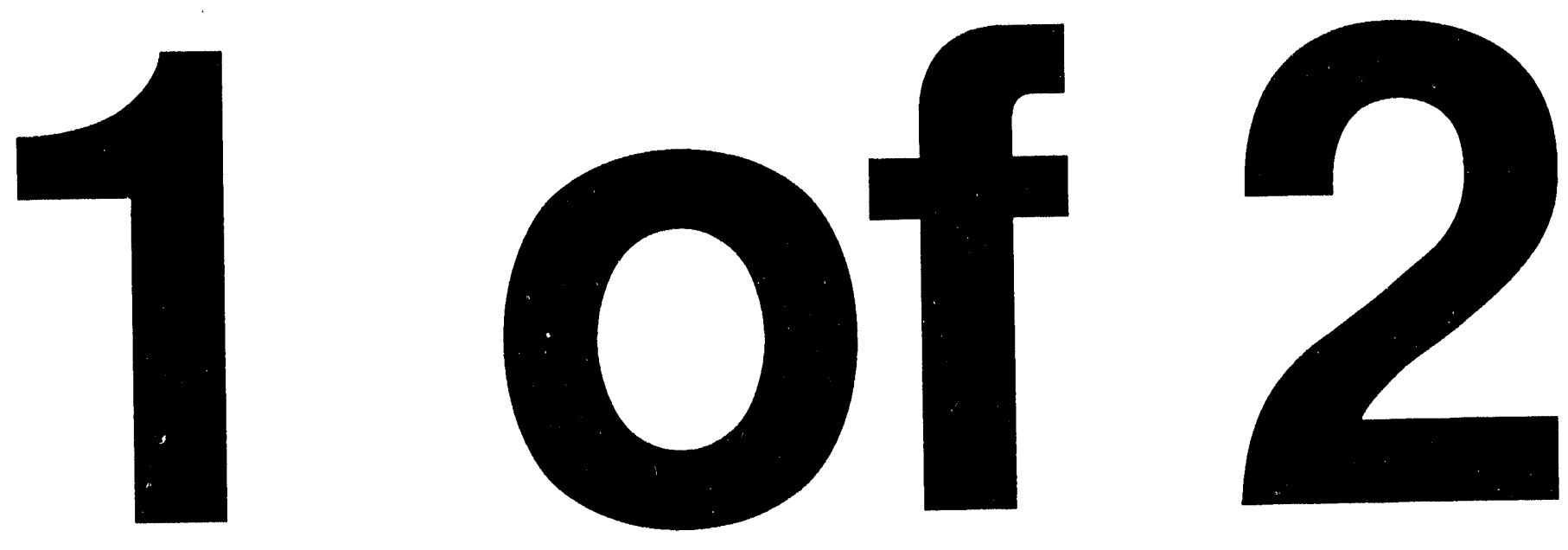


\title{
Conceptual Plan: \\ Two-Phase Flow Laboratory Program for the Waste Isolation Pilot Plant
}

\author{
Susan M. Howarth \\ Fluid Flow and Transport Department 6115 \\ Sandia National Laboratories \\ Albuquerque, NM 87185
}

\begin{abstract}
The Salado Two-Phase Flow Laboratory Program was established to address concerns regarding two-phase flow properties and to provide WIPP-specific, geologically consistent experimental data to develop more appropriate correlations for Salado rock to replace those currently used in Performance Assessment models. Researchers in Sandia's Fluid Flow and Transport Department originally identified and emphasized the need for laboratory measurements of Salado threshold pressure and relative permeability. The program expanded to include the measurement of capillary pressure, rock compressibility, porosity, and intrinsic permeability and the assessment of core damage. Sensitivity analyses identified the anhydrite interbed layers as the most likely path for the dissipation of waste-generated gas from waste-storage rooms because of their relatively high permeability. Due to this the program will initially focus on the anhydrite interbed material. The program may expand to include similar rock and flow measurements on other WIPP materials including impure halite, pure halite, and backfill and seal materials.

This conceptual plan presents the scope, objectives, and historical documentation of the development of the Salado Two-Phase Flow Program through January 1993. Potential laboratory techniques for assessing core damage and measuring porosity, rock compressibility, capillary and threshold pressure, permeability as a function of stress, and relative permeability are discussed. Details of actual test designs, test procedures, and data analysis are not included in this report, but will be included in the Salado Two-Phase Flow Laboratory Program Test Plan pending the results of experimental and other scoping activities in FY93.
\end{abstract}

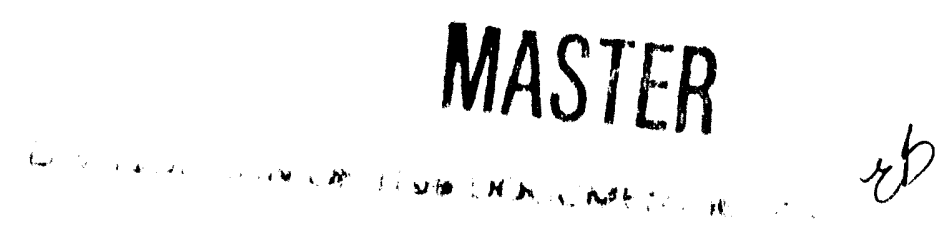




\section{ACKNOWLEDGMENTS}

The author thanks Rick Beauheim and Hans Papenguth for their helpful review comments on this report. The author also appreciates the review of previous drafts of this report by Norm Warpinski, Peter Davies, Ray Ostensen, and Elaine Gorham. In addition, the author thanks the members of the 6100 Salado Two-Phase Flow Laboratory Program Technical Advisory Group for their insightful and useful ideas and suggestions for the test program. Finally, the author would like to thank Ed Lorusso and Sally Woerner (Tech. Reps., Inc.) for their help in getting this document into final form. 


\section{CONTENTS}

1.0 SUMMARY $\ldots \ldots \ldots \ldots \ldots \ldots \ldots$

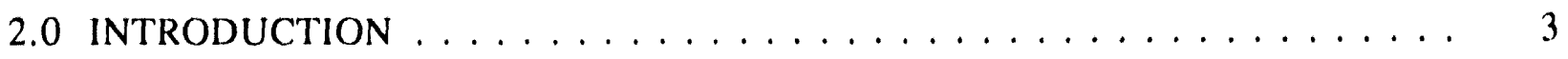

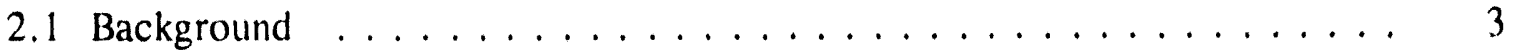

2.2 Rationale ............................ 8

2.3 Related Work ........................... 11

2.3.1 Sensitivity Studies $\ldots \ldots \ldots \ldots 11$

2.3 .2 Laboratory Studies . . . . . . . . . . . . . . . . . . . . . . . . . . . . . . . . .

2.3 .3 Field Studies . . . . . . . . . . . . . . . . . . . 15

3.0 PROGRAM DEFINITION $\ldots \ldots \ldots \ldots \ldots \ldots \ldots$

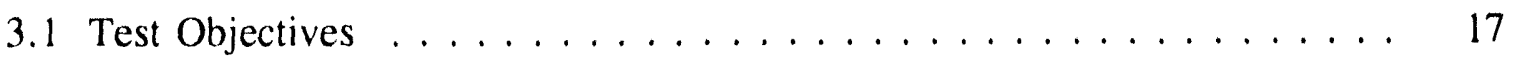

3.1.1 FY92: Determination of Program Needs-Scoping Activities . . 17

3.1.2 FY93: Determination and Evaluation of Test MethodsPreliminary Experimental Activities .............. 18

3.1.3 FY94-FY97: Testing Program-Experimental Activities/Analyses 18

3.2 Program Scope . . . . . . . . . . . . . . . . . . . . . 19

3.2.1 FY92: Determination of Program Needs-Scoping Activities . . 19

3.2.2 FY93: Determination and Evaluation of Test MethodsPreliminary Experimental Activities .............. 21

3.2.3 FY94-FY97: Testing Program - Experimental Activities/Analyses 25

3.3 Measurement Systems . . . . . . . . . . . . . . . . . 25

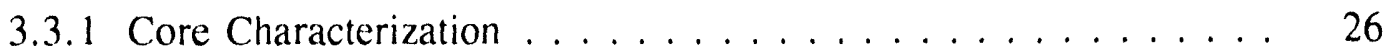

3.3 .2 Core Damage Assessment . . . . . . . . . . . . . 27

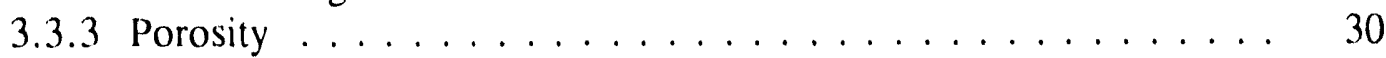

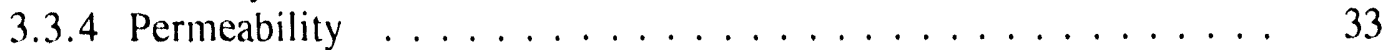

3.3.5 Capillary and Threshold Pressure . . . . . . . . . . . . . 39

3.3 .6 Relative Permeability . . . . . . . . . . . . . . . . . 45

3.3.7 Rock Compressibility and Effective Stress . . . . . . . . . . . 49

3.4 Program Milestones $\ldots \ldots \ldots \ldots \ldots \ldots \ldots$

4.0 SITE SUPPORT $\ldots \ldots \ldots \ldots \ldots$ 


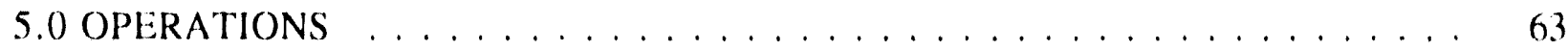

5.1 Personnel Responsibilities (Delegation of Authority) . . . . . . . . 63

5.1 .1 Site Operations Test Activities . . . . . . . . . . . . 63

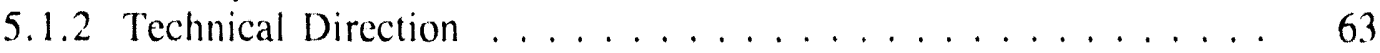

5.1 .3 WIPP Quality Assurance Chief ............... 64

5.2 Test Schedule ... . . . . . . . . . . . . . . . . . . 65

5.3 Operational Safety and Environment . . . . . . . . . . . . . 65

5.3 .1 Safety Requirements . . . . . . . . . . . . . . . 65

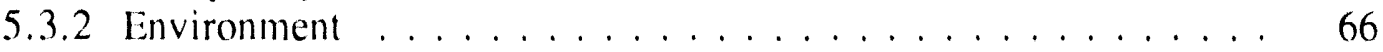

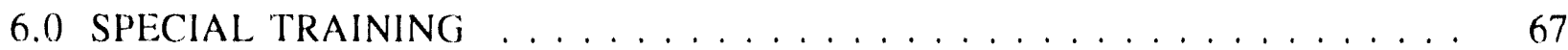

7.0 TEST MANAGEMENT $\ldots \ldots \ldots \ldots \ldots \ldots$

7.1 Test Plan Review and Approval . . . . . . . . . . . . . . . . . . . . 69

7.2 Management Interface . . . . . . . . . . . . . . . . . . . . 69

7.3 Procurement Procedures . . . . . . . . . . . . . . . . . . . 70

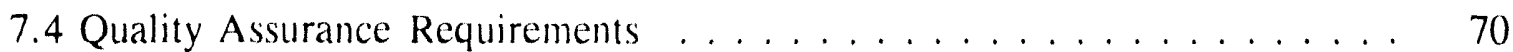

7.5 Data Transter . . . . . . . . . . . . . . . . . . . 71

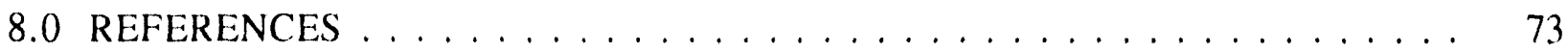

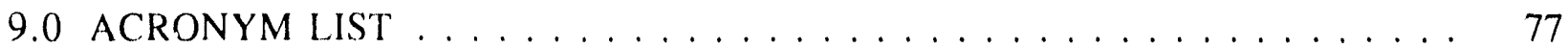

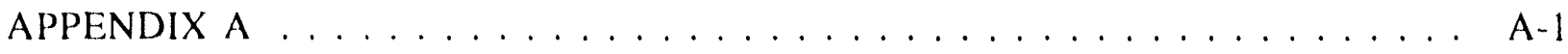

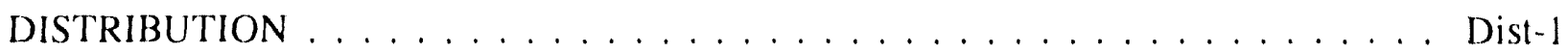




\section{Figures}

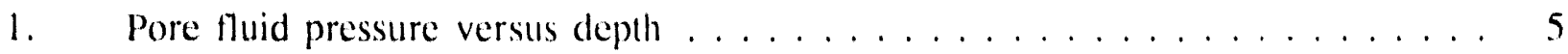

2. Capillary pressure versus saturation $\ldots \ldots \ldots \ldots \ldots$

3a. Plot of correlation of threshold pressure with intrinsic permeability for a composite of data from all consolidated rock lithologies . . . . . . . . . . 12

b. Plot summarizing estimated threshold pressure for various lithologic units in the Salado Formation based on correlation with intrinsic permeability . . . . . 13

4. Salado Two-Phase Flow Laboratory Program road map . . . . . . . . . . . . . . 20

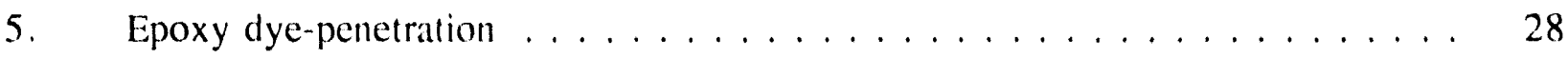

6. CT scanning of $\mathrm{MB} 139$ cores $\ldots \ldots \ldots \ldots$

7. Permeability versus reciprocal mean pressure . . . . . . . . . . . 36

8. Schematic of porous-plate method of capillary pressure . . . . . . . . . . 43

9. Relative permeability as a function of saturation . . . . . . . . . . 46

10. Salado Two-Phase Flow Laboratory Program tentative schedule and milestones 55

\section{Tables}

1. Experimental Data from Permeability Testing of Anhydrite Interbeds . . . . . 6

2. Summary of FY92 Scoping Activities . . . . . . . . . . . . . . . . 57

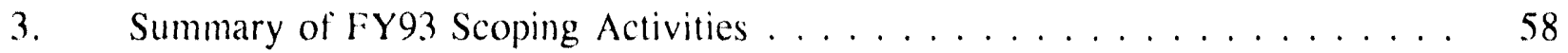

4. Summary of FY93 Program Development Activities . . . . . . . . . . . . . 58

5. Summary of FY93 Experimental Scoping Activities . . . . . . . . . . . . . 59 


\subsection{SUMMARY}

The Salado Two-Phase Flow Laboratory Program was established in January 1992 to measure threshold pressure and relative permeability for Salado rock in the laboratory. FY92 scoping activities focussed on investigating Waste Isolation Pilot Plant (WIPP) program needs in the area of two-phase flow and assessing current laboratory measurement technology. As a result of the FY92 scoping activities, the Salado Two-Phase Flow Laboratory Program was expanded to include measurement of capillary pressure, single-phase permeability as a function of stress, total and effective porosity, rock compressibility, and the investigation of coringinduced damage in addition to threshold pressure and relative permeability. FY93 experimental scoping activities are designed to characterize the Salado anhydrite rock and measure singlephase flow properties in the laboratory. Information gained from these initial tests will be used to design and implement two-phase flow moasurement tests including threshold pressure, capillary pressure, and relative permeability scheduled to begin in FY94. These measurements support the development of the numerical models used to predict the long-term hydrologic and structural response of the WIPP repository to waste-generated gas, an activity critical for assessing the long-term performance of the repository.

This report presents the scope, objectives, and milestone schedule for the Salado TwoPhase Flow Laboratory Program. In addition, this report documents the development of the Salado Two-Phase Flow Program through January 1993. Current laboratory techniques for assessing core damage and measuring porosity, capillary and threshold pressure, permeability, rock compressibility, and relative permeability are also discussed. Research and experimental scoping activities will continue throughout FY93 to determine the specific experiments to be performed. Details of actual test designs and procedures for each experiment and data analysis are not included in this report, but will be included in the Two-Phase Flow Laboratory Program Test Plan. 


\subsection{INTRODUCTION}

\subsection{Background}

The WIPP is the U.S. Department of Energy's (DOE's) planned repository for transuranic waste generated by our nation's defense programs. This underground research and development effort is generating the technology base for the safe disposal of radioactive wastes in bedded salt. The Salado Formation was chosen for the repository because of salt's natural ability to creep under the effects of stress and ultimately to encapsulate and isolate the waste. A significant part of this effort is to develop a numerical capability to predict the hydrologic and structural response of a bedded salt repository, an activity critical for assessing the long-term performance of the facility.

The Salado Formation consists of thick halite layers with interbeds of minerals such as clay and anhydrite. The polycrystalline Salado salt contains small quantities of brine in intragranular fluid inclusions and as intergranular (pore) fluid. The anhydrite interbed layers also contain small quantities of brine. It is important to quantify the amount of brine in the Salado Formation and determine its mobility and flow properties because the accumulation of significant quantities of brine in the repository could potentially lead to problems that affect the salt's ability to isolate waste. One such problem is gas generation from the microbial degradation of organic waste and anoxic corrosion of steel drums and metallic waste in the presence of brine. Waste-generated gas may be produced in quantities sufficient to reach high pressures and retard the natural flow or creep effects of the salt. Potential negative impacts of high room pressure are that (1) waste-generated gas may serve as an additional driving force and push contaminated brine far out into the formation, and (2) the high pressure may fracture the formation and result in increased permeability of the transport pathways.

From a technical point of view, we need to quantify the Salado rock and flow parameters that describe its ability to transmit and store fluids as a function of the initial conditions and 
time-dependent material damage. For example, permeability data from in situ tests indicate that the anhydrite and impure halite interbeds within the Salado Formation have higher permeability, by 1 to 2 orders of magnitude, than the pure halite intervals. Sensitivity analyses show that the anhydrite interbeds could be the primary inward flow path for brine to the repository and outward flow path for waste-generated gas into the formation (Davies et al., 1991). Thus, the role of the anhydrite marker beds in the long-term hydrological response of the WIPP facility has become an issue that revolves around (1) the initial state of the material, (2) the mechanism(s) and potential for brine and gas flow in the material, and (3) the influence of excavation-induced damage on these flow parameters (if only to be able to separate damaged from undamaged behavior). There are a number of laterally continuous anhydrite interbeds within the Salado Formation in the vicinity of the repository horizon including Marker Beds 1.38 and 139 and anhydrites "a" and "b."

One anhydrite interbed that forms a potential gas flow path is the 1 -meter (m) thick Marker Bed (MB) 139, which lies approximately $1 \mathrm{~m}$ below the planned waste storage rooms. MB 139 is one of about 45 siliceous or sulfatic units within the Salado Formation consisting of polyhalitic anhydrite. Permeability values of $5 \times 10^{-17}$ to $8 \times 10^{-21} \mathrm{~m}^{2}$ have been inferred from eight in situ borehole tests in MB 139 (Davies et al., 1992). To date, laboratory examination and testing of the anhydrite interbed material is extremely limited.

The flow of waste-generated gas from the repository is predicted to be controlled by three physical properties of the surrounding rock (Davies, 1991): (1) pore fluid pressure, (2) threshold displacement pressure, and (3) gas-brine relative permeability. Flow of wastegenerated gas into the Salado Formation surrounding the repository will occur only when the gas pressure $\left(\mathrm{P}_{\mathrm{gus}}\right)$ in the repository exceeds the sum of the formation near-field pore fluid pressure $\left(P_{p}\right)$ and the formation's threshold pressure $\left(P_{t}\right)$ as described in Equation 1. This pressure, $P_{\text {gas }}$, is termed the gas-threshold displacement pressure.

$$
P_{\text {gas }}>P_{p}+P_{t}
$$


Pore fluid pressure $\left(P_{p}\right)$, also referred 10 herein as pore pressure, is delined as the pressure of the fluid (brine) within the rock's pore space. The pore Muid pressure in the undisturbed regions of the Salado formation is expected to range between hydrostatic and lithostatic, 6.4 MPa (pure water, $1 \mathrm{gm} / \mathrm{cm}^{\prime}$ ) to $14.8 \mathrm{MPa}$ (rock, $2.32 \mathrm{gm} / \mathrm{cm}^{\prime}$ ), because the pore fluid may partially support the load of the $655 \mathrm{~m}$ of rock overlying the repository (Figure 1). Pore pressure inferred from in situ permeability test data in the Salado far-field and undisturbed regions ranges from 9.5 to $12.6 \mathrm{MPa}$ (see Appendix A). As expected and exhibited in Group 2 shown in Table 1, pore pressures measured in the depressurized and disturbed regions are significantly lower because of flow into the repository, excavation-induced stress changes, and possible dilatation effects (Davies, 1991; Davies et al., 1992).

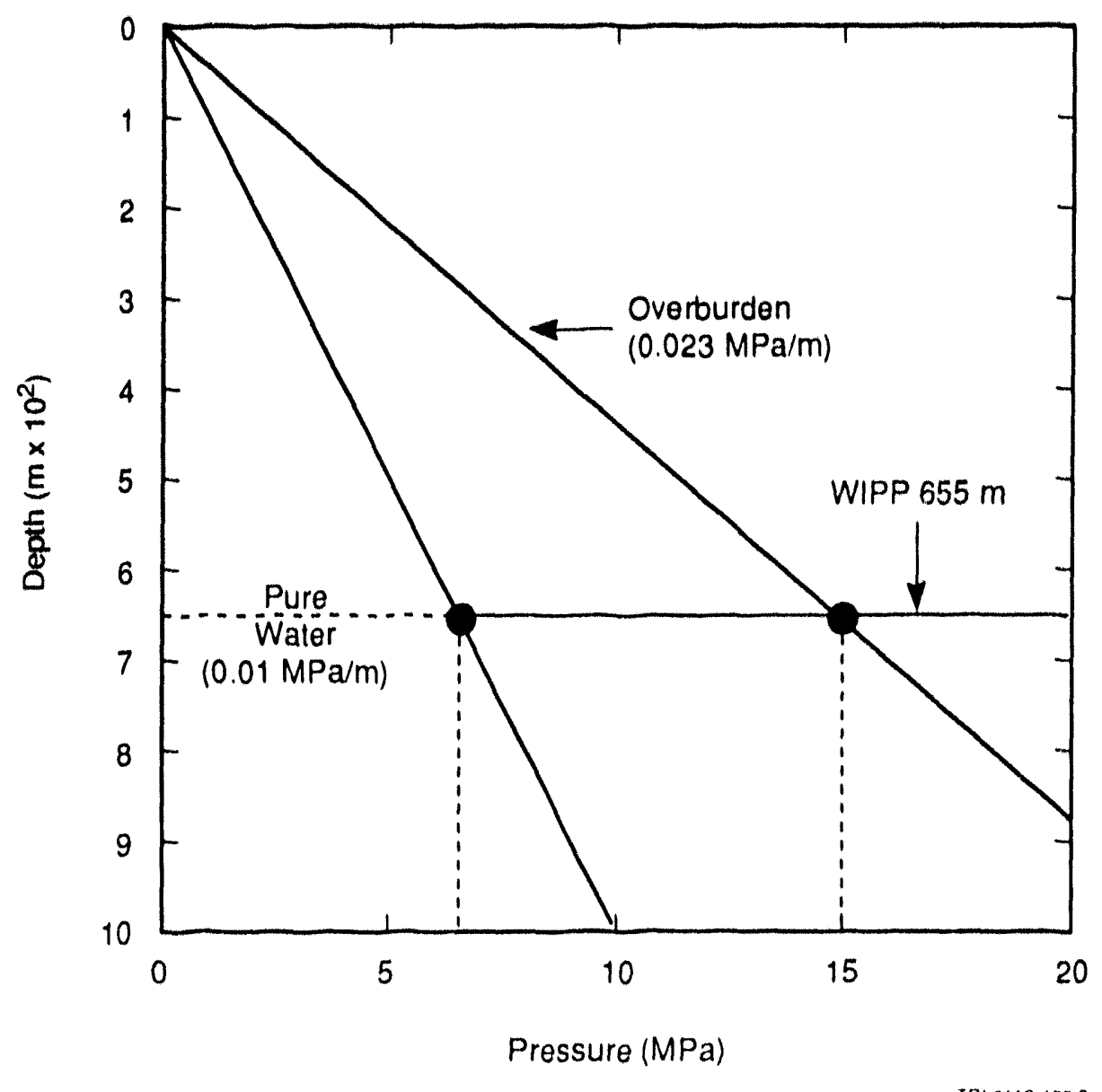

Figure 1. Pore thuid pressure versus depth. 
Table 1. Experimental Data from Permeability Testing of Anhydrite lanterlods (1)avies of al. 1992)

\begin{tabular}{|c|c|c|c|}
\hline Test & Iniit & Normeatiliny (m) & 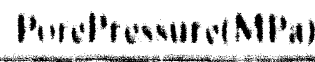 \\
\hline SCPOI & $M|3| 34$ & $10 \times 10^{\prime \prime}$ & 124 \\
\hline QPPIS & Preminchy M13130 & $+1 \times 10^{*}$ & 129 \\
\hline QPPOB & Pre-minehy anhydrite " $h "$ & $4.4 \times 10^{*}$ & 12.6 \\
\hline
\end{tabular}

\begin{tabular}{|c|c|c|c|}
\hline Tes & Unit & Permeshility (In) & Pindelfenure(Alla) \\
\hline $\mathrm{C} 2 \mathrm{HO} 2$ & $M B 134$ & $7.8 \times 10^{\prime \prime}$ & 91 \\
\hline $1.41 .51 \cdot 13$ & Anhydrile "c" & $50 \times 10^{\prime \prime}$ & $\$ 1$ \\
\hline$S|P 7|-13$ & Anliydrite "ঃ" & $68 \times 10^{*}$ & +0 \\
\hline $\mathrm{C} 2 \mathrm{HO}) \mathrm{C}$ & $M|B| 34)$ & $95 \times 10 \%$ & so \\
\hline$(1 \times 10$ & $M B(30$ & $50 \times 10$ & 71 \\
\hline QPP03 & Anhydrilu "h" pust minchy & $7.9 \times 10^{11}$ & 70 \\
\hline QPPI.3 & MB139) pust-minuthy & $4.7 \times 10^{\prime \prime}$ & 81 \\
\hline$L 41552 \cdot A$ & Anliydrite "a" & $1.0 \times 10^{\circ}$ & 64 \\
\hline OPBOI & $M(11,39$ & $90 \times 10:$ & 50 mumumed \\
\hline QPBO2 & $M(3131)$ & $10 \times 10^{11}$ & 50 ansulmed \\
\hline QPBO3 & $M B 13^{\prime \prime}$ & $1.2 \times 10^{71}$ & 50 assumbed \\
\hline
\end{tabular}


Cias llireshold displacement pressure $\left(P_{k n s}\right)$ is defined as the minimum pressure at which a ninwelling phase fluid (wasle generaled gas) can overcome pore pressure and capillary effects, snlet a $l(x)$ percent welling-phase-fluid saturated porous medium, and cause displacement of the netling pliase huid (brinc in the Salado formation). Capillary effects are quantified as capillary preswere (l'), which for high-permeability rocks, is typically measured directly on core samples In the laboratory.

Threshold pressure $\left(P_{1}\right)$ is related to the capillary-pressure characteristic curve as shown in ligure 2 and is defined as either (1) the endpoint pressure on the capillary pressure-versuswelling phase salluration curve corresponding to a wetting-phase saturation of 1.0 , or (2) the prewure oll the capillary pressure-versus-wetling-phase saturation curve corresponding to the nonwelling phase critical saluration. The first definition applies to initial penetration of the Inowwelling phase fluid into the welting-phase saturated porous medium; the second applies to Ihe development of a nonwelling phase continum through the core and initial breakthrough of noinwelling phase Muid (1)avies, 1991).

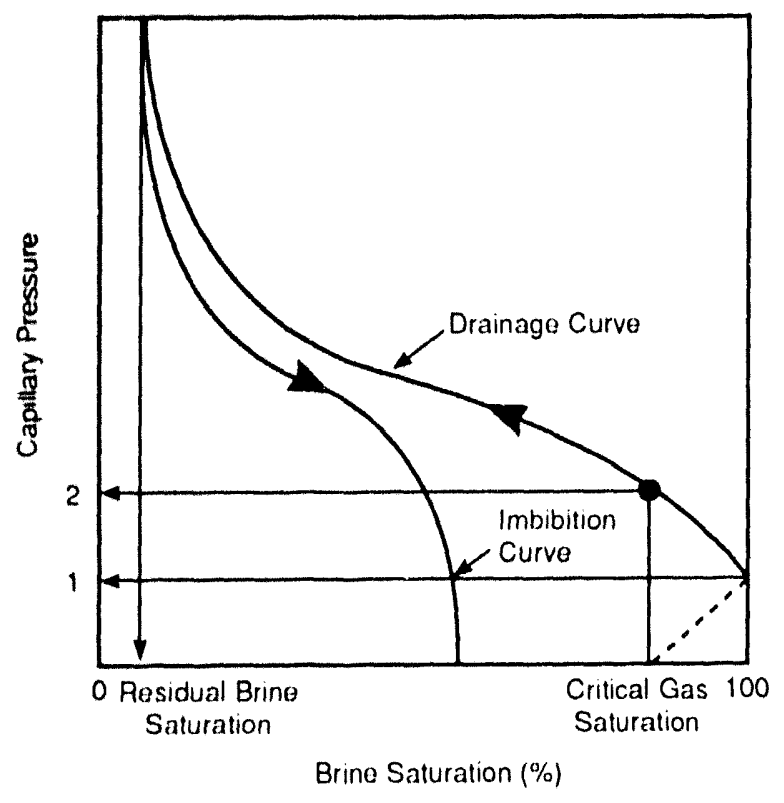

ligure 2. Capillary pressure versus saturation. 
Whereas absolute or intrinsic permeability $(\mathrm{k})$ is a measure of the rate at which a single fluid will flow through interconnected pores (single- or one-phase flow), relative permeability relationships must be considered when evaluating flow properties of more than one fluid in porous media. Relative permeability $\left(k_{r}\right)$ compares the rate at which a fluid will move through interconnected pore space when another fluid is present: gas flowing in the presence of brine. Relative permeability is especially important in WIPP performance-assessment calculations because prediction of repository behavior, such as brine inflow to repository rooms and gas outflow to the formation, is strongly dependent upon this parameter.

\subsection{Rationale}

Pore pressure is measured in situ as part of the Large-Scale Brine Inflow Experiment (Room Q) and the Permeabiiity Testing Program, and preparations are being made for the first in situ threshold pressure test. However, neither threshold pressure nor relative permeability has been measured on Salado cores in the laboratory, so the Brooks and Corey (1964) and Parker et al. (1987) correlations are used in the current WIPP Performance Assessment (PA) models for these parameters. These two models are based upon capillary pressure relationships from which weting-phase relative permeability is derived (Webb, 1992).

The Brooks and Corey (1964) relationship for capillary pressure (Equation 2) is expressed below in terms of effective saturation, $S_{e}$; threshold pressure, $P_{1}$ at $S_{c}=1.0$; and pore-size distribution parameter, $\lambda$. Effective saturation is a function of the wetting-and nonwetting-phase fluid saturations, $S_{w}$ and $S_{n w}$, and the wetting- and nonwetting-phase fluid residual saturations, $S_{w, r}$ and $S_{n w, r}$.

$$
P_{C}=\frac{P_{t}}{S_{e}^{1 / \lambda}}
$$


where

$$
S_{\theta}=\frac{S_{w}-S_{w, r}}{1-S_{n w, r}-S_{w, x}}
$$

The Brooks and Corey (1964) correlation is intended for use only over that portion of the capillary pressure curve where $P_{c}$ is greater than the pressure corresponding to $S_{e}=1.0$.

Similarly, the Parker et al. (1987) relationship for capillary pressure (Equation 4) is expressed in terms of a reference pressure, $\mathrm{P}_{\mathrm{o}}$; effective saturation, $\mathrm{S}^{*}$; and a pore-size distribution parameter, $m$. The Parker et al. (1987) equation differs from the Brooks and Corey (1964) equation in that the former assumes that threshold pressure is zero and effective saturation is a function of the minimum wetting-phase saturation, $S_{w, m}$. All other terms are the same as those defined for the Brooks and Corey (1964) relationship.

$$
P_{C}=P_{0}\left(S^{*-1 / m}-1\right)^{1-m}
$$

where

$$
S^{*}=\frac{S_{w}-S_{w, r}}{S_{w, m}-S_{w, r}}
$$

Both the Piooks and Corey (1964) and Parker et al. (1987) correlations used in current WIPP PA numerical models were developed using data from one core sample analyzed for the Tight Gas Sands project. The pore-size distribution parameter, $\lambda$, and residual non-wetting phase saturation are based upon data from a single core, MWX-3 67-35, described in Rechard et al. (1990) and Morrow et al. (1986). Other input values to these models include threshold pressure, residual wetting-phase saturation, and minimum wetting-phase saturation. 
None of the input values to the Brooks and Corey (1964) and Parker et al. (1987) correlations has been measured for the Salado Formation rock. The validity of using correlations based on tight gas sands data to predict Salado threshold pressure, capillary pressure, and relative permeability has not been experimentally justified; the tight gas sands data are simply the closest analog for which detailed data are available. In addition, detailed laboratory measurements of anhydrite capillary pressure and relative permeability made over a wide range of saturations would support interpretation of the in situ permeability tests.

Uncertainty in expected threshold displacement pressure values for the Salado Formation is large, and estimates range from 0.5 to $50 \mathrm{MPa}$ depending upon lithology (Davies, 1991). This wide range of values may prevent a clear prediction of repository behavior in both the undisturbed and human-intrusion WIPP PA scenarios. Credibility of the two-phase hydrologic modeling in support of PA relies on measurement of this sensitive Salado Formation parameter. Threshold displacement-pressure measurements in the laboratory and/or field will provide data to support the development and evaluation of Salado models and performance-assessment calculations.

In summary, the work of both Davies and Webb emphasized the need for investigating and measuring capillary and threshold pressure and relative permeability of Salado rock. Subsequent scoping activities showed that other related parameters including porosity, rock compressibility, and intrinsic permeability should also be measured to support WIPP Performance Assessment and Fluid Flow and Transport numerical modelers and analysts. The anhydrite interbed layers were identified as the most likely path for the dissipation of wastegenerated gas from waste storage rooms because of their relatively high permeability and likely low threshold displacement pressure. In addition to the interbed layers, two-phase measurements may be needed for impure halite, pure halite, backfill material, and possibly seal material. 


\subsection{Related Work}

The primary objective of this test program is to measure two-phase flow properties for the anhydrite interbeds at WIPP. To make these measurements properly, fundamental rock properties, including porosity, rock compressibility, and intrinsic (single-phase) permeability, should first be measured and the issue of coring-induced damage should be addressed. Work associated with the WIPP in areas pertinent to those described in this conceptual plan include sensitivity studies, laboratory studies, and field studies.

\subsubsection{Sensitivity Studies}

The combined effect of waste-generated gas and high gas-threshold displacement pressure in the Salado was identified as a WIPP PA issue by John Bredehoeft and George Hornberger at the June 1989 National Academy of Sciences (NAS) WIPP Panel Meeting (Davies, 1991). In response to concerns that waste-generated gas pressure might exceed lithostatic pressure and cause unpredictable fracturing, Davies (1989) provided threshold pressure estimates and preliminary two-phase waste-gas and brine-flow simulations. In their September 1990 presentation to the NAS, Davies et al. (1990) identified two-phase properties of Salado interbeds and sensitivity to these properties as important sources of uncertainty that may affect room pressurization.

Davies (1991) followed with a report evaluating the role of threshold pressure in controlling the flow of waste-generated gas into the Salado Formation. In that report, he provided estimates of Salado threshold pressure as a function of lithology, and as shown in Figure 3a and b, he found that threshold pressure increases with decreasing permeability. Davies identified the nonhalite interbeds as the likely dominant flow paths for waste-generated gas from a pressurized repository because of their relatively high permeability and correspondingly low gas threshold pressure. In providing estimites for Salado threshold pressure, he cautioned that the values were based upen intormation for nonsilt rock types and 
that they "must be confirmed with in situ or laboratory measurements that are specific to the Salado Formation at the WIPP repository" (Davies, 1991).

Webb (Davies et al., 1991) performed sensitivity analyses to determine the effect of formation permeability, two-phase (relative permeability and capillary pressure) characteristic curves, and other variations on the long-term performance of the repository. In particular, he focussed upon identifying the dominant variables influencing pressurization of the repository and gas migration distance. Webb found that relative permeability and the residual saturation can have a dramatic effect on the gas migration distance. Likewise, he found that formation permeability can have a dramatic effect upon peak room pressure.

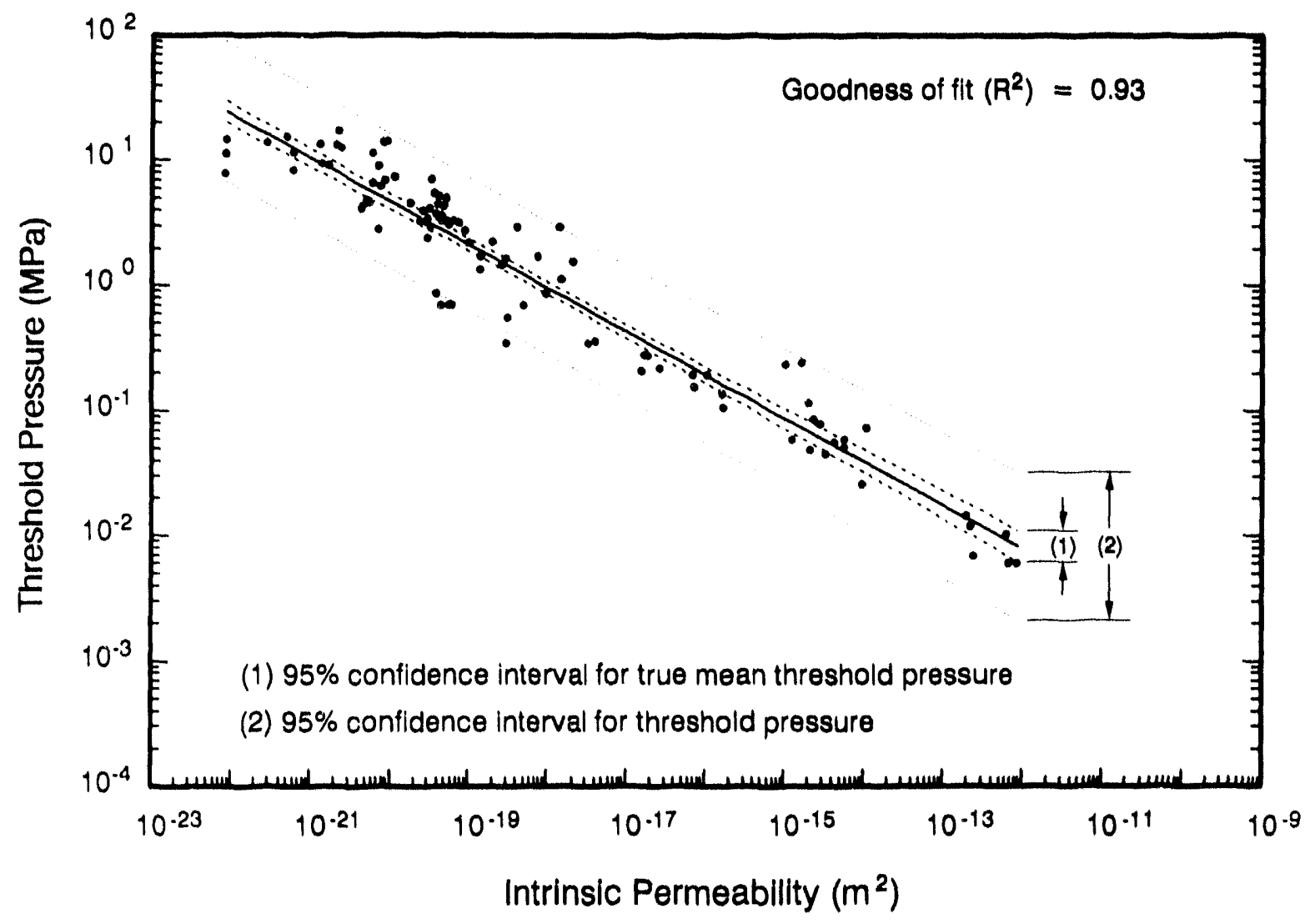

TRl.6344.730.0

Figure 3a. Plot of correlation of threshold pressure with intrinsic permeability for a composite of data from all consolidated rock lithologies (Davies, 1991). 


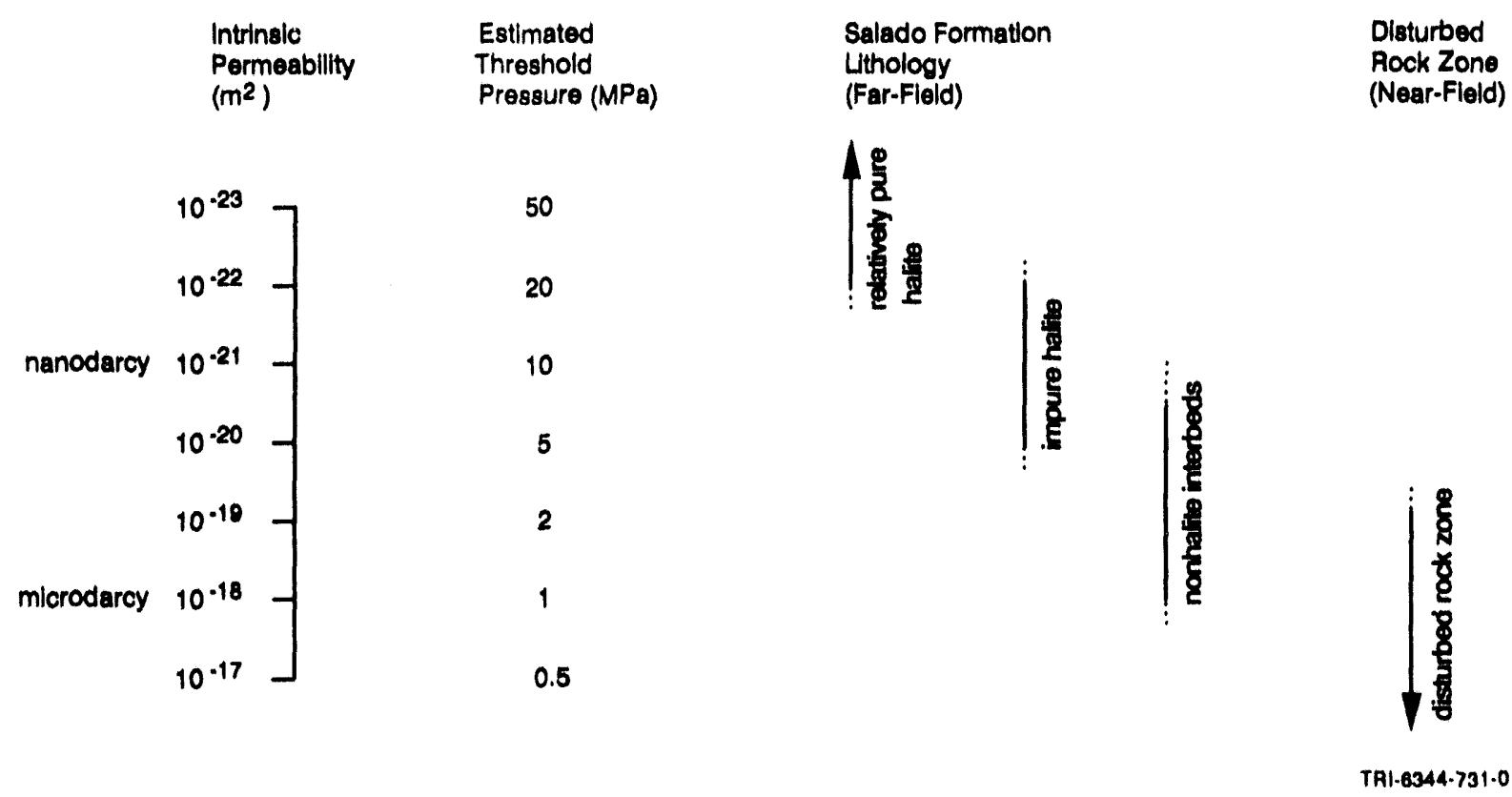

Figure $3 \mathrm{~b}$. Plot summarizing estimated threshold pressure for various lithologic units in the Salado Formation based on correlation with intrinsic permeability (Davies, 1991).

\subsubsection{Laboratory Studies}

Characterization of core damage, fractures, porosity, permeability, relative permeability, and capillary and threshold pressure are performed routinely in the laboratory. The techniques used to make these laboratory assessments were developed to support the petroleum industry in providing data to quantify oil and gas reserves and optimize reservoir productivity. In 1960, the American Petroleum Institute (API) set standards and guidelines for measuring porosity and intrinsic permeability on rock core samples. While these original standards for measuring rock and single-phase flow properties are being updated as a result of technological advances, the revised guidelines are not expected to include any references to relative permeability, threshold pressure, or capillary pressure measurements. The Society of Core Analysts (SCA) recognized this oversight and initiated a program in 1992 to establish guidelines for laboratory measurement of threshold and capillary pressure and relative permeability. The SCA study is still in progress, and guidelines have not been published. 
Because no formal standards or guidelines exist for measuring threshold and capillary pressure or relative permeability, especially in low-permeability media, it is necessary to evaluate current laboratory techniques for these measurements to determine the most appropriate one(s) to use within the scope of the Two-Phase Flow Laboratory Program. Investigation and determination of appropriate methods for making these measurements will be addressed in two separate reports: (1) Evaluation of Experimental Techniques to Measure Threshold Pressure for the Salado Formation Anhydrite Interbeds at the Waste Isolation Pilot Plant, and (2) Evaluation of Experimental Techniques to Measure Relative Permeability for the Salado Formation Anhydrite Interbeds at the Waste Isolation Pilot Plant. Laboratory techniques under consideration for assessing core damage and measuring single- and two-phase rock and flow properties within the scope of the Salado Two-Phase Flow Program are discussed in Section 5.0.

\subsubsection{LABORATORY PERMEABILITY TESTS ON ANHYDRITE INTERBED MATERIAL}

The only permeability tests performed on Salado anhydrite interbed material to date were done as part of the Site Validation Experiments in 1983 (Black et al., 1983). (ias permeability (single-phase) measurements were made on three anhydrite core samples in the laboratory at the Waterways Experiment Station, U.S. Army Corps of Engineers, Vicksburg, MS. All three cores (HPC 1, HPC 2, and HPC 3) were laken from a single hole, approximately 64-cm deep, located in the outer rib of the b:140) drift at the WIPP. The report describes the material only as "interbed" and reveals nothing in terms of specific stratigraphic unit or mineralogy. The 5 -cm-diancter cores were drilled using a diamond core bit and brine as the drilling thuid, with the axis of the core cut parallet to the bedding plane of the interbed layer. The core was cul inlo three $15-1024 \cdot \mathrm{cm}$ - long cylindrical simples, and lests were performed in a Hassler-type permeahility cell using nitrogen an the llowing medium with water providing the confining pressure. Details of the pore- and confining pressure and oflerer lest conditions were not included in the sted report. 
The gas permeability tests were performed so that the flow was measured parallel to the bedding plane. According to the report, permeability tests on HPC 1 and HPC 2 yielded permeabilities of 71 and 148 microdarcies, respectively. When a confining pressure of 1200 psi was applied to HPC 1, the permeability decreased to 0.02 microdarcies after 50 hours. When the confining pressure was increased up $101700 \mathrm{psi}$, the permeability decreased to 0.002 microdarcies after 246 hours, below the resolution of the test system. Similarly, the permeability of HPC 2 decreased to 1 microdarcy after one day at 1200 psi confining pressure. The third core, HPC 3, which was approximately half the length of HPC 1 and HPC 2, exhibited an initial permeability described only as "high." After 272 hours at 1200 psi confining pressure, the permeability of HPC 3 reduced to 7 microdarcies. It was suggested that the shorter length of HPC 3 contributed to its slower "healing" and resulting higher permeability at similar confining pressure than HPC 1 and HPC 2.

No other laboratory tests to measure llow properties of WIPP-specific Salado anhydrile have been performed.

\subsubsection{Field Studies}

In situ and laboratory measurements of porosity and permeability (single-phase measurements) are routinely performed for oil and gas reservoir media. Two phase flow measurements, however, are performed in the laboratory on recovered core samples because Iwo-phase thow measurements are a function of the saturation state of the porous medium, which is difficule to accuratlely measure in silu.

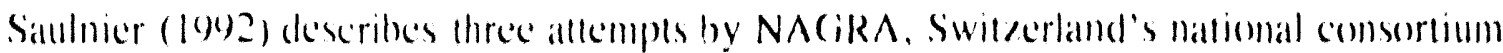

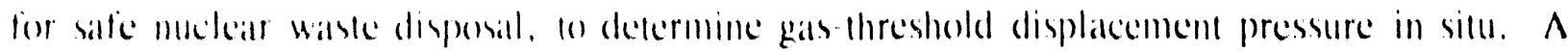
comslaml pressure kest was allempled all the cirimsel Underground Rock laboralory, and both constant pressure and comstant rille lests were allempted al Wellenberg. Nonte of the lests was sucessstul becallse of experiment design and instrumentation limilations. 
A test plan to measure gas-threshold pressure in MB 139 at the WIPP was published in March 1992 (Saulnier, 1992), and the initial in situ threshold pressure test is expected to be completed in FY93. The test should result in a capillary pressure measurement. However, because the saturation will not be determined during this in situ test, a laboratory-determined capillary pressure characteristic curve will be necessary to assess whether a true threshold pressure was measured. No other in situ two-phase flow measurements at the WIPP are planned at this time. 


\subsection{PROGRAM DEFINITION}

This section contains the test objectives, program scope, a description of measurement systems under consideration for use, and general program milestones. Additional sections including (1) Experimental Process Description, (2) Instrumentation/Test Equipment/Facilities, (3) Test Requirements, (4) Data Acquisition Plan, and (5) Data Quality Objectives are not contained in this conceptual plan, but will be included in the Test Plan.

\subsection{Test Objectives}

The Salado Two-Phase Flow Laboratory Program is designed to provide single- and twophase flow data, characteristic curves, and statistical (distribution) information as well as information regarding appropriate data use to WIPP Program numerical modelers and analysts (Fluid Flow and Transport and Performance Assessment Departments). The program objectives for each fiscal year are described below.

\subsubsection{FY92: Determination of Program Needs-Scoping Activities}

FY92 was spent performing the following scoping activities:

1. Determine which research efforts require two-phase flow data, how the data is to be used, which rock and flow parameters need to be measured, which rock and flow parameters are required for proper data interpretation, and which stratigraphic units are to be lested.

2. Set priorities for all parameters to be measured and stratigraphic units to be tested.

3. Determine the state of lechnology development for measuring these parameters and identify and address outstanding programmatic, logistic, or experimental issues. 


\subsubsection{FY93: Determination and Evaluation of Test Methods - Preliminary Experimental Activities}

The completion of scoping activities initiated in FY92 and the following preliminary experimental activities will be performed during FY93:

1. Determine the appropriate test methodology for each parameter to be measured (as identified in FY92).

2. Make preliminary measurements of porosity, rock compressibility, single-phase permeability-versus-stress and investigate the use of computed tomography (CT) imaging technology for core damage assessment and tracking fluid flow through cores.

3. Use conventional core analysis techniques to fully characterize samples in terms of mineralsgy, composition, and microfractures.

4. Review technical publications and perform preliminary tests to identify potential problem areas.

5. Perform experiments to investigate potential problems identified in the scoping activities.

6. Complete Test Plan.

\subsubsection{FY94-FY97: Testing Program-Experimental Activities/Analyses}

Using data and information gained from scoping and preliminary experimental activities performed in FY92 and FY93, execute appropriate la'soratory tests to provide two-phase flow data, other rock and flow data, characteristic curves, statistics, and other information to WIPP Program numerical modelers and analysts. 


\subsection{Program Scope}

\subsubsection{FY92: Determination of Program Needs-Scoping Activities}

The FY92 activities described in Section 3.1 are designed to set the groundwork and determine the scope of the Salado Two-Phase Flow Laboratory Program. Figure 4 contains a road map identifying the flow of program activities. As detailed in Figure 4, these activities are intended to answer the following questions:

1. Who is the customer(s) for this work?

2. What rock and flow properties need to be measured?

3. What stratigraphic units/materials should be tested?

4. What are the state-of-the-art technologies, and what is their availability for two-phase flow and other required measurements?

5. Are there any outstanding programmatic, logistic, or experimental issues?

As a result of FY92 activities, WIPP PA numerical modelers, SNL. Fluid Flow and Transport numerical modelers and mechanistic model developers, and huid tlow analysts were identified as program customers. The rock and now properties requested by these customers include porosity, rock compressibility, single-phase permeability, threshold and capillary pressure, and relative permeability. The program customers also identified and set a priority order for the stratigraphic units or other material to be tested: (1) anhydrite interbeds, (2) halite and impure halite, (3) seal material, and (4) backtill material.

Technical discussions were held with Sandia National Laboratories (SNL) scientists and external researchers who have experience in two-phase flow measurements in low-permeability rocks including those from the Institute for (ias Technology (Chicago, IL), the New Mexico Petroleum Recovery Research Center (Socorro, NM), Core Laboratories (Dallas, TX), Golder Associates, US Geological Survey (USGS) (Yucca Mountain), RI:/SPIC. (Rapid City, SD), Rock Physics Associales (San Jose, CA), and Terratek (Salt Lake City, UT). An extensive literature review was initiated that covered related topics including core imaging techniques, conventional 


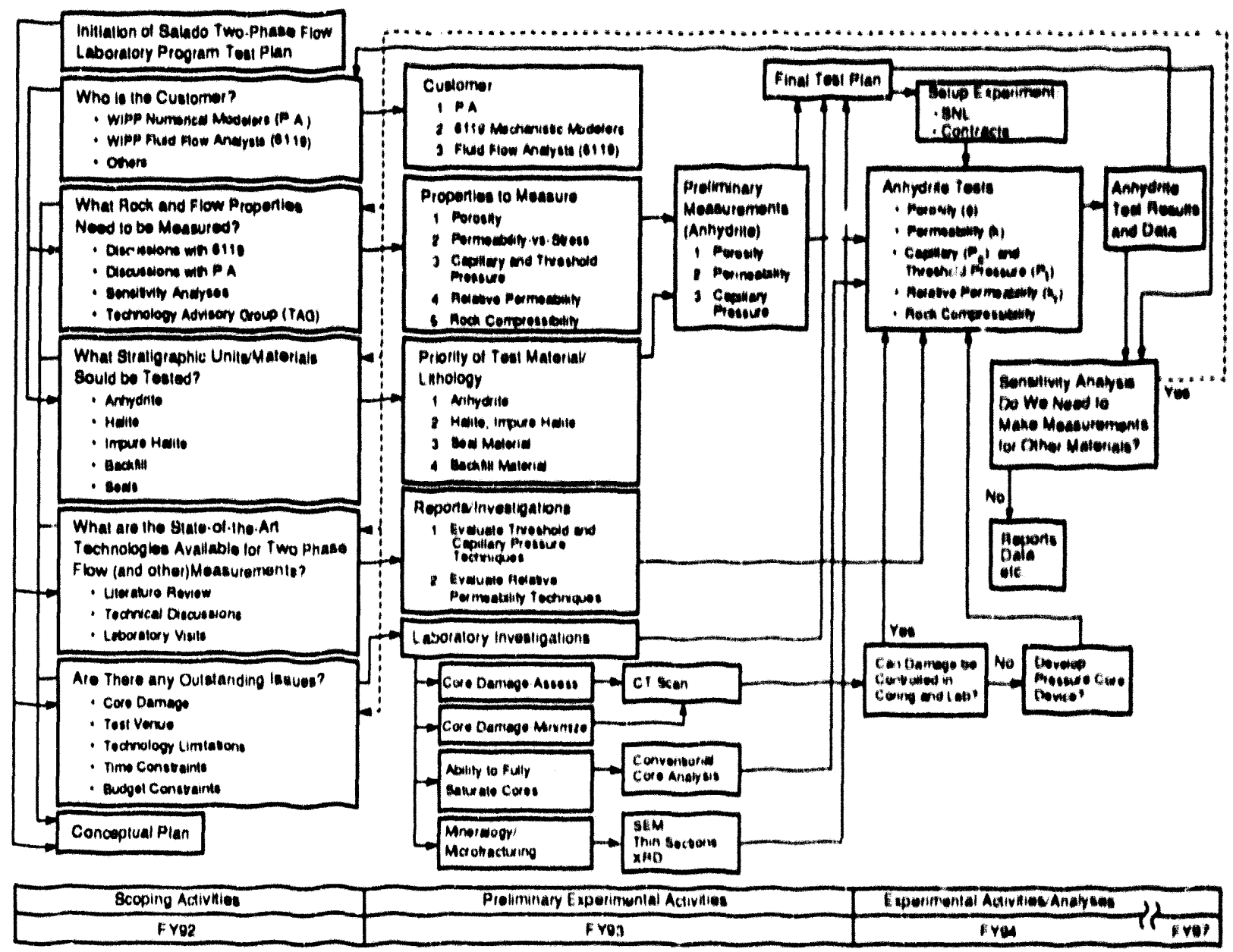

10101101000

Figure 4. Salado Two-Phase Flow Laboratory Program road map. 
and special core analysis, relative permeability measurements, threshold pressure measurements, capillary pressure measurements, and historical research on the Salado Formation anhydrite interbed layers.

A Technology Advisory Group (TAG) was formed consisting of members of SNL's lechnical staff from the Geoscience and Geotechnology Center who have experience, expertise, or knowledge in relevant areas including natural fractures, core damage, stress state and effective stress, permeability, porosity, capillary pressure, anisotropy, threshold pressure, heterogeneity, and permeability/stress relationships. The TAG meets regularly and provides advice and guidance to the Principal Investigator to address programmatic, logistic, and experimental issues.

\subsubsection{FY93: Determination and Evaluation of Test Methods-Preliminary Experimental Activities}

Activities planned for FY93 are divided into four areas: (1) laboratory core characterization, (2) preliminary laboratory experiments, (3) reports, and (4) program development. Information gained from FY93 activities will be used to design the long-term twophase flow laboratory program, remediate problems, evaluate the suitability of using tight gas sands correlations as an analog, and assess our ability to restore specimens to their in situ state.

\subsubsection{LABORATORY CORE CHARACTERIZATION}

There are two objectives of the laboratory core characterization activity. The first objective is to characterize MB 1.39 because it varies vertically and laterally in composition, and data is needed to correlate variations in transport properties with composition. The second objective is to assess coring-induced damage to MB 139 specimens because damage induced during coring and laboratory subcoring and finishing may affect laboratory porosity and permeability measurements. To meet these goals, core samples from MB 1.39 will be examined and tested to assess the extent of coring-induced damage (fractures) and characterize lithology, 
mineralogy, and porosity. In addition, the CT core imaging technique will be tested to evaluate its applicability for identifying and characterizing surface and internal fractures in cores and for tracking fluid flow through Salado anhydrite cores.

MB 139 anhydrite will be tested using techniques including standard petrographic analysis and $x$-ray powder diffraction. Grain-size distribution and composition will be determined using the petrographic microscope. X-ray diffraction techniques will be used for mineral identification and quantitative compositional analysis.

The extent of surface damage and the crack density will be assessed using epoxy dyepenetrants and CT scanning techniques. Techniques to minimize surface damage, including varying cutting and coring rates, and techniques to remediate surface damage will be investigated. The results of the core-damage assessment experiments will be used to determine whether specialized coring equipment such as pressurized core barrels could reduce coringinduced damage and should be investigated and developed for this application. Also, the results of tests using the CT core imaging technique will be used to make recommendations regarding its applicability in assessing core damage and tracking fluid flow during tests.

\subsubsection{PRELIMINARY LABORATORY EXPERIMENTS}

The objectives of the preliminary laboratory experiments are to measure porosity (total and effective) as a function of stress, measure single-phase permeability under various hydrostatic stress conditions and flow directions, determine the maximum achievable liquid saturation, and perform preliminary capillary pressure measurements. The need for these preliminary measurements is described below:

- Porosity, a fundamental rock property, is a measure of the pore volume within a rock. Porosity has not been measured for the Salado anhydrite material. 
- Permeability, a measure of the ability of a rock to transmit fluids, has been measured in situ as part of two other test programs and in the laboratory on three poorly described cores (see Section 2.3.3). Because many parameters required for interpretation of the in situ permeability tests have large uncertainty ranges, it will be necessary to measure single-phase permeability in the laboratory under more controlled conditions. In addition, single-phase permeability is required for determining relative permeability.

- Relative permeability and capillary and threshold pressure are defined in terms of the relative saturation of the fluids present in a given porous medium. Single-phase (gas or liquid) permeability and gas threshold pressure measurements require complete saturation of interconnected pore space. Verifying the ability to completely saturate the interconnected pore space of MB 1.39 specimens will substantiate laboratory tests of both single- and two-phase permeability and threshold pressure.

- As described in Section 3.3.6, there are a number of methods available for measuring capillary pressure in the laboratory. Two methods will be used to measure capillary pressure on a small set of core samples to help determine which method(s) should be used in subsequent lests.

Knowledge gained from this activity will be used to design and implement future tests to measure threshold pressure, capillary pressure, and relative permeability. Additionally, this information will be used to evaluate the suitability of using tight gas sands correlations as a Salado analog and to justify the laboratory approach by assessing the ability to restore specimens to their in situ state.

\subsubsection{REPORTS}

Four reports are planned for FY93 to meet program objectives: 
1. "Evaluation of Laboratory Techniques to Measure Relative Permeability for the Salado Formation Anhydrite Interbeds at the Waste Isolation Pilot Plant,"

2. "Evaluation of Experimental Techniques to Measure Threshold Pressure for the Salado Formation Anhydrite Interbeds at the Waste Isolation Pilot Plant,"

3. A report containing the results of core-damage assessment including recommendations for core-damage minimization, and

\section{4. "Salado Two-Phase Flow Laboratory Program Test Plan."}

The first two reports will be used to determine the appropriate test methodology for twophase flow parameters, and the third report will address concerns related to core damage assessment and recommendations for damage minimization. The recommendations from the evaluation of threshold-pressure and relative permeability measurement techniques reports will be used to determine the appropriate methodology for making these measurements and to determine whether such tests should be performed in-house or by contractors. The Test Plan will be an expansion of this conceptual plan and will incorporate recommendations from the twophase flow method evaluation reports and the results from the core characterization and preliminary laboratory tests.

\subsubsection{PROGRAM DEVELOPMENT}

Technology Advisory Group

The Salado Two-Phase Flow Laboratory Program will continue to evolve and change to meet program demands and needs. The TAG will continue to act in an advisory capacity to address concerns and issues.

Collaborative Program with Gesellschatt fur Reaktorsicherhelt and Forschungszentrum Jullich

In March 1992, scientists from Gesellschaft fur Reaktorsicherheit (GRS) and Forschungszentrum Julich (KFA) attended the Radioactive Waste Technical Exchange in Albuquerque. At the meeting, a tentative agreement was made for technical exchange and 
collaborative work in developing techniques to measure two-phase flow properties in salt and anhydrite. As a result, information exchange and coordination mecungs were held with these scientists from GRS and KFA in November 1992 in Julich, Germany, to discuss coordination of work on two-phase flow properties. These meetings were intended to formally establish a cooperative program and included technical discussions of the planned WIPP two-phase flow laboratory program, experimental methods, and the need to develop new experimental techniques. During the meetings in Germany, it was acknowledged that the German two-phase flow program was currently unfunded and that when funding is received, their efforts will focus on measuring two-phase flow properties of halite, rather than anhydrite. In light of the GRS and KFA funding situation and area of interest, it was agreed that a cooperative program is not appropriate at this time. However, informal information exchanges between the two programs will continue, and the possibility of developing a collaborative program will be reconsidered in December 1993.

\subsubsection{FY94-FY97 Testing Program-Experimental Activities/Analyses}

The Salado Two-Phase Flow Laboratory Program is expected to be ready to begin measurements for anhydrite threshold and capillary pressures and relative permeability (gas and liquid) in FY94, as shown in Figure 4. Details of the long-term, two-phase flow test program will be included in the upcoming Test Plan.

\subsection{Measurement Systems}

The American Petroleum Institute (API, 1960) established standards and guidelines for measuring porosity and intrinsic permeability (single-phase tests) on full-diameter cores and core plugs. These original standards are being updated as a result of technological advances, but as in the original standards, the new guidelines are not expected to include any reference to relative permeability, threshold pressure, or capillary pressure measurements. The SCA recognized this oversight and in 1992 initiated a program to establish guidelines for laboratory measurement of 
capillary pressure and relative permeability. As of the publication date of this report, the SCA study is still in progress and relative permeability, capillary pressure, and threshold pressure measurement guidelines have not been published.

Core characterization, core damage assessment, porosity, and single-phase permeability measurements and analyses will follow API or other accepted standards. Because no standards or guidelines exist for measuring relative permeability, capillary pressure, or threshold pressure, test methodology evaluations will be performed during FY93 to determine the appropriate approach for measuring these (wo-phase parameters. In some cases, more than one measurement technique may be used to accurately quantify these parameters.

As required, all design drawings and material specifications will be made part of the SNL "Quality Assurance Program Description" (QAPD). Details of the measurement systems and analysis will be found in the evaluation reports (see Section 4.2.2) and Test Plan, but a general discussion of measurement systems for the two-phase flow tests is found in this section.

\subsubsection{Core Characterization}

The composition of MB 1.39 varies in the lateral and vertical directions, and data are needed to correlate variations in flow properties with composition. MB 139 core samples will be examined and tested on a microscopic scale to assess the extent of coring-induced damage (fractures) and characterize lithology, mineralogy, and porosity using standard petrographic analysis techniques as described by Basan et al. (1988). Thin-section analysis will be used to identify matrix, detrital, cement, and pore composition and define the nature (type and distribution) of porosity. X-ray diffraction (XRD), which can account for components too small to be identified using light microscopy (LM) techniques, will be used to identify and quantify bulk rock and clay mineralogies. In addition, scanning electron microscopy (SLM) will be used to determine the morphology and location of clays, qualitatively evaluate pore geometry, and further define porosity. 


\subsubsection{Core Damage Assessment}

Damage in the form of microfractures may be induced during drill coring, laboratory subcoring, and finishing operations on recovered rock specimens. Core damage may affect laboratory measurements of porosity, capillary and threshold pressure, and permeability, and unless the core can be restored to its in situ state, laboratory-derived parameters may not be representative of the Salado far-field. In addition to the microscopic core characterization tests previously described, lwo macroscopic techniques (standard epoxy dye-penetrant impregnation techniques, and C? imaging) will be applied during the preliminary core analysis in F:Y9.3 to evaluate their effectiveness for damage delection and quantification in MB 1.39 cores. Techniques to minimize surfice damage, including varying culling and coring rates, and lechniques to remediate surface damage will also be investigated. Oher lechniques, such as acoustic wave velocity and resistivity measurements, may be used to determinc the relationships between stress state, damage, and permeability.

The results of the core-damage assessment experiments will be used fo delermine whether specialized coring equipment could effectively reduce coring induced damage and should be investigated and developed for this application. Also, the resulls of lests using the ("T core imaging technique will be used to make recommendations regarding its applicability in assessing core damage and tracking Muid now during lests.

\subsubsection{EPOXY DYE-PENETRANT IMPREGNATION}

Standard epoxy dye-penetrant impregnation is intended to provide materescopic quantitative information and qualitative visual illustration of coring-induced damigge effects. In this simple lechnique, the outer surface of a cylindrical core simple is injected with an epoxy dye-penedrant while under pressure. The epoxy-dye mixture then flows into the core lhrough surfice or internal fractures. The epoxy is allowed to cure, then the epoxy-coated core is removed from its container and cut in half longitudinally as shown in ligure 5. Coring induced damage is quantified by comparing the outer core surlace with the inner malcrial by counting fractures that 


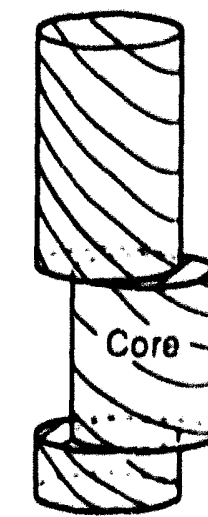

Marker Bed 139

Coro Samplo

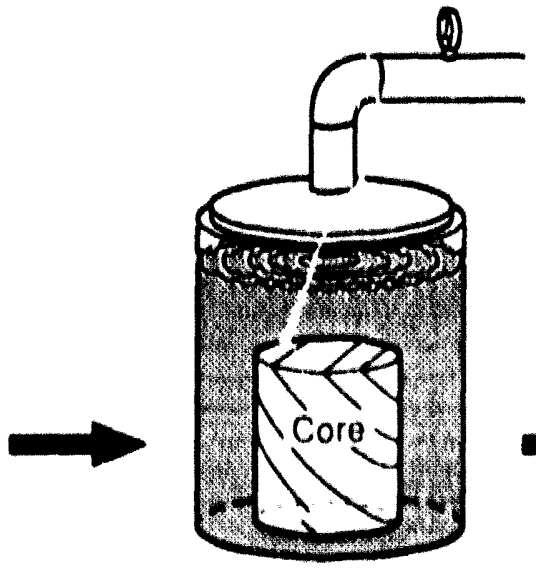

Epoxy Dye Penelrant

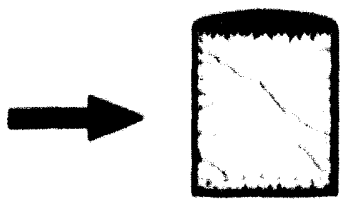

Core X-Section

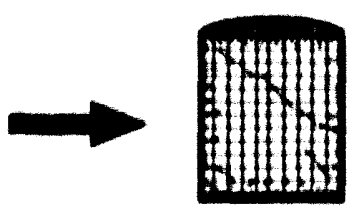

Grid lor Crack

Donsify Calculation

III. 119190

ligure 5. Iipoxy dye penctrallion.

cross lines on an overlain grid. (rack density adjacent to the field conred surfice and at the sample center are determined, using stamdard slerewelogical procederes.

\section{$332 ?$ COMPUTED TOMOGRAPHY}

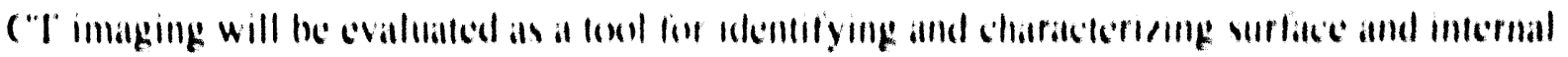

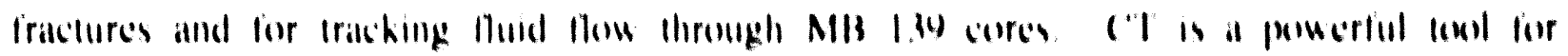

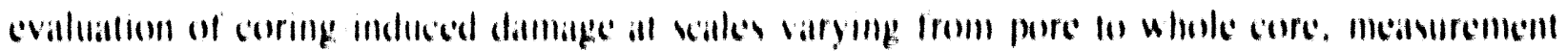

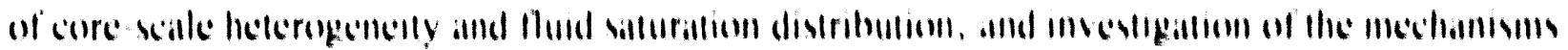

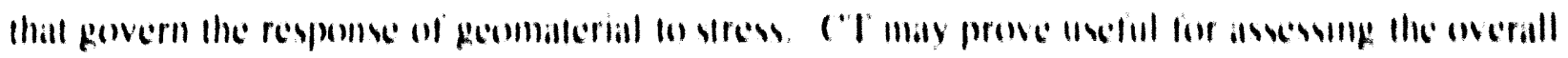

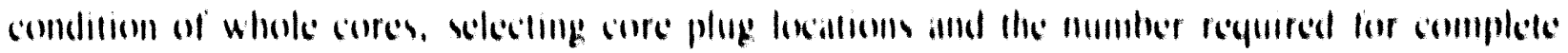

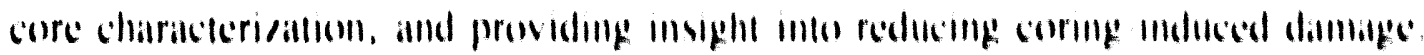

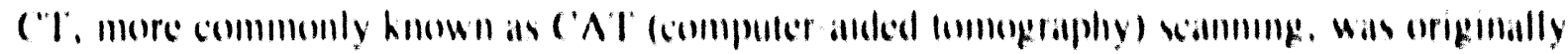

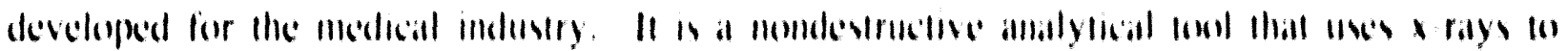

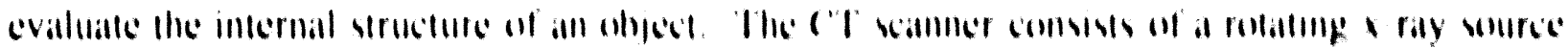

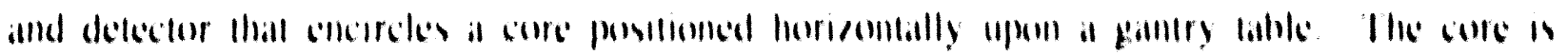


advanced through the apparatus and scinned at lixed incfements. Compuler soltware reconstructs two-dimensional images (or slices) in the plane of an $x$-ray beam directed through the object at many differem angles. A series of the Iwo dimensional images is used lo show three-dimensional fealures within an object.

Good agreement exists helween ("l delermined porosily and porosity delermined from slandard petrography and core analysis for oil field cores. $\mathrm{Cl}$ lmaging will be evalualed in FY9.3 for use in identifying and characterizing surface and intermal fraclures. As illustrated in Pigure 6, a whole-core scinn will be performed on a 1.5 - 11 - /ong verlical section of core drilled through MB 1.39 lo detecl coring induced surface fractures and nalural or coring induced internal fracture. After the inilial scan, the whole coure will be sub cored lo proxluce smaller plug size

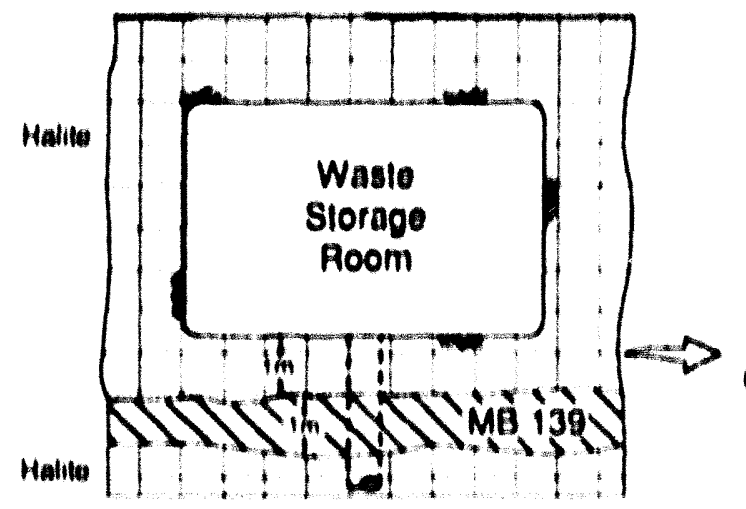

Drill Coro

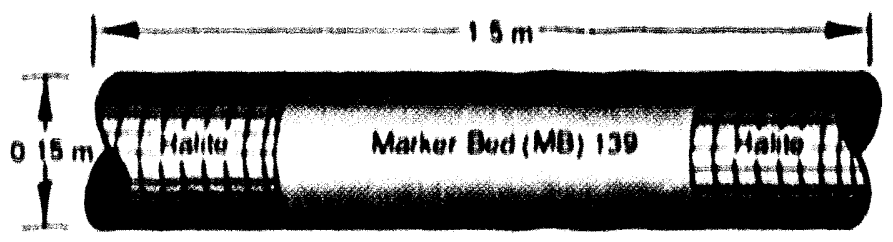

Scan Whole Core
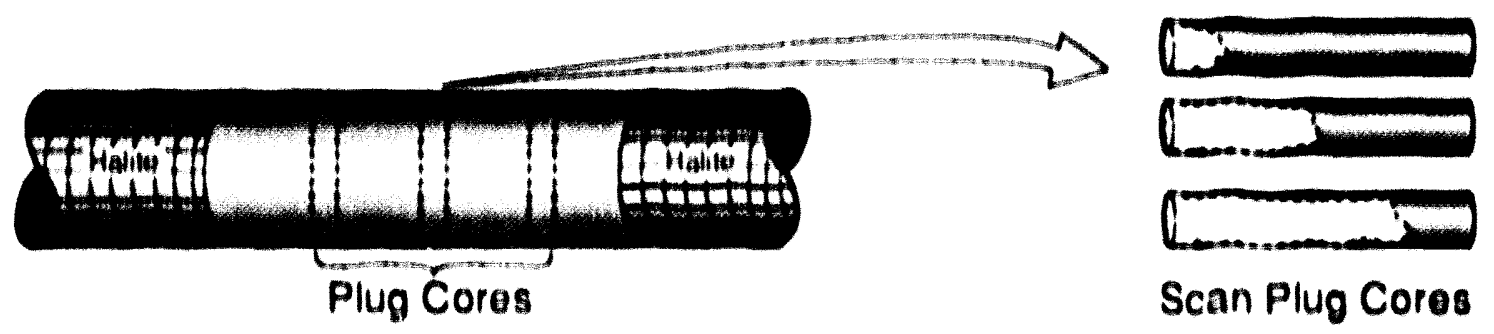

14i 110100

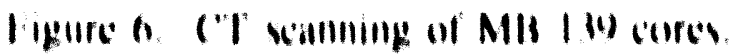


cores. The plug cores will then be scanned while dry and during a fluid flow test to detect any new laboratory-coring-induced of linishing-induced fractures.

\subsubsection{Porosity}

Porosity is a measure of the void space or storage capacity of a rock and is quantified as the ratio of void (pore) volume of a rock sumple lo its total or bulk volume (grain volume plus pore volume). Determination of porosity, $\phi$, requires solution of Lquations 6 and 7 and measurement of two of the following three variables: pore volume $\left(V_{p}\right)$, grain volume $\left(V_{k}\right)$, and bulk volume $\left(V_{n}\right)$.

$$
\begin{gathered}
\phi v_{n} / v_{b} \\
v_{b} * v_{0} \cdot v_{0} .
\end{gathered}
$$

Choice of perosity measurement lechnique depends upen the lype of rock, time available, and whether one secks fo measure fotal or effective purosity. Folal perosity is calculated using the tolal pore volume of the sumple, whereas effective porosity is calculated using only the interconnected pore volume of the simple. The difference hetween tolal and effective porosity

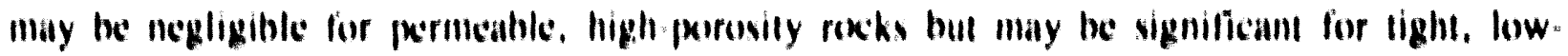
perosity recks where the peres are nell well connected. In general, effective porosity is

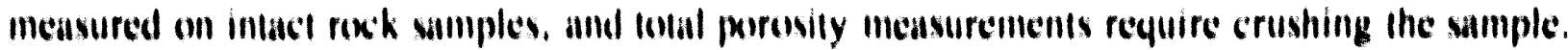
Details of the following lechmenes for measuring pere. grailn, and bulk volumes are found in

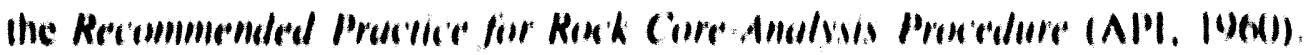

\section{31 POAE VOL.UME $\left(V_{t}\right)$}

Pore volume can be measured direcily by resiluraling the void space of a clean, dry core by one of iwo methods: I) evacualing and viluraling with liquid, or 2) miluralling the nonevacuated 
pore space with helium or other gas. Because liquids may drain from large surface pores, the liquid saturation method is not suitable for vaggy samples. However, if proper precautions are taken (i.e., the core is wrapped with a screen and contained within a rubber sleuve-the screen prevents the rubber sleeve from extruding into surface vugs-and confining pressure is applied to seal surfaces of the sample), the gas saturation method can be used. The gas saturation technique, which applies Boyle's law, is an excellent method especially when helium is used. Helium molecules are small, they rapidly penetrate into tiny pores, and because helium is inert. it is not adsorbed on rock surfaces as air might be (Keclan, 1972).

\section{BULK VOLUME $\left(V_{H}\right)$}

Bulk volume can be determined a number of ways including calipered length measurements, use of a calibraled mercury pump (porosimeter), or applicalion of Archimedes principle. Becianse none of these standard metheds is designed to be performed under overburden stress conditions. errors cin be introduced if the rock compacts significantly al overburden stress.

In the caliper methed, core dimension is measured with a caliper and appropriate mathematical formulac are applied to calculate the bulk volume. This technique is simple and does not require sophisticalled equipmeml, but it is not applicable to irregularly shaped cores (i.e., monright cylinders) hecanse valid average dimensions cannon be delermined.

Bulk volumes of sillall plugs can be determined using a calibriled mercury pump, also known as a mercury peressimeter. In lhis mellede, the bulk volume is calculated in the following manner: 1) the volume of a chamber $\left(V_{1}\right)$ is determined by filling it wilh mercury, 2) mereury is drained from the chamber, 3) the core simple is placed in the chamber, t) the chamber (with core in place) is refilled will mercury $\left(V_{3}\right)$. The bulk volume is thenl collculalled by subtracting $V_{\text {, }}$ irom $V_{, 1}$, as shown in liquallon 8 .

$$
V_{b}=V_{0}+V_{c 2}
$$


This method is not applicable for rocks with surface pores because mercury may penetrate surface vugs or pores and the bulk volume of the samples would be underestimated.

Archimede's principle is applied to measure bulk volume using mercury as described in Basan et al. (1988): (1) a core sample is cleaned, dried and weighed, (2) a beaker of mercury is weighed $\left(W_{H_{t}}\right),(3)$ the core is submerged in the mercury-filled beaker, and (4) the core in the mercury-filled beaker is reweighed $\left(W_{\text {Hg +ome }}\right)$. Bulk volume is calculated as described in Equation 9, where $\rho_{H y}$ is the density of mercury.

$$
V_{b}=\left|W_{H g}+\cot \theta-W_{H g}\right| / \rho_{H g}
$$

Although less toxic huids can be used, mercury is a nearly perfect nonwetling fluid because it will not enter the pore space. Error in this and the porosimeter methods can be introduced by the development of a hydraulic head as the rock is immersed in mercury. Studies show that the most reliable procedure is to submerge the sample under less than $4 \mathrm{~mm}$ of mercury (Basan et al., 1988).

\subsubsection{GRAIN VOLUME $\left(V_{0}\right)$}

The Boyle's law double-cell porosimeter is the most widely used device for determining grain volume. In the method outlined by Basan et al. (1988), the eore is placed in a sample chamber that is connected by a valve lo a reference chamber, where a transducer measures pressure. The reference chamber is initially isolated from the sample chamber and filled with gas, often helium, to a reference pressure. The comnecting valve is then opened to allow the helium pressure to equilibrate between the two chambers, and the final pressure is a function of the grain volume. This quick lechnique is valid on clean and dry samples. (irain volume in whole cores may also be calculated using measured sample weight and knowledge of average grain density, but this method is not applicable for heterogeneous rocks. 
Two other methods, summation-of-fluids and resaturation, are also used to determine porosity directly, but are better suited to high porosity/high permeability (i.e., oil reservoir rocks). According to Basan et al. (1988), summation-of-fluids uses a retort to drive off and recover fluids (oil, water, and/or gas) from a crushed core. The volume of each recovered fluid is determined, and, on another crushed core sample, the bulk and void volumes are determined by mercury displacement and injection, respectively. Porosity is calculated by dividing the sum of the recovered fluid volume by the bulk volume. Error may be introduced because two different cores are used and, because some of the huid may remain in the rock, low porosity measurements may result, especially in tight rocks. In the restoration method, bulk and pore volumes are obtained by comparing the weight of a clean dry core with that of the same core saturated with a fluid of known density. This technique should not be used in vuggy carbonates because fluids may be lost from the surface during weighing. Also, because the core is saturated in a vacuum, when the sample is returned to atmospheric pressure for weighing, the fluid draining from the core may carry grains away.

Total and effective porosity will be measured for MB 1.39 core samples as part of the preliminary tests scheduled for FY93. Information on the specific measurement systems is not available at this time, but will be included in the Test Plan.

\subsubsection{Permeability}

Permeability is a measure of the ability of a porous medium to transmit fluid. Permeability measurements can be made in the laboratory using steady-state or unsteady-state techniques. Using standard steady-state laboratory equipment developed for the oil and gas industry, measurements of absolute permeability (also referred to as intrinsic or single-phase permeability) ranging from $10^{1 \mathrm{th}} 102 \times 10^{11} \mathrm{~m}^{2}$ (approximately $1 \times 10^{4}$ 10 20 darcys) can be made on full diameter and plug-size cores (Keelan, 1972). Specialized techniques incorporating unsteady-state or transient techniques were developed for the underground gas storage industry and yield measurements as low as 10 " $\mathrm{m}^{\prime}\left(10^{4}\right.$ darcys). 


\subsubsection{STEADY.STATE METHODS}

Steady-state permeability is delermined in the laboralory by measuring the llow rale and pressure differential across a shaped core while a fluid is passed through the core. This technique is valid if laminar how conditions exist (i.e., flow rale is proportional to the pressure gradient) and if no reaction occurs between the rock and flowing huid. Standard procedures for

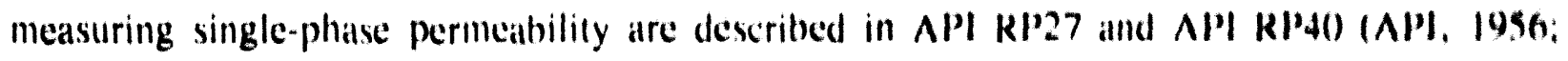
1960), which also include schematic diagrams and equations for calculating permeability for specific test conditions. Steady state methods are slow, especially for low permeability rexks.

Dry gas is the standard Muid used in permeability measurements because it is non-reactive with rock and easy to use, but non-reactive liquids are also applicable. Slcady-state permeability is determined by placing a clean dry core of known dimensions into a chamber, or permeancter. and flowing gas or liquid through the core while measuring the pressure difference across the core and the gas or liquid flow rate. Ciencralied equations for calculating permeability on a core cut as a right-circular cylinder under laminar llow conditions are presented below as lequations 10a and l(0) for gass and liquid, respectively.

$$
\begin{aligned}
& k_{0}=\frac{2 \theta_{0} p_{0} L \mu_{4}}{\left(p_{1}^{2}-p_{0}^{2}\right) A} \\
& k_{1}=\frac{\Omega_{0} L \mu_{1}}{\left(p_{1}-p_{0}\right) A}
\end{aligned}
$$


where

$k_{\mathrm{g}}=$ gas permeability

$k_{1}=$ liquid permeability

$Q_{0}=$ gas flow rate at outlet end

$P_{0}=$ outlet pressure (often equal to atmospheric pressure)

$P_{1}=$ inlet pressure

$\mu_{\mathrm{g}}=$ gas viscosity

$\mu_{1}=$ liquid viscosity

$\mathrm{L}=$ length of core

$\mathrm{A}=$ cross-sectional area of core, perpendicular to direction of flow.

(Note that permeability can be measured in the laboratory under turbulent flow conditions using several different flow rates and Forscheimer's equation. )

Differences between gas and liquid permeabilities measured in the laboratory are noted in the literature and are generally attributed to the Klinkenberg, or gas slippage, effect (i.e., gas has higher velocity near a grain surface than a liquid, see below). Likewise, differences between in situ and laboratory measured permeability for either gas or liquid may be attributed to the absence of sufficient confining stress on the core during laboratory measurements.

Klinkenberg Effect

Klinkenberg (1941) investigated gas flow through porous media and found variations in the measured permeabilities depending upon the gas or nonreactive liquid used and the mean pressure, $P_{m}$, existing in the core during the test. The differences in gas permeabilities were altributed to gas slippage, which occurs when the diameter of the pores approaches the mean free path of the gas. As expected, low permeability rocks are more sensitive to the Klinkenberg effect than high-permeability rocks (Keelan, 1972).

As shown in Figure 7 , in a plot of gas permeability versus the reciprocal of the mean pressure, a straight line is formed for each gas that can be extrapolated to a single infinite mean 


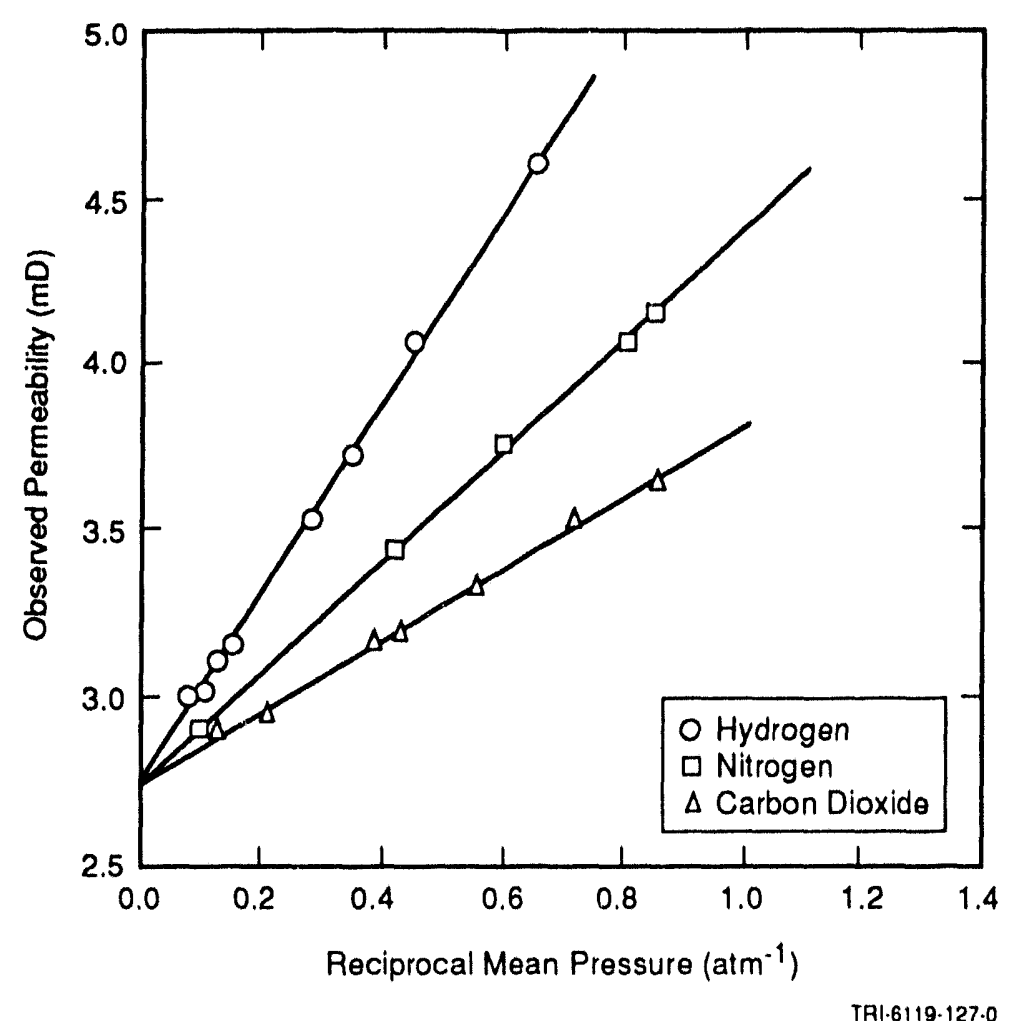

Figure 7. Permeability versus reciprocal mean pressure (after Klinkenberg, 1941).

pressure value. This extrapolated mean pressure corresponds to a permeability, $k_{1}$, that is comparable to a permeability measured for a core fully saturated with a nonreactive liquid. The relationship between measured gas permeability and equivalent liquid permeability, $k_{\mathrm{g}}$ and $\mathrm{k}_{1}$, respectively, is expressed in Equation 11.

$$
k_{g}=k_{1}\left(1+b / P_{m}\right)
$$

where

$\mathrm{P}_{\mathrm{m}} \quad=$ the mean flowing pressure (absolute) of the gas during the test

$k_{1}=$ the value of permeability corresponding to infinite mean pressure and liquid permeability

$\mathrm{k}_{\mathrm{g}} \quad=$ the value of permeability for a gas at $\mathrm{P}_{\mathrm{m}}$ 
$\mathrm{b}=\mathrm{a}$ rock- and gas-specific constant that depends upon the mean free path of the gas and the pore structure of the rock and varies inversely with the average pore radius.

Correlations are available that relate the laboratory-measured air permeabilities to equivalent liquid permeabilities. These correlations yield values of sufficient accuracy for sandstones and some limestones, but are not applicable to whole core permeability measurements because of the larger degree of heterogeneity.

\subsubsection{UNSTEADY-STATE METHODS}

Unsteady-state methods, including pulse decay (Freeman and Bush, 1983) and pressure transient (Hseih et al., 1981), are used for measuring hydraulic properties of low permeability core samples in the laboratory. These methods use pressure transient analysis to infer permeability.

Pulse-Decay

This transient flow method was introduced by Brace et al. (1968) to measure the permeability of Westerly Granite. In this method, a cylindrical core sample is connected to two fluid reservoirs-one on the upstream end and the other on the downstream end of the core-each initially at the same pressure. The experiment is initiated by suddenly increasing, or pulsing, the pressure in the upstream end of the core causing the fluid to flow through the core to the downstream reservoir. The pressure decay in the upstream end of the core is monitored, and the permeability is calculated from the pressure decay versus time data. This method can be performed at simulated in situ stress conditions.

\section{Pressure Transient}

As described by Freeman and Bush (198.3), the sample is also connected to two reservoirs in this method; however, the downstream reservoir volume is approximately the same 
as the sample pore volume. $A$ gas is introduced into the upstream end of the sample at a pressure greater than atmospheric, but well below the sample's external confining pressure. As the gas flows through the sample, the pressure in the small-volume downstream reservoir is monitored as it increases. Permeability is then calculated from the pressure buildup data used to determine the flow rate out of the sample. This method can be performed at simulated in situ stress conditions.

\subsubsection{EFFECTS OF STRESS ON PERMEABILITY}

Differences between in situ and laboratory measured permeability for either gas or liquid may be attributed to differences in, or the absence of, sufficient confining stress on the core during laboratory measurements. Tests show that laboratory-measured single-phase permeability is significantly reduced when confining pressure is applied to cores during permeability tests (Fall and Davis, 1952; (jray et al., 196.3). Jones and Owens (1980) noted that for their Tight Gas Sands core samples, permeability was reduced by an order of magnitude when hydrostatic confining pressure equal to a net overburden pressure was applied. Further, their findings agreed with Mclatchie et al. (1958) and showed that, in general, the lower the core permeability, the more it is affected by confining pressure. (The effects of stress and the concept of effective stress are addressed in Section 3.3.7.)

Single-phase permeability measurements planned for F:Y9.3 as part of the preliminary MB 1.39 tests will include both gas and liquid (brine and non-reactive mineral spirits) permeability tests. The brine permeability tests will be designed to allow for sampling of the brine prior to entering the core and after flowing through the core, and the brine composition will be analyzed to determine if the brine is reacting with the core material. These gas and liquid permeability lests will be configured so that the now direction is parallel to the bedding plane. Another set of gas permeability tests will be performed with permeability measurements made perpendicular to the bedding plane. These tests will help determine the magnitude of permeability anisotropy in MB 139. The gas permeability measurements will be corrected for Klinkenberg effects. All 
permeability tests will be performed under net effective stress conditions to simulate in situ stress conditions.

\subsubsection{Capillary and Threshold Pressure}

Several WIPP numerical modelers requested measurement of gas threshold displacement pressure and capillary pressure for the Salado anhydrite interbeds. Gas threshold pressure, as described below, is actually a point on a capillary pressure characteristic curve, and can be measured directly or in conjunction with capillary pressure curves. It is intended, within the scope of this program, to measure capillary pressure characteristic curves over a complete saturation range, thus providing both threshold pressure and capillary pressure data and independent measurement of threshold pressure.

Gas threshold displacement pressure is the pressure that the gas (nonwetting phase) must reach to overcome the pore pressure and capillary effects (threshold pressure) to enter a porous media and displace the wetling-phase fluid. Capillary effects are quantified as capillary $\left(P_{c}\right)$ or threshold pressure $\left(P_{1}\right)$. Threshold pressure is related to the capillary pressure characteristic curve as shown in Figure 2 and is defined as either: 1) the endpoint pressure on the capillary pressure-versus-saturation curve corresponding to a wetting-phase saturation of 1.0 , or 2 ) the

pressure on the capillary pressure-versus-saturation curve at the nonwetting-phase critical saturation. The first definition applies to the initial penetration of the nonwetting phase fluid into the wetting-phase saturated porous medium, and the second applies to the development of a nonwetting phase continuum through the core and initial breakthrough for the nonwetting-phase fluid.

\subsubsection{DIRECT LABORATORY MEASUREMENT OF THRESHOLD PRESSURE}

Direct methods for measuring threshold pressure in the laboratory include the pressure leveling technique, constant rate technique (Rudd, 1974), and the pressure-step method described by Thomas et al. (1968). Historically, the natural gas storage industry was interested in 
determining the threshold pressure of low-permeability media, and most of the direct threshold pressure measurement techniques were developed to support gas storage technology.

Constant-Rate Technique

Constant-rate injection techniques are used to determine threshold pressure independent of capillary pressure. A known quantity of gas is introduced into a brine-saturated core at a very low constant rate. Pressure is recorded at the inflow face as the pressure increases. When the threshold pressure is reached, the slope of the pressure buildup curve decreases or reverses as gas enters the sample (Rudd, 1974).

\section{Pressure Leveling Technique}

The pressure leveling technique was developed from a constant rate test to overcome some of the problcms inherent to the pressure-step technique: a fixed volume of gas at a known pressure (greater than the expected threshold pressure) is applied at the input end of a core. The gas expands into the core until it equilibrates or "levels" with the threshold pressure. Rudd (1974) compared results from this method with threshold pressure measured using the pressurestep method and found good agreement. Where discrepancies did exist, he found the pressure leveling technique to be more valid.

Rudd also applied this technique sequentially to the same core sample, and as expected, found that the threshold pressure is dependent upon the specific surface encountered within a core, usually at or very near the gas-input end of the core. He recommends applying the technique at a minimum of two zones in a single core.

Compressibility and gas diffusion problems can be factors in this technique when gas is used as the nonwetting phase fluid. However, because the gas pressure is monitored throughout the test, equilibration is readily observed and test time is significantly reduced. 


\section{Pressure-Step Method}

The pressure-step method has been used for the past 30 years to measure threshold pressure in the laboratory. This method consists of introducing gas into the end of a brine saturated core, allowing the core/gas/brine system to equilibrate, and observing the outflow end of the core to deted the first fluid movement from the core. The gas pressure is increased incrementally until lluid flows from the core. There are Iwo signilicant problems with this method: (1) long equilibration times, and (2) compressibility of the gas, brine, rock, and experimental apparatus. Equilibration time at each pressure step can range from hours to days, depending upon the permeability of the sample. Compressibility of the gas and brine can also be a problem because the initial input of gas into the pore is accommodaled by compression of the gas and brine until it can be bled off lhrough the whole core (Rudd, 1974). Because lhis must be repeated al every pressure slep, this method is very time-comsuming. The length of time required for these lests adds experimental complications such as contimuously maintaining constant pressure for days and preventing minule gas leaks. Anollere problem that may he encountered is gas diffusing into the brinc, which may be miligalled by sillurating the gas wilh water.

\subsubsection{INDIRECT LABORATORY MEASUREMENT OF THRESHOLD PRESSURE}

Threshold pressure is obtained indirecily from capillary pressure characteristic curves. The capillary pressure curve also provides dilla on the irreducible welling phase salluration thall is crucial for defining effective saluration for both the Brooks and corey (1964) and Parker et al. (1987) correlations. Threshold pressure is determined by extrapolatting or interpolating llic capillary pressure curve to the apprepriate salluration value of eilher $1(0) \%$ welling phase (brinc) saturation or critical nonwelling phase (gas) satturation as shown in ligure 2. Ilsing the indirect methods for determining threshold pressure is advantageous becaluse these methods provide the entire capillary pressure curve, which is necessary for justifying the use of the Browks and corey (1964) and/or Parker el al. (1987) correlations in the PA models. 
Capillary pressure, $P$, is the pressure difference across an interface between Iwo immiscible Muids as described in liquation 12.

$$
P_{*}=P_{\text {rw }}-P_{*}=0\left(\frac{1}{r_{1}}-\frac{1}{t_{2}}\right)
$$

where

$$
\begin{aligned}
& P_{n *} \rightarrow \text { pressure of the nonwelling phase } \\
& P_{*} \quad \text { pressure in the welling phase } \\
& \text { o interfacial iension } \\
& r_{1}, r_{2} \text { principal radii of curvillure of a poinl an the inlertace. }
\end{aligned}
$$

I aboratery lechniques lo measure capillary pressure are divided into slatic of dynamie

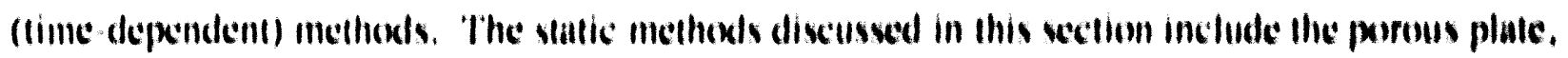
centrifige, and the mercury injection melloxds. In addition, one dynamic methex is alw discussed.

\section{Porous Plate}

As described by Biss (1987) and shown in ligure 8 . Whe persous plate, of porous

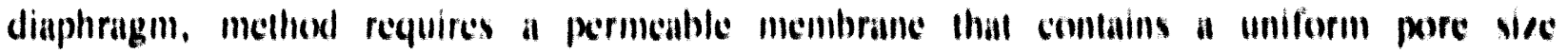
distribution. The pore siede distribution is selected so that the displacillg flutd will not penetrate the membrane when the applied pressure is below a selected value. Pressure is applied acrows the membranc, made of malerials such as frilled gliss of cellophome, and is increased in small increments. The core is allowed lo slahilize al each pressure slep where the sallurallon of the core is calculated. This method has the advallage that any combinalion of Hoids may be uned and both drainage and imbihillon curves can be oblatined, but if is fime comsuming hecause of long equilibration times and may lake several wecks of complete an entire cappillary pressure

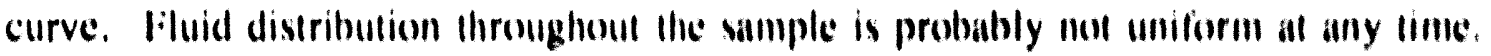




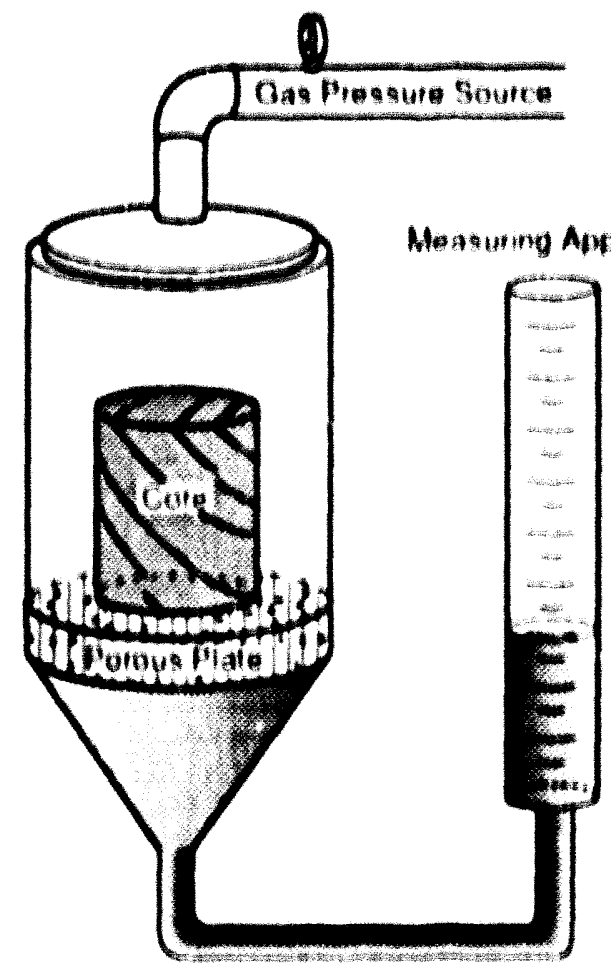

Not to heale

at in

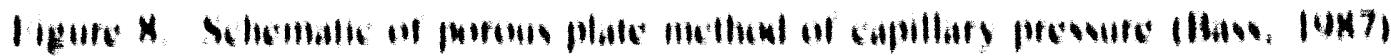

\section{Centringe}

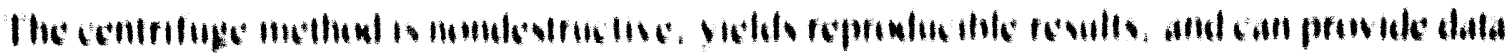

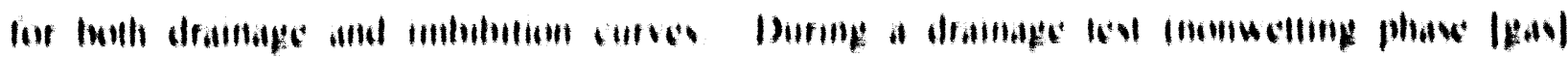

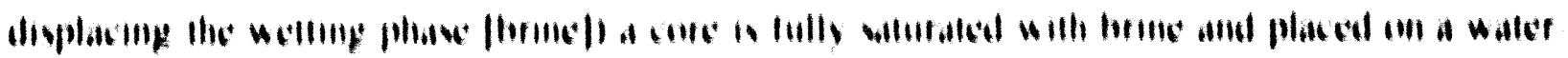

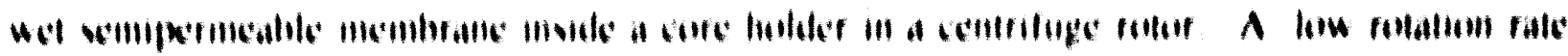

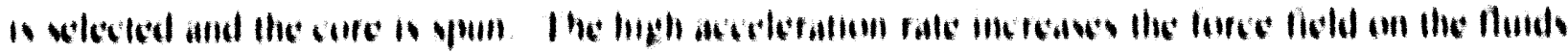

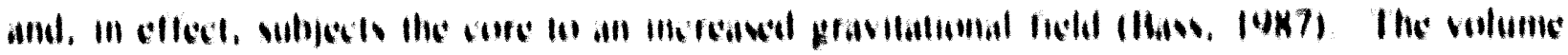

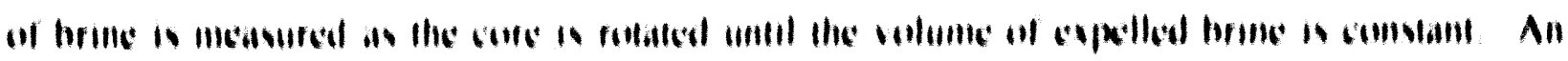

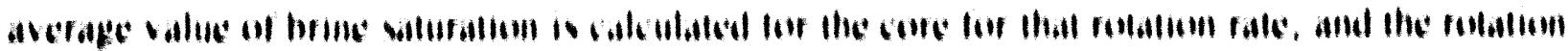

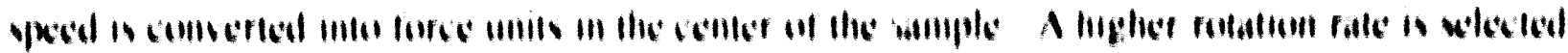

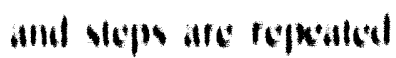


In addilion lo lecing very fasl, the centrifige methoxl has weveral advanlages: II provides

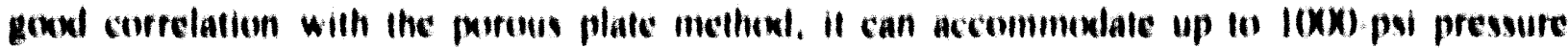
differential beiween phaws in an air/liquid sydem, If can be uxed for lime dependent valuralion measurements and 2 and I phawe relative permeability teving. and il can miligate capillary end effects and viscous invability of gas displacing liquid. However, Nuid distribution throughoul the sample may nur be uniform.

\section{Mercury Injection}

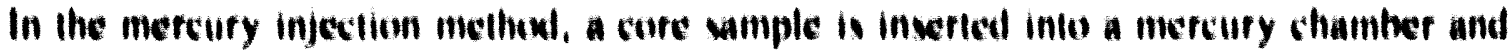
evacuated. Volumes of mercury, a monwelling huid, are then insementally forced into the core

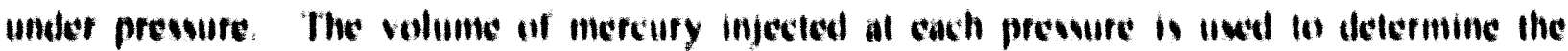
nonwelling phawe valurallon. and the prowew is repeated unlil the whole capillary presulfe curve is ohtained (llaws, 1989). This to a deveruedive method for determining capillafy prewure, and

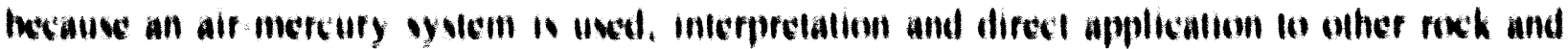

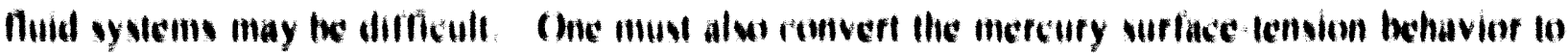
that of the flulds in the rewervolif

Drratruc

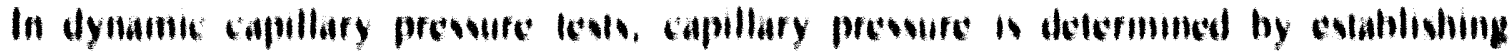

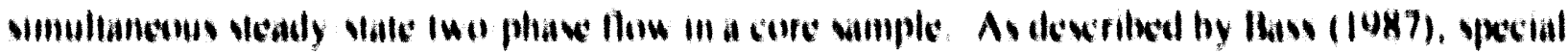

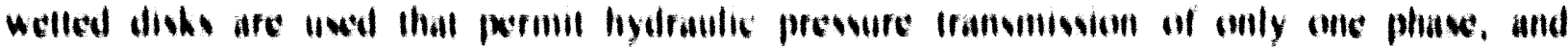

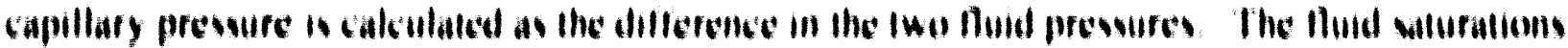
are varied by fegulating the volume of the lluids al the inlet end $A$ compleste capillary prewure eurve is ohtalined usilig linis melhow

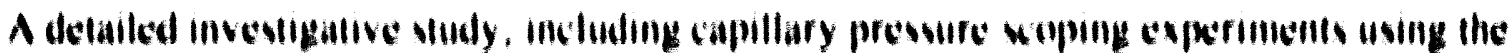

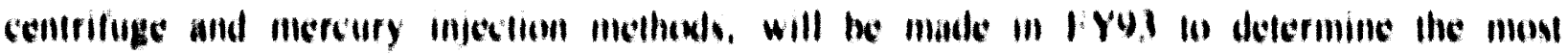

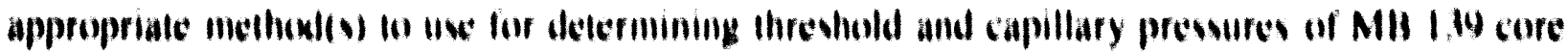


samples. As part of the FY91 Ixperimental Scoping Activilies, preliminary laboratory lests are planned using the inercury injection and centrifuge methods 10 assess their applicability in this progrum. The results of this sludy will be included in the Test Plan.

\subsubsection{Rolallve Permeabilliy}

Whereas intrinsic or aboulute permeability is a measure of the ease with which a single nuid will now through a porous medium, relative permeability compares the ease with which a nuid will how through a porous inedium when another fluid is present. When iwo nuids flow through a porous medium simulianeously, each nuid has its own effective permeability, and the sum of the two effective permeabilities is always less than the intrinsic or absolute permeability. Relative permeability for welling and nonwelling phases is described in liqualions 1,3 and 14. and a plois of relative permeability is shown in ligure 9.

$$
k_{1, w}\left(s_{w}\right)=\frac{k_{n *}\left(s_{*}\right)}{k}
$$

where

$$
k_{1},\left(s_{w}\right) \cdot \frac{k_{*}\left(s_{w}\right)}{k}
$$

$k \quad$ Abolute or intrinsic permeability

$K_{n *}\left(S_{*}\right)$ - liffective permeabilily of nonwelling phase al silluration $S_{*}$

$K_{*}\left(S_{*}\right)$ - Iiflective permeahility of welling phase al siluralion $S_{*}$

$K_{m \infty}\left(S_{*}\right)=$ Relallive permenbility of nonwelling phase all valurallon $S_{*}$

$k_{* \infty}\left(S_{*}\right)$ Relalive permeability of welling phase al wilurallon $S_{*}$ 


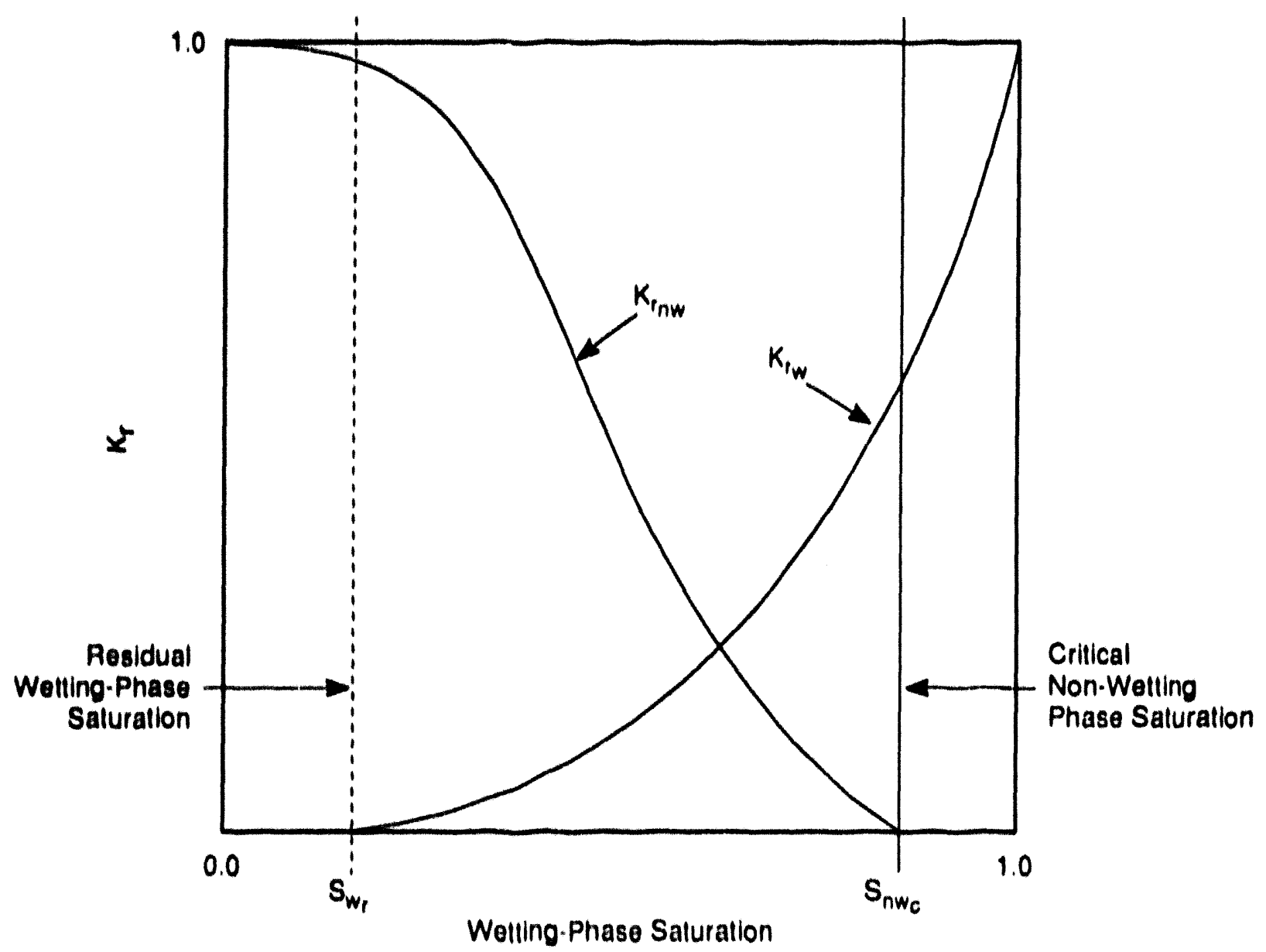

IF161101200

ligure 9. Relative permeability as a function of saturation. 
Techniques used to measure relative permeability fall into one of two categories: steadystate tests and unsteady-state or transient tests. Unsteady-state tests are more common, requiring less time than steady-state tests, but the debate continues as to which technique better reflects in situ flow conditions (Basan et al., 1988).

\subsubsection{STEADY.STATE METHODS}

In steady-state measurements of relative permeability, effective permeability is calculated as a function of saturation, and calculations are based upon the assumption that Equations 13 and 14 correctly model two-phase flow. Direct measurements are then required of volumetric flow rates, pressure differences across the core sample, and saturation levels. Steady-state methods are slow because time is required for the fluids to equilibrate in the rock at each saturation point, typically taking a few days to weeks, depending upon the permeability. The literature refers to a number of techniques for making steady-state relative permeability measurements including the Hassler method, Penn State method, Hafford method, and dispersed-feed method. Basically, each of these lechniques depends upon the same now mechanism, and they differ only in the way fluid is introduced into the core and in the way adjustments are made for end effects.

End effects arise from a saturation discontinuity existing at the outllow face of the core because the fluids flowing through the core are discharged into a region void of the porous medium. At the outflow face, all the fluids exist at the same pressure; whereas immediately within the pores of the rock at the outflow face, capillary pressure conditions require that the saturation of the wetting phase approach $100 \%$ and a saturation gradient is established in the wetting phase of the flow system (Amyx et al., 1960).

Steady-state measurements typically follow these steps to obtain a drainage or desaturation curve (Amyx et al., 1960): 1) a core sample is selected, finished, fully saturated with the welting-phase fluid, and mounted in a core holder or rubber sleeve; 2) the test cell is prepared, and the ends of the core sample are connected to appropriate porous disks or other devices to minimize end effects; 3) the two huids are introduced at the inlet end through separate 
systems at a predetermined ratio; 4) the huids are howed through the core until the produced fluid ratio equals the inlet fluid ratio; 5) the core system is considered to be in sleady-state now, and the saturations are measured and relative permeability calculated for that saluration point: 6) the inlet fluid ratio is increased as more of the welting - phase huid $i$. removed until sleady state conditions are reached. These steps are repeated until the entire relative permeability curve is obtained. An imbibition curve can also be obtained by initially salurating the core wilh the nonwetting phase fluid, and the inlet lluid ratios begin with high nonwelling phase values and end with high wetting-phase values.

Saturations are measured either internally or externally ill a variely of fashions. lixfernal methods include measurement of core resistivily, removal of core from lest cell for weight measurement, and a volumetric balance of all huids injected and produced from the sample. The saturation can be measured internally using $x$-ray or radioactive tracer scans.

\subsubsection{UNSTEADY.STATE METHODS}

According to Rose (1987), in unsleady-stale relative permeability tests. the idea is to observe the cumulative production from controlled iwo phase llow experiments and then back. calculate relative permeability values that are consistemt with the observed oulcomes. This lack of certainty in interpretation of these indirect measurements is ofliset by the small amoumt of time required for the lests and the corresponding lower cost. Unsleady slate lests cain be performed rapidly on small core samples wilh only a small amounl of equipment.

In unsteady state measurements, a core sample is selected, finished, fully silluralled will the welting phase Muid, and mounled in a core holder or rubber slecve. Then gas or other displacement fhuid is injected into the core and outlet end fluid volumes are recorded. Relative permeability is calculated using mathematical models usually based upon the Buckley loverell equation and saturation is calculated using the cumulative production values. The Buckley. leverell equation does not apply until the displacement huid is produced at the outhlow end of the core. According to Amyx ef al. $(1960)$, end effects are not important when gas is the 
displacement fluid because of the high pressure drops involved. The magnitude of capillarypressure end effects is extremely small compared with the imposed flow gradient, so that the equipment required to counteract end effects is unnecessary. In addition, the test time is short, so all effects of gravitational forces can be neglected. If the condition of negligible capillary pressure and gravily effects is satisfied, the only measurements required are cumulative fluid injected and produced as a function of time.

Steady-state and unsteady-state relative permeability measurements do not always agree: many steady-state measurements show little or no hysteresis in the wetting-phase wettability, whereas large amounts of hysteresis occur in unsteady-state measurements (Basan et al., 1988). A detailed investigative study will be made in F:Y9.3 to determine the most appropriate method(s) to use for determining relative permeability of $\mathrm{MB}$ 139. The results of this study will be included in the Test Plan.

\subsubsection{Rock Compressibility and Effective Stress}

\section{ROCK COMPRESSIBILITY}

Rock grain and bulk compressibility values $\left(C_{g \text { man }}\right.$ and $C_{h}$, respectively) are used to calculate specific s: rage (S、), an important input parameter in WIPP PA calculations. Specific storage is defined as the huid volume released from storage per unit decline in hydraulic head per unit bulk volume, and liquation is shows the relationship between specific storage and other rock paramelers (fireen and Wang. 199(1),

$$
S_{s}=\rho, g\left[\left(\frac{1}{K_{b}}-\frac{1}{K_{\text {grain }}}\right)\left(1-\frac{4 G\left(1-K_{b} / K_{\text {grain }}\right) / 3}{K_{b}+4 G / 3}\right)+\phi\left(\frac{1}{K_{t}}-\frac{1}{K_{\text {grain }}}\right)\right]
$$


where

$$
\begin{aligned}
& \rho_{1} \quad=\text { fluid density } \\
& \mathrm{g}=\text { acceleration of gravity } \\
& \mathrm{K}_{\mathrm{b}} \quad=\text { drained bulk modulus of rock }=1 / \mathrm{C}_{\mathrm{b}} \\
& \mathrm{K}_{\mathrm{grain}}=\text { unjacketed bulk modulus of rock (also known as grain, matrix or solids } \\
& \text { modulus) }=1 / \mathrm{C}_{\text {grain }} \\
& \mathrm{G}=\text { drained shear modulus of rock } \\
& \phi \quad=\text { porosity } \\
& \mathrm{K}_{1}=\text { bulk modulus of fluid. }
\end{aligned}
$$

Neither rock grain nor bulk compressibility has been measured for Salado halite or anhydrite material. Estimation of specific storage for PA calculations comes from two sources: (1) data in the literature for other halite and anhydrite samples (Beauheim, 1991) and (2) an $R^{2}$ $\times S_{\mathrm{s}}$ term (where $R$ is the effective wellbore radius) that results from interpretation of in situ borehole flow tests. Because the effective well-bore radius, $\mathrm{R}$, is not a known parameter, inference of specific storage from in situ flow tests may not be justified. Grain and bulk compressibility should be independently measured for Salado rocks to support calculation of specific storage.

As so well stated by Scorer and Miller (1974), the term "rock compressibility" used without further qualification can be almost meaningless or at best incorrectly interpreted. Zimmerman et al. (1986), define four different rock compressibility relationships that relate changes in pore or bulk rock volume $\left(V_{p}\right.$ and $V_{b}$, respectively) to changes in pore or confining pressure $\left(P_{p}\right.$ and $P_{c o m l}$, respectively). As shown in Equations 16 and 17, two of these compressibility relationships are referred to as bulk compressibility, and the other two, shown in Equations 18 and 19, are referred to as pore compressibility. 
Bulk Compressibility - Constant pore pressure, varying confining pressure:

$$
C_{b, \text { conf }}=-\frac{1}{V_{b}}\left[\frac{\delta V_{b}}{\delta P_{\text {conf }}}\right]_{P_{p}}
$$

Bulk Compressibility - Constant confining pressure, varying pore pressure:

$$
C_{b, p}=\frac{1}{V_{b}}\left[\frac{\delta V_{b}}{\delta P_{D}}\right]_{P_{\text {cunt }}}
$$

Pore Compressibility - Constant pore pressure, varying confining pressure:

$$
C_{p, \text { conf }}=-\frac{1}{V_{p}}\left[\frac{\delta V_{p}}{\delta P_{\text {cont }}}\right]_{P_{p}}
$$

Pore Compressibility - Constant confining pressure, varying pore pressure:

$$
C_{p, p}=\frac{1}{V_{p}}\left[\frac{\delta V_{p}}{\delta P_{p}}\right]_{P_{c u n t}} .
$$

In some cases, it may be useful to know or measure one or more of these compressibility relationships for a given rock sample. Because this may not always be practical, it is desirable to have some method of correlating the different compressibility values to each other. As derived by Zimmerman et al. (1986) for an idealized porous solid (i.e., isotropic, homogeneous, with elastic matrix containing void spaces of various shapes and sizes, which forms a completely connected network), the four rock compressibility relationships are not independent, and three 
relationships can be found between them and porosity and rock grain compressibility. In the derivation of these relationships, applied pressures and the resulting strains are incremental changes superimposed on a pre-existing state of stress and strain. While the stress-strain relations that result from this analysis are nonlinear, representing the integration of incremental relations, the total strains will still be infinitesimal in the sense of classical linear elasticity. The boundary conditions assumed in the derivations are (1) uniform hydrostatic pressure, $\mathrm{P}_{\text {comr }}$, over the entire outer surface of the porous body, and (2) uniform hydrostatic pressure, $P_{p}$, over the entire pore surface. Equations 20,21, and 22 express the interrelationships among the rock compressibility relationships shown in Equations 16, 17, 18, and 19.

$$
\begin{gathered}
C_{b, p}=C_{b, \text { cont }}-C_{\text {grain }} \\
C_{p, \text { cont }}=\left(C_{b, \text { cont }}-C_{\text {grain }}\right) / \phi \\
C_{p, p}=\left[C_{b, \text { cont }}-(1+\phi) C_{g r a i n}\right] / \phi
\end{gathered}
$$

where

$$
C_{g r a i n}=\frac{1}{V_{g r a i n}}\left[\frac{\delta V_{\text {grain }}}{\delta P_{D}}\right]_{P_{\text {cunt }} P_{t}}
$$

$C_{\text {mann }}=$ compressibility of the rock grain or matrix material $=1 / \mathrm{K}_{\text {gam }}$

$\mathrm{V}_{\text {grain }}=$ volume of rock grain or matrix material.

The problem with this simplified approach is that most real rocks are neither isotropic, homogeneous, linear, elastic, nor have fully connected pores. Thus, these relationships may be in considerable error, and rock compressibility should be measured. An effort is under way to review methods for measuring rock compressibility and to develop an experimental-lest matrix 
for rock compressibility measurements. A detailed discussion of measurement system(s) for rock compressibility will be included in the Test Plan.

\subsubsection{EFFECTIVE STRESS}

For a given material property or process, the effective stress law is used to describe the appropriate stress state of a rock by defining a relationship between internal pore pressure, $P_{p}$, and confining stress, $\sigma$. A generalized effective stress law is shown in Equation 24, and the classical definition for net effective stress is shown in Equation 25 (Warpinski and Teufel, 1992). The classical definition for net effective stress is the effective stress law for $\alpha=1.0$ so that the net effective stress is given by $\sigma-P_{p}$. While this definition, widely used in soil and hard rock analyses, assumes that $\alpha$ is constant, thereby resulting in a linear effective stress law, there is no reason that $\alpha$ cannot vary with either $\sigma$ or $P_{p}$ (Warpinski and Teufel, 1992).

$$
P=G\left(\sigma-\alpha P_{p}\right)
$$

where

$\mathrm{P} \quad=$ the specific material property or process (i.e., permeability, deformation, rock compressibility, or capillary pressure)

$\mathrm{G}=$ generalized function which describes the effect of stress on the property or process

$\sigma \quad=$ external confining stress on the sample (for hydrostatic conditions $\sigma=\mathrm{P}_{\text {conf }}$ )

$\mathrm{P}_{\mathrm{p}} \quad=$ pore pressure

$\alpha \quad=$ poroelastic parameter that relates stress and pore pressure

$\left(\sigma-\alpha \mathrm{P}_{\mathrm{p}}\right) \quad=$ net effective stress.

$$
\sigma^{\prime}=\sigma-P_{p}
$$

where

$$
\begin{array}{ll}
\sigma^{\circ} & =\text { net effective stress } \\
\sigma & =\text { external confining stress on the sample (for hydrostatic conditions } \sigma=P_{\text {cont }} \text { ) } \\
P_{\mathrm{p}} & =\text { pore pressure. }
\end{array}
$$


Warpinski and Teufel (1992) studied the effective stress law for permeability and deformation of tight sandstones and chalk and showed that the effective stress law is different for different processes. Their results for permeability measurements of tight sandstone, showed that $\alpha$ is near 1.0 for small stresses, but that behavior can become uncertain for large stresses. For the chalk samples, there was not a large amount of change in permeability with stress or pressure, so the effective stress law was of questionable value, although the effective stress behavior was very nonlinear. Sandstone deformation measurements resulted in $\alpha$ values ranging between 0.65 and 0.95 , varying with both stress and pressure. For chalk deformation measurements, $\alpha$ was relatively constant: 0.8 in loading and 0.9 in unloading stress conditions. The researchers noted that agreement between their alpha values and those calculated from theoretical considerations was "poor," stating "the non-linear, anisotropic, nonhomogeneous behavior typical of rocks invalidates any theory of the effective stress law that is based on linear elasticity and constant material properties."

Warpinski and Teufel (1992) found low-permeability low-porosity rocks difficult to work with because many of the rock properties, including permeability and deformation, are dominated by microcracks that do not exist at in situ stress condition. They recommend that the effects of microcracks be eliminated or minimized to obtain acceptable measurements.

An effort is under way to more completely consider and evaluate the need for determining the effective stress laws for Salado single- and two-phase how properties within the scope of this laboratory program. A detailed discussion of the need for effective stress law evaluation and (if necessary) test methodologies will be included in the Test Plan.

\subsection{Program Milestones}

Tentative milestones and a schedule for the Salado Two-Phase Flow Laboratory Program, which coincides with the roadmap exhibited in Figure 4, are shown in figure 10. Program activities began in January 1992 with the initiation of scoping activities, and anhydrite experiments are scheduled to begin in FY94. The program life-span, including tests on halite material, is projected through FY97. 


\begin{tabular}{|c|c|c|c|c|c|c|c|c|}
\hline & $F Y 92$ & FY93 & FY94 & EY95 & FY96 & FY97 & FY96 & EYQ2 \\
\hline Two. Phase Flow Program Test Plan & $2 / 22$ & Prolim Fim & & & & & & \\
\hline Experiment Bcoping Activilies & 292 29 & & & & & & & \\
\hline Cooperedive Program with GRS/KFA & & 323. & $\ldots$ ? con holes & & & & & \\
\hline $\begin{array}{l}\text { Prolliminary Tosis-Porm, Porosity } \\
\text { Capillary Press and Cors Damage } \\
\end{array}$ & 80 & & $12 / 93$ & & & & & \\
\hline Exporimenls & & & $12 / 23 \quad 6 / 94$ & & & & & \\
\hline Reports & & & $6 / 24$ & 8104 & & & & \\
\hline Develop Tool/ Techniques & & & $3 / 94 \quad 9$ & 94 & & & & \\
\hline Threshold/Capillary Pressure & & $11 / 192 \quad 0 / 83$ & & & & \multirow{2}{*}{\multicolumn{2}{|c|}{$\begin{array}{l}\mathrm{D}=\text { Design Develop } \\
\mathrm{O}=\text { Order } \\
\mathrm{B}=\text { Build } \\
\mathrm{C}=\text { Calibrale }\end{array}$}} & \\
\hline Relallve Premeability & & $11 / 102 \quad 6 / 83$ & & & & & & \\
\hline Sol. Up Laboralory & & 2/93 & & 84 & & & & \\
\hline $\begin{array}{l}\text { Single Phase (pormeabilly-vs porcosty) } \\
\text { - Ropon }\end{array}$ & & $\mid \begin{array}{c}1 / 934936 / 93 \\
0\end{array}$ & $\frac{9 / 93}{\text { Tosis }}$ & 89.5 & $12 / 95$ & & & \\
\hline $\begin{array}{l}\text { Two.Phase (relative perm, ihreshold } \\
\text { Prese. capillary press) } \\
\text {-Report }\end{array}$ & & $\frac{3 / 93}{010}$ & 0 & $\mid \begin{array}{l}9412 / 94 \\
\end{array}$ & $\begin{array}{l}0 / 96 \\
6 / 86 \\
\end{array}$ & 12106 & & \\
\hline $\begin{array}{l}\text { Single Phase } \\
\text { - Peport } \\
\end{array}$ & & & 0,0 & 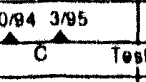 & $\frac{8196}{8 / 96}$ & $12 / 90$ & & \\
\hline $\begin{array}{c}\text { Two Phase } \\
\text { - Aepont }\end{array}$ & & & & $1 / 85$ & 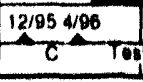 & $\begin{array}{l}407 \\
407 \\
\end{array}$ & 97 & \\
\hline
\end{tabular}

191. 6110.1240

Figure 10. Salado Two-Phase Flow Laboratory Program tentative schedule and milestones. 
Fy92 was spent detining the program in terms of identifying the customers and their needs, determining which Salado or other malerials to test. lest priorilies, which wate of the art technologies ate available and applicable for the lests, and idsonfifying potential

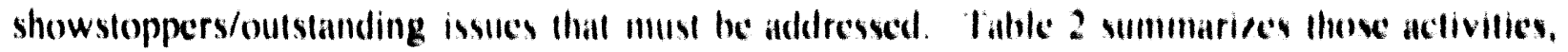
including a listing of the issues, how they were addressed, and the rewolution.

The tasks outlined for l:Y93 lall into three calcegories: Scoping Activities, Program

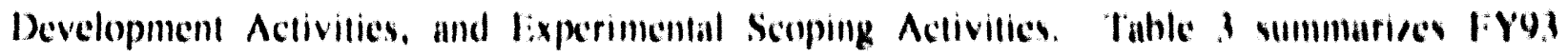
scoping activities, which comsist of (1) the coaluation of two phase how techmologeses for measurement of threshold and capillary pressure and relative permetibility and (2) preliminaty scoping experiments. Program Developmentur activities, exhibiled in Table to include the completion of a program test plan, the establishment of a colliaburative prongram with (iermann scientists at GRS/KI:A, and the development of rock and single and two phase flow lithoratury facilities at SNL. Table 5 summariess the experimental activities, including core characterization, core danage assessment, and reck and llow properties. Table 5 also identifies the properties that will be measured and the type and number of tess that will be performed in 1:Y9.3.

PYY94 will be spent performing single phatse llow expermenents, designing and building

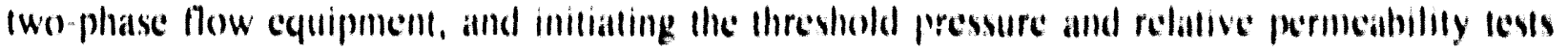

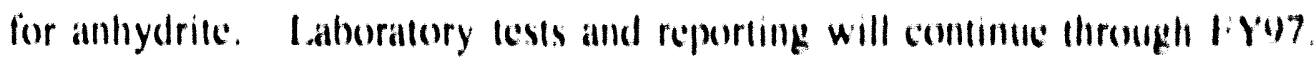


Table \& Summary of 1:Y92 Scoping Activilics

\begin{tabular}{|c|c|c|}
\hline Invice & How Adltreswe & Ohilcome \\
\hline Whe we the Invtumen" & 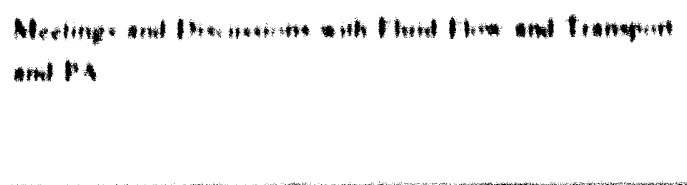 & 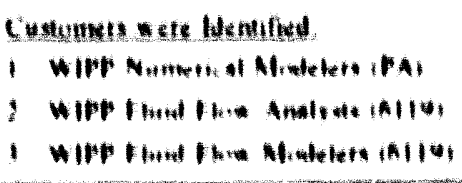 \\
\hline 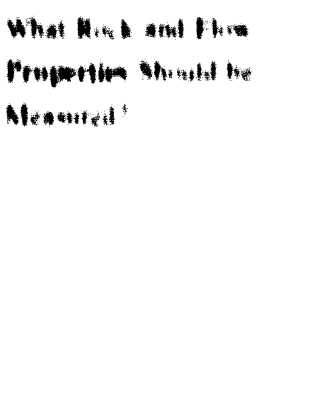 & 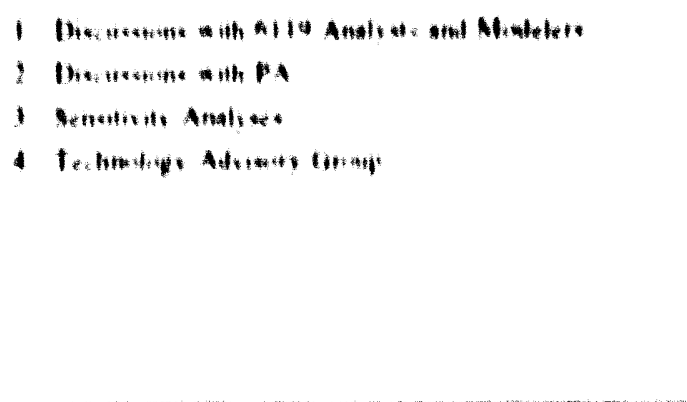 & 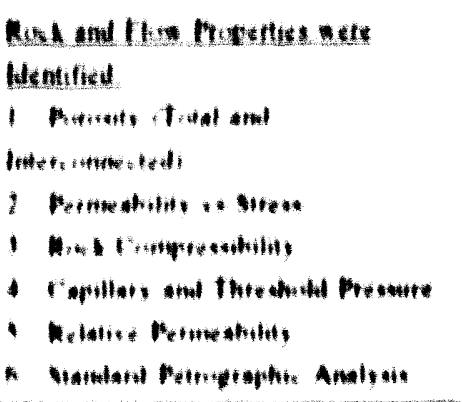 \\
\hline 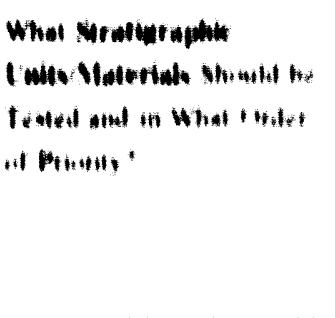 & 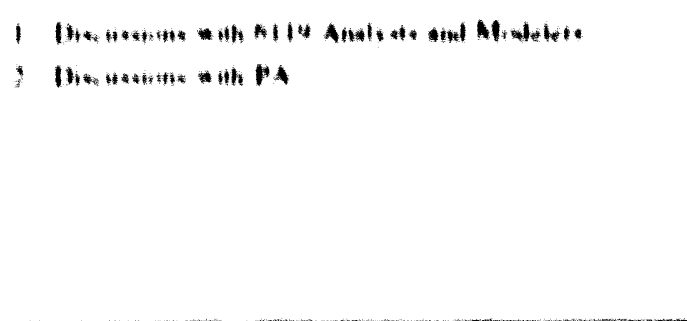 & 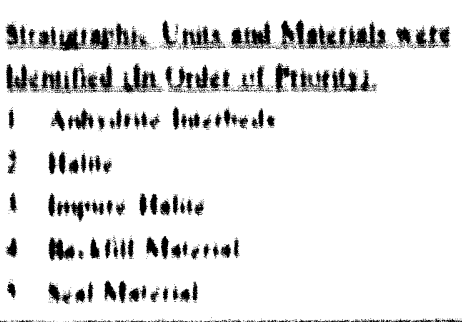 \\
\hline 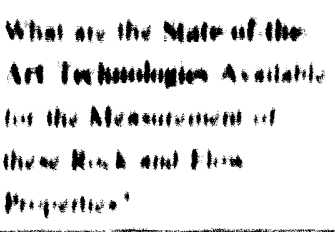 & 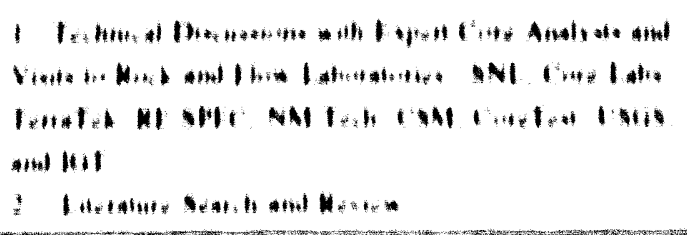 & 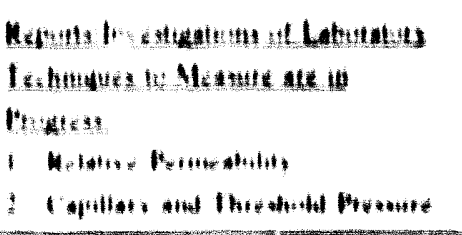 \\
\hline 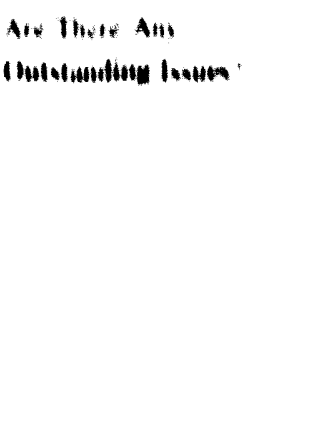 & 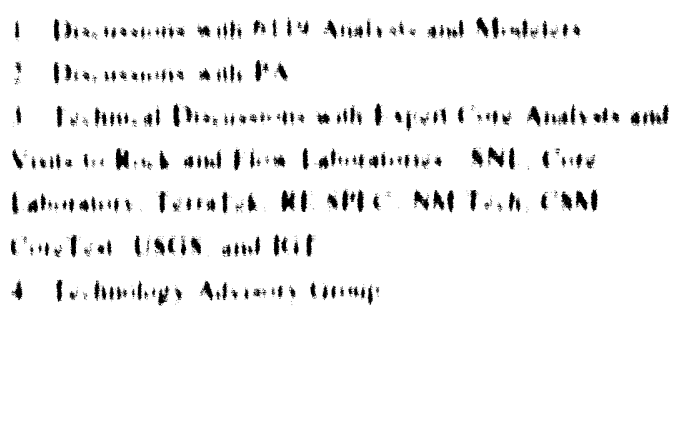 & 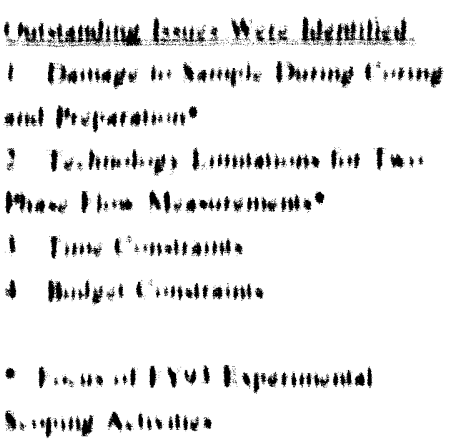 \\
\hline
\end{tabular}


Tahle I. Summary of It YOI Scoping Activities

\begin{tabular}{|c|c|}
\hline Actlivily & Slatis \\
\hline 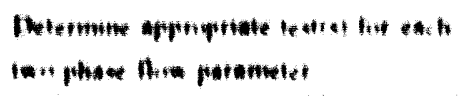 & 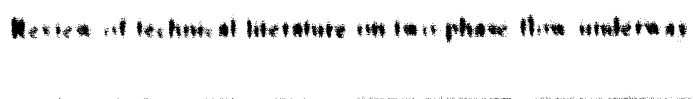 \\
\hline 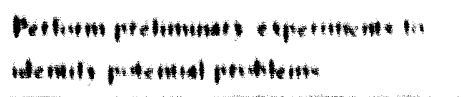 & 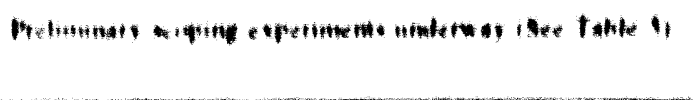 \\
\hline
\end{tabular}

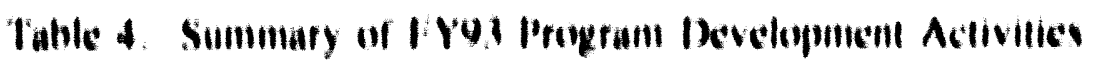

\begin{tabular}{|c|c|}
\hline Acllvily & Statis \\
\hline 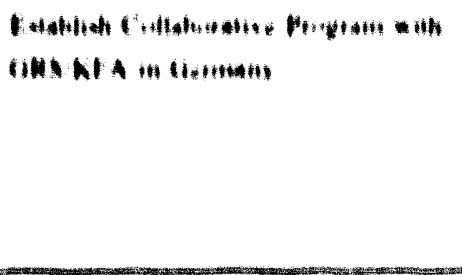 & 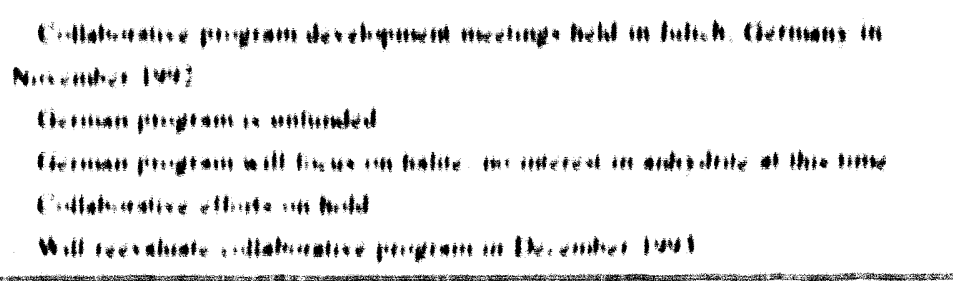 \\
\hline 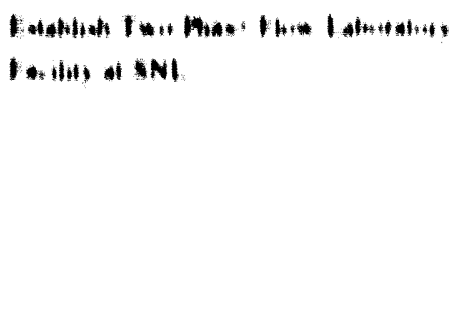 & 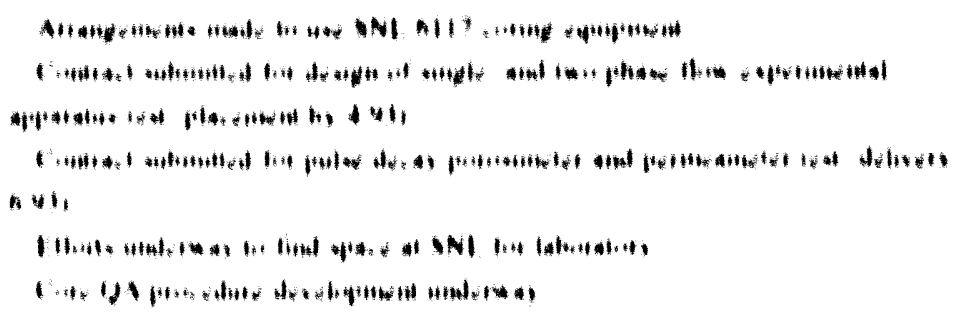 \\
\hline 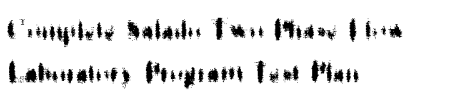 & 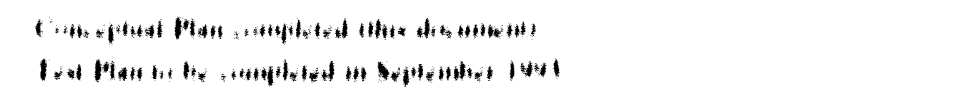 \\
\hline
\end{tabular}


Table S. Summary of liy93 lexperimental Scoping Activilles*

\begin{tabular}{|c|c|c|}
\hline Iroperty & Teut & Number of Tests \\
\hline 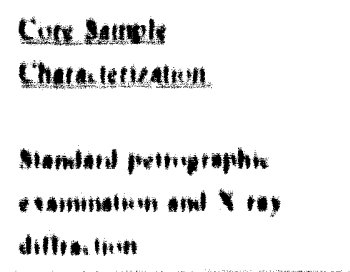 & 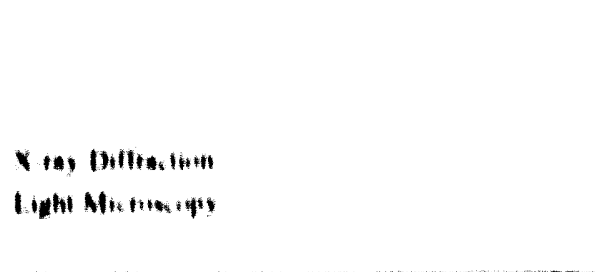 & $\begin{array}{l}12 \\
12\end{array}$ \\
\hline 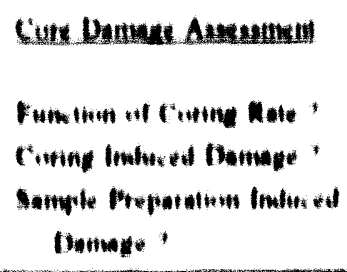 & 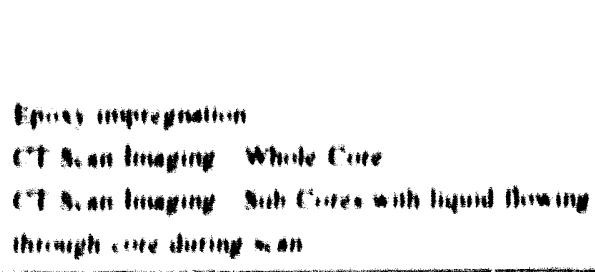 & 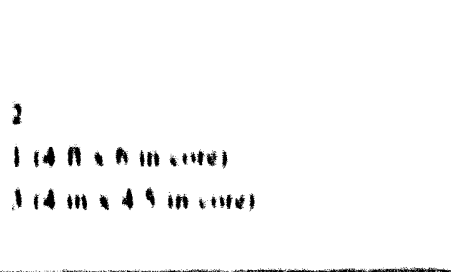 \\
\hline $\begin{array}{l}\text { Eal un } 1 \text { les } \\
\text { Minesil }\end{array}$ & $\begin{array}{l}\text { Tital } \\
\text { lowitatumited }\end{array}$ & ii \\
\hline 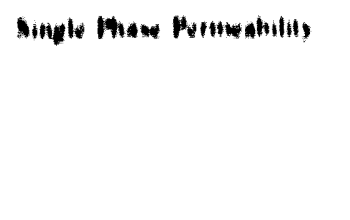 & 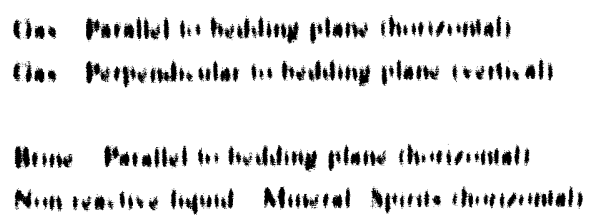 & $\begin{array}{l}11 \\
111 \\
n\end{array}$ \\
\hline Enpilient Herenter & 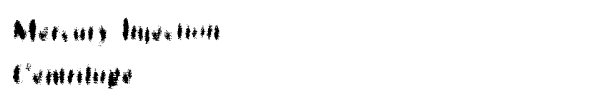 & I11 \\
\hline
\end{tabular}

- All lesis lo be performed on Marker Bed 1,39 anhydrile corse samples 


\subsection{SITE SUPPORT}

Because the two-phase flow tests will take place at SNL's Albuquerque location or at a contractor's laboratory facility, limited WIPP-site support will be required. The core material necessary for these lests will require drill-coring and core-logging services provided by the WIPP Management and Operating Contractor (MOC). These and any additional services will be coordinated through the SNL manager of WIPP-site operations, using standard procedures.

Anticipated services will be identified at the completion of preliminary tests and will be addressed in the Test Plan. 


\subsection{OPERATIONS}

\subsection{Personnel Responsibilities (Delegation of Authority)}

The following procedures and program policies apply to test implementation and operation.

\subsubsection{Site Operations Test Activities}

The WIPP Site Operations Department (6343) Manager is responsible for coordinating site activities and ensuring worker safety at the WIPP site. As part of these overall site duties, the manager is specifically responsible for:

- coordinating SNI, requirements with DOE and the Westinghouse Electric Corporation's Waste Isolation Division (WID)):

- coordinating overall test operations between SNI. and WID Experimental Operations;

- controlling and coordinating all underground visits to the test areas;

- reporting progress of the test activities to SNI, management, DOE, and WID as deemed appropriate;

- managing the safely and security requirements for SNL underground testing programs.

\subsubsection{Technical Direction}

S.M. Howarth (Department 6119, phone (505) 844-0303) is the Principal Investigator (PI) for the technical work to be performed under this conceptual plan. Howarth has primary 
responsibility for the two-phase flow laboratory program. The PI has responsibility for conducting the tests within the following specific areas of authority:

- $\quad$ test objectives and test configurations;

- direction of WIPP-site and laboratory contractors;

- selection of locations for coring, and selection and approval of equipment design and modifications;

- determination of experiment operating parameters, such as pressures, rates of pressure buildup, flow rates, test fluids, test duration, data acquisition sampling rates, and other parameters related to the conduct of tests;

- test analysis;

- approval of any proposed changes to the testing equipment and procedures;

- approval of procedures for documentation and control of field and laboratory log books;

- approval of installation forms, calibration forms, data readings, etc.;

- $\quad$ preparation of data reports, analyses, and evaluations;

- approval for data dissemination and report distribution, both within SNL and externally.

\subsubsection{WIPP Quality Assurance Chief}

S.Y. Pickering (Department 6303, phone (505) 887-8430; WIPP site) is the WIPP Quality Assurance (QA) Chief with the following responsibilities:

- to establish and maintain a documented and approved "Quality Assurance Program Description (QAPD)";

- $\quad$ to conduct periodic QA audits to ensure compliance with the QAPD;

- $\quad$ to ensure that data are acquired and maintained in accordance with QA requirements;

- to review and approve test and reporting procedures to verify that all experimental work is conducted in accordance with those procedures; 
- to ensure that staff are appropriately trained and operationally familiar with QA requirements;

- to review Nonconformance Reports and verify implementation of corrective actions;

- to ensure that all gages and instruments are calibrated in accordance with documented calibration procedures, using standards that are traceable to nationally recognized standards;

- to ensure that SNI. QA requirements are transmitted to contractors associated with the testing program; and

- to coordinate Sandia QA and Westinghouse QA personnel.

\subsection{Test Schedule}

Nonexperimental scoping activities associated with this conceptual plan began in January 1992. Experimental scoping activities began in October 1992 and will continue through calendar year 1993. The results and recommendations from these scoping activities will be used to establish the scope of the Test Plan for the Two-Phase Flow Laboratory Program.

\subsection{Operational Safety and Environment}

\subsubsection{Safety Requirements}

The equipment for this testing program will consist of commercially acquired or SNLfabricated components that will be rated for appropriate maximum allowable operating pressures. Pressure ratings of individual parts, such as valves and pressure lines, are either marked by the supplier or documented in data packages according to guidelines of the SNI Department 6343 Safety Representative for WIPP Site Operations or the SNL 6100 or 6300 Pressure Safety Advisor for WIPP site lest operations or SNI. New Mexico laboratory operations, respectively. 
Operational safety will be addressed through the SNL Environmental Safety and Health (ES\&H) standard operating procedures (SOPS) developed by the site supervisor, and other relevant procedures. Project-specific WIPP-site safety procedures will be approved through the PI, WIPP-site safety personnel, and the SNL safety organization. The ES\&H SOP's include:

- identification of potential hazards;

- emergency shutdown procedures;

- personnel to be contacled in case of emergencies.

\subsubsection{Environment}

SNL facility and WIPP-site environmental considerations of the specific Two-Phase Flow Laboratory Program tests will be determined once the appropriate testing techniques and methods are identified. Environmental concerns will be addressed in the Two-Phase Flow Laboratory Program Test Plan. 


\subsection{SPECIAL TRAINING}

Personnel responsible for performing the tests within the Two-Phase Flow Laboratory Program will be trained in the design and operation of the test equipment and in all attendant safety procedures. A formal safety briefing will be part of the testing procedures and all personnel will affirm that they have read and understood the relevant SOPs for the laboratory and WIPP-site tests. No additional special training is anticipated. 


\subsection{TEST MANAGEMENT}

\subsection{Test Plan Review and Approval}

The "Test Plan: Two-Phase Flow Laboratory Program For The Waste Isolation Pilot Plant" will be reviewed and approved according to standard SNL/WIPP procedures. This conceptual plan will be reviewed according to all applicable SNL guidelines for SAND reports.

\subsection{Management Interface}

Development of the WIPP is the responsibility of the DOE and is supported by two major participants: SNL and Westinghouse Electric Corporation. The Technology Development Program is the responsibility of Sandia. Westinghouse Electric Corporation's WID is the MOC for the WIPP facility, which includes design support, overall safety assurance support, facility operations, and environment and institutional support.

The drill-coring and core-logging required to support the tests described in this document will be implemented by SNL with the assistance of WID experimental support personnel under the direction of SNL. Coordination of coring activities may include the procurement of needed hardware, implementation of coring activities, and preparation of interface documents.

In accordance with the management organization, the SNL PI is responsible for all aspects of the tests, from planning to final data analysis and evaluation of the results. The PI reports to the Fluid Flow and Transport Department (6119) of the Geoscience and Geotechnology Center (6100). The PI will also direct, as needed, the activities of other organizations and contractors through the matrix management structure established within SNL. 


\subsection{Procurement Procedures}

Services, malcrial, and equipment for the lesting program will be procured by the SNI. Purchasing Organization (7216) or through SNI, s contractors, using DOI:-accepled procedures and practices. Purchases of hazardous materials must be approved the SNI. Safety Representative for WIPP Site Operations if the materials are intended to be used at the WIPP. Procured materials and equipment will be shipped to SNI. Shipping and Receiving Division (3912) and transferred to an assembly point al SNI. or to the designated SNI. or subcontractor representative at the WIPP site. Itemis can be shipped directly to the WIPP site and will be properly received by the designated SNL. or subcontractor representative at the site.

\subsection{Quality Assurance Requirements}

All SNL tests are implemented in accordance with SNI.'s Waste Isolation Pilot Plant "Quality Assurance Program Description (QAPD)." The QAPD meets the requirements of NQA-1-1989, DOE: 570().6c, and Chapter II of the Final Safe'y Allalysis Report. This QA plan has been approved by the DOI:/WPIO and DOE/WPSO for all WIPP activities assigned to SNI. and is specific to the WIPP Project. Contractor personnel working with SNI, personnel, either at the WIPP site or in Albuquerque, are subject to the WIPP QAPI) or their own SNI.-approved QA program. Specific applications of the WIPP QAPI) to the present tests have been incorporated throughout this conceptual plan.

Documentation of the preparation for this experiment may include:

- the test plan and appropriate approvals;

- photographs showing equipment and interconnections of apparalus;

- instrument calibration records;

- notebooks, logbooks, WIPP procedures, worksheets, and forms for installation and operation. 
The Pl, contractors, of personnel designated by the PI will be responsible for dala acquisition and storage and for assuring that all documentation at the WIPP site is maintained in accordance with the WIPP QAPD. Deviations from lest plans and nonconformances of unusual occurrences will also be recorded in Test Plan Appendices, and appropriale forms will be completed.

\subsection{Data Trancefer}

Throughout the lests, data will be acquired and documenled in notebooks and on lloppy disks. Copies of all basic data reports and interpretive reports with accompanying analyses/evaluations will be transferred through DOE/WPIO to interested agencies, institutions, and scientific and enginecring communities for application to radioactive waste projects. Photographs for lechnical examination, illustrations, and records will be made available for lechnical evaluation as well as for public viewing, as authorized hy the DOP/WPIO. 


\subsection{REFERENCES}

Amyx, J.W., D.M. Bass, Jr., and R.I. Whiting. 1960. Petroleum Reservoir Engineering: Physical Propertices. New York, NY: McGraw-Hill, Inc.

API (American Petroleum Instilute). 1956. Recommended Practice for Determining Permeabiliry of Pormus Media. API RP 27. Washinglon, DC: American Petroleum Institute.

API (American Petroleum Instifule). 1960). Recommended Practice for Rock Core-Analysis Procedure. API RP 40. Washington, DC: American Petroleum Institute.

Basan, P., J.R. Hook, K. Hughes, J. Kathmell, and D.C. Thomas. 1988. "Measuring Porosity, Saturation and Permeability from Cores: An Appreciation of the Difficulties," The Terhnical Review (A Schlumberger Publiculiom). Volume 36, no. 4, 22-36.

Bass, D.M., Jr. 1987. "Properties of Reservoir Rocks," Poiroloum Engincering Ilamdbook. Ed. H. B. Bradley. Richardson, TX: Society of Petroleum Engineers. Chapter 26.

Beauheim, R.L., G.J. Saulnier, Jr., and J.D. Avis. 1991. Imerpronutom of Brime-Permenohility Tesss of the Salado Fommanion at the Waste Isolarion Pilon Plame Site: First Interim Report. SANID90-(0)8.3. Albuquerque. NM: Sandia National Laboratories.

Black, S.R., R.S. Newion, and D.K. Shukla, eds. 1983. Resulls of the Sire Validarion Experiments. Volume II, Supporting Dociume'ml 14. TME: 3177, Rev, 2.0. Carlsbad, NM: US Deparment of linergy.

Brace, W.F., J.B. Walsh, and W.T. Frangos. 1968. "Permeability of Ciranite Under High

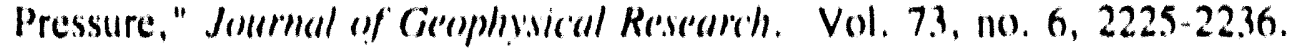

Brooks, R.H., and A.T. Corey. 1964. Hydraulic Propertices of Poroms Media. Hydrology Paper No, 3, loort Collins, (O): Colorado State University.

Davies, P.B. 1989. "Preliminary Threshold Pressure Estimates and Status of Two-Phase Simulation of Waste-Cienerated Cias," Nollomal Academy of Scicences WIPP Review Panel, Holf Moom Bay, CA, Do'cember 13, 1989. (Copy on lile at the Waste Management and Transporlation Library. Sandia National Laboratories, Albuquerque, NM).

Davies, P.B. 1991. Evaluanion of the Role of Threshold Pressure in Combrolling Flow of

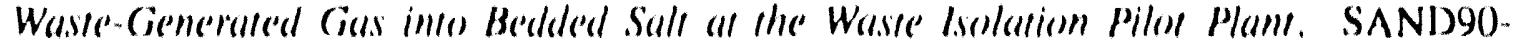
3246. Albuquerque, NM: Sandia National I aboratories. 
Davies, P.B., (i. lireese, M. Reeves, and T. Cauffinan. 1990. "Status Report on Multi-Phase Simulations of Waste-Ciencrated Gas at the WIPP Repository," National Acodemy of

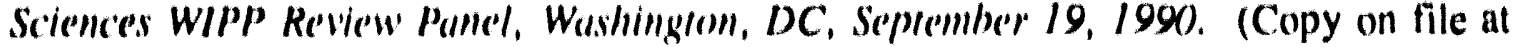
the Waste Management and Transportation Library. Sandia National Laboratories, Albuquerque, NM).

Davies, P.B., L.H. Brush, M.A. Molecke, F.T. Mendenhall, and S.W. Webb, eds. 1991. Waste-Cionerated Gas al the Waste lsolation Pilot Plant: Paperis Pressemed at the

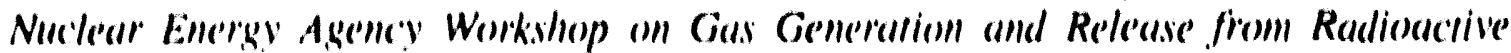
Waste Reposilories. SANI)91-2378. Albuquerque, NM: Sandia National Laboratories.

Davies, P.B., R.L. Beauheim, and I.D. Gorham. 1992. Appendix A: "Additional Comments on Far-Field Anhydrite Permeability Distribution in 'PA Modeling Usi.lg

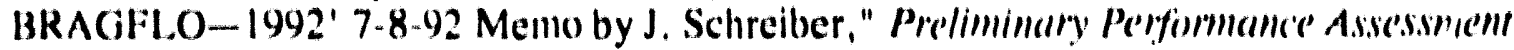

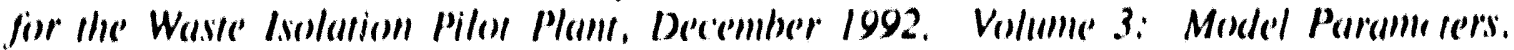
Sandia WIPP Project. SANID92-(07(0)/3. Albuquerque, NM: Sandia National Laboratories. A-39 through A-4.5.

Falt, I., and D.H. Davis. 1952. "Reduction in Permeability with Overburden Pressure," Protrols'um Trumsurnioms, AIME. Vol. 195, 329.

Freeman, D.L., and D.C. Bush. 198.3. "Low-Permeability Laboratory Measurements by Nonsteady-State and Conventional Methods," Society of Petroletem Engine'ers Jourmal. Vol. 23, no., 6, 928-9.36.

Ciorham, L. 1993. "Appendix A: Documentation of RCRA Recommendations to PA for Salado Formation Permeability and Pore Pressure," Comcepmonal Plan: Two- Phase Flow

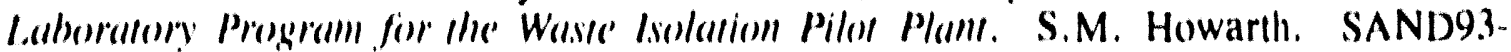
1197. Albuquerque, NM: Sandia National Laboratories.

(iray, D.H., I. Fall, and (j. Bergamini. 196.3. "The leffect of Stress on Permeability of

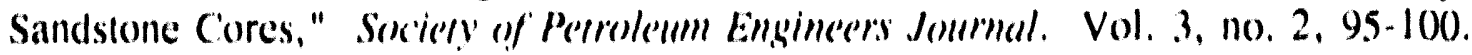

Green, D.H., and H.F, Wang. 1990, "Specific Storage as a Porcelastic Coefficient," Waller Resourcess Reseserch. Vol. 26, no, 7, 16.31-16.37.

Hsich, P.A., J.V. Tracy, (.L:. Neuzil, J.D. Bredehoeft, and S.L., Silliman. 1981. "A 'Transient Laboratory Method for Determining the Hydraulic Properties of 'Tight' Rocks - 1. Theory," Intermational Jommal of Rock Medhanics and Mining Sciences \& Geomechanicis Abstracks, Vol. 18, no. 3, 245-252.

Jones, F.O., and W.W. Owens. 1980. "A Laboratory Study of L.ow-Permeability Gas Sands,"

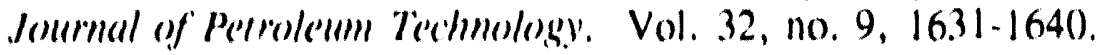


Keclan, D.K. 1972. "A Critical Review of Core Analysis Techniques," The Journal of Canadian Petroleum Technology. Vol. 11, no. 2, 42-55.

Klinkenherg, L.J. 1941. "The Permeability of Porous Media to Liquids and Gases," API Drilling and Production Practice. 200-213.

McLatchie, A.S., R.A. Hemstock, and J.W. Young. 1958. "The Effective Compressibility of Reservoir Rock and its Effects on Permeability," Journal of Petroleum Technology. June 1958, 49-51.

Morrow, N.R., J.S. Ward, and K.R. Brower, 1986. Rock Matrix and Fracture Analysis of Flow in Western Tight Gas Sands - 1985 Annual Report. DOE/MC/21179-2032. Socorro, NM: New Mexico Institute of Mining and Technology, New Mexico Petroleum Recovery Research Center.

Parker, J.C., R.J. Lenhard, and T. Kuppusamy, 1987. "A Parametric Model for Constitutive Properties Governing Multiphase Flow in Porous Media," Water Resources Research. Vol. 23, no. 4, 618-624.

Rechard, R.P., H. luzzolino, and J.S. Sandha, 1990. Data Used in Preliminary Performance Assessment of the Waste Isolation Pilot Plant (1990). SAND89-2408. Albuquerque, NM: Sandia National Laboratories.

Rose, W. 1987. "Relative Permeability," Petroleum Engineering Handbook. Ed. H.B. Bradley. Richardson, TX: Society of Petroleum Engineers. Chapter 28.

Rudd, N. 1974. "New Techniques for Threshold Pressure Determination in Gas Storage Cap Rock " Geo-Engineering Laboratories, Inc. Tech Memo No. 6. Chicago, IL: Institute of Gas Technology.

Saulnier, G.J. Jr. 1992. "Test Plan: Gas-Threshold-Pressure Testing of the Salado Formation in the WIPP Underground Facility." Albuquerque, NM: Sandia National Laboratories. (Copy on file at the Waste Management and Transportation Library, Sandia National Laboratories, Alhuquerque, NM).

Scorer, J.D.T., and F.G. Miller. 1974. A Review of Reservoir Rock Compressibility, and Its Relationship to Oil and Gas Recovery. IP-74-003. London, England: Institute of Petroleum.

Thomas, L.K., D.L. Katz, and M.R. Tek. 1968. "Threshold Pressure Phenomena in Porous Media," Society of Petroleum Engineers Journal. Vol. 8, no. 2, 174-184. 
Warpinski, N.R., and L.W. Teufel. 1992. "Determination of the Effective Stress Law for Permeability and Deformation in Low-Permeability Rocks," SPE Formation Evaluation. Vol. 7, no. 2, 123-131.

Webb, S.W. 1992. "Appendix A: Two-Phase Characteristic Curves," Steady-State Saturation Profiles for Linear Immiscible Fluid Displacement in Porous Media. S.W. Webb. SAND91-2924. Albuquerque, NM: Sandia National Laboratories. A-1 through A-6.

Zimmerman, R.W., W.H. Somerton, and M.S. King. 1986. "Compressibility of Porous Rocks," Journal of Geophysical Research. Vol. 91, no. B12, 12,765-12,777. 


\subsection{ACRONYM LIST}

API

API RP American Petroleum Institute Recommended Practice

CSM Colorado School of Mines; Golden, Colorado

CT Computed Tomography or Computer Aided Tomography

DOE U.S. Department of Energy

IGT Institute for Gas Technology; Chicago, Illinois

LM Light Microscopy

MB $139 \quad$ Marker Bed 139

MOC Management and Operating Contractor

NAGRA Switzerland's national consortium for safe nuclear waste disposal

NAS National Academy of Sciences

NMR Nuclear Magnetic Resonance imaging

PA Performance Assessment

PI Principal Investigator

QA Quality Assurance

QAPD Quality Assurance Program Description

RE/SPEC RE/SPEC Inc.; Rapid City, South Dakota

RCRA Resource, Conservation, and Recovery Act of 1976 (Public Law 94-580) and subsequent amendments (e.g., HSWA - Hazardous and Solid Waste Amendments of 1984)

SCA Society of Core Analysts 


\section{ACRONYM LIST (CONTINUED)}

SEM Scanning Electron Microscope

SNL Sandia National Laboratories

SOP Standard Operating Procedure

SPE Society of Petroleum Engineers

TAG Technical Advisory Group

USGS U.S. Geological Survey

WID Waste Isolation Division of Westinghouse Electric Corporation

WIPP Waste Isolation Pilot Plant

WPIO WIPP Project Integration Office

WPSO WIPP Project Site Office

XRD X-ray Diffraction 


\section{APPENDIX A}

Gorham, E.D. 1992. "Documentation of RCRA Recommendations to PA for Salado Formation Permeability and Pore Pressure." Internal memorandum to B. Butcher, 6342.

Albuquerque, NM: Sandia National Laboratories. August 19, 1992. 
date: August 19, 1992

Sandia National Laboratories

to: Barry Butcher, 6342

Albuquerque, New Mexico 87185
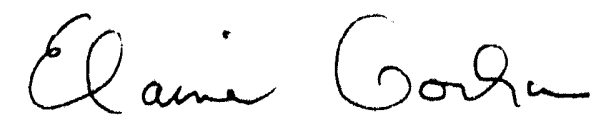

from: Elaine Gorham, 6119, 4-1401

subject: Documentation of RCRA Recommendations to PA for salado Formation Permeability and Pore Pressure

Attached is complete documentation of the rationale for the 6119 recommendation to $P A$ for the RCRA calculations. In this document we remained true to our original recommendations, although, now that we understand your models better, we would change the recommendations.

You may publish the documentation as part of your RCRA documentation. The format we used is more appropriate for publication than memos.

If this format seems appropriate for your purposes we will record our 40 CFR 191 part $B$ recommendations in a similar format shortly. If you have any questions or comments, please call me.

Distribution

$\begin{array}{ll}6100 & \text { P. Hommert, Acting } \\ 6119 & \text { R. Beauheim } \\ 6119 & \text { P. Davies } \\ 6119 & \text { S. Howarth } \\ 6119 & \text { S. Webb } \\ 6300 & \text { D. Miller } \\ 6303 & \text { W. Weart } \\ 6342 & \text { D. R. Anderson } \\ 6342 & \text { M. Tierney } \\ \text { WPIO } & \text { R. Becker }\end{array}$


Recommendations to PA on

Salado Formation Intrinsic Permeabli ity and Pore pressure for

RCRA Calculations

April I, 1992
Elaine Gorham
$\frac{\text { Bichard Beauheim }}{\text { Peter Davies }}$
$\frac{\text { Susan Howarth }}{\text { Stephen Webb }}$

Department 6119

\section{Introduction}

In March 1992, the Fluid Flow and Transport Department was asked to recommend salado Formation permeability and pore pressure probability distributions to be used in the 1992 RCRA calculations for the WIPP. The recommendations were requested and transmitted informaliy. This description is to satisfy the requirement to record the recommendations supplied on April 1, 1992 and the rationale for them.

since input parameters, such as permeability or formation pore pressure, are, for the most part, inferred from complex hydrologic tests, the interpretive model assumptions should be compatible with the predictive or performance assessment model in which the parameters will be used. Thus a suggested excavation geometry and zoning scheme was supplied along with recommended distributions for permeability and pore pressure. The recommended initial geometry is shown in Figure 1 and the distributions suggested for permeability and pore pressure (Table 1 and Figures 2-8) were referenced with respect to those zones.

\section{Our Assumptions}

Assumptions about the models to be used in the PA calculations that were essential in formulating the RCRA data recommendations were not included in any written material transmitted to the performance Assessment Department. Our assumptions were

1. The Salado Formation was described as consisting of layers of either halite or anhydrite. Parts of the salado Formation described as argillaceous halite were lumped with the halite; clay seams were lumped with the type of lithology in which they occurred. Anhydrites a and b were lumped together.

2. The salado Formation was isotropic and homogeneous within each layer of halite or anhydrite. The halite and anhydrite have interconnected porosity. 
3. The repository will have been open, dry and at atmospheric pressure for at least 30 years before the performance assessment calculations begin, that is, during the repository operational phase. An explicit calculation of formation depressurization or other effects resulting from the operational phase will not be performed as part of the PA calculations but will be taken into account in the initial conditions of the calculation.

4. Excavation closure effects will be included in the PA model as well as pressurized fracture opening in the anhydrite beds. [These assumptions were incorrect, as it was later learned that neither of these processes were modeled in the PA RCRA calculations.] Pressurized fracture opening in the anhydrite beds may have the potential to significantly increase far-field interbed permeabilities.

5. The nature of the disturbed rock zone (DRZ) is uncertain, reflecting the diversity of technical hypotheses that have been formulated, documented and undocumented. These include the hypothesis that the DRZ is a zone of increased porosity surrounding the excavation, that is stable in extent or increasing in extent with the age of the excavation. other hypotheses concerning the nature of the DRZ are that the bulk properties of the halite within the DRZ are unchanged, but that within the DRZ fractures form that result in a large increase in permeability with a relatively small increase in porosity or storativity within the DRZ. The size of the DRZ cil vary from a few inches into the formation from an excavation surface to a few "room-radil" away from the excavation surface. It was assumed that all possible descriptions of the DRZ should be included in the probability distributions for permeability and porosity in the DRZ.

6. The DRZ does not reconsolidate during the post-closure calculations due to repository re-pressurization or creep closure of the excavation.

\section{Bources of unoertainty in interpreting data.}

The process of inferring permeablilty from a hydrologic pulse or shut-in test requires that one make an assumption about the diffusivity or specific storage in the formation, about the size of a damaged zone surrounding the test zone, and that the compressiblilty of the test-zone fluid is constant and can be quantifled by a single measurement of fluid withdrawn from the test zone vs test zone pressure drop during withdrawal. A value of speciflc storage calculated using 1 iterature values for halite and and brine compressibilities may not be correct. Recent improvements in the measurement of permeability involve combining a constant-pressure flow test and a shut-in test to directly infer a value of specific storage. However, the improved interpretive technlque was used only on permeability tests SCP01, S1P73-B, C1X10, L4P52-A and L4P51-B. For the remaining permeability tests, what is in reality obtained is a value of permeablifty given an 
assumed value of specific atorage. Sensitivity calculations have shown that our inferred permeability values may range over one order of magnitude as our assumed values of specific storage range over three orders of magnitude. (Beauheim et al, 1990; Beauheim et a], 1992) Inasmuch as our assumed values of specific storage do rot range over more than three orders of magnitude, we estimate our uncertainty in permeability to be about an order of magnitude.

other assumptions in analysis of permeabllity tests include the assumption that gas dissolved in formation brine does not significantly affect the permeability interpretation and that signiflcant amounts of free gas are not present in the formation. In numerous permeability tests, gas was observed to bubble from the formation shortly after the test zone was drilled. A sensitivity analysis is planned for FY93 in which the effect of these phenomena on permeability interpretation will be investigated. For the RCRA recommendations, Rick Beauheim, who has been conducting interpretations of permeability tests, provided the (subjective) input that resulted in an order of magnitude confidence in interpreted permeability values.

Uncertainties in the interpretation of brine-inflow tests are due to (a) scatter in the brine-inflow data and (b) the use of a onedimensional model which neglects loss of fluld to the surface of the excavation and assumes a uniform pore pressure unaffected by the excavation. In a one-dimensional data analysis by McTigue (1992), it was found that the uncertainties in the inferred values of diffusivity due to data scatter could be substantial. Uncertainties in inferred values of permeabllity may be smaller. (See Table 2.) In addition, recent analyses (Gelbard, 1992) indicate that the use of a one-dimensional model may introduce significant errors in the interpretation of diffusivity and permeability from brine-inflow data.

\section{Rationale for Formulating Permeability Distributions}

Table 3 represents a current (as of $1 / 5 / 92$ ) compilation of interpreted values of permeability and formation pressure from the Permeability Testing Program, the Small-scale Brine Inflow Program and Room $Q$. For the 1992 RCRA PA calculations, interpreted values of permeability in Table 3 were classifled according to the regional map shown in Figure 1.

The disturbed rock zone is poorly defined. For these recommendations, test zones were classifled as being in the disturbed rock zone if the zone could sustaln little or no formation pressure and if the permeabllity of the zone was clearly higher than expected in competent rock.

The tests for which a reasonable pressure could be sustained in the test zone, but the pressure was not high enough to approach our (subjective) estimate of the far field pressure, were classified as being in a "depressurized" zone. The "depressurized zone" is 
hypothesized as having experienced some hydraulic depressurization and possibly some elastic stress relief due to the excavation, but probably no irreversible rock damage and large permeablitity

changes. Clearly, the depressurized zone extent will be different in higher permeability layers, such as the Marker Beds, than in lower permeability layers, such as pure halite. It is important to note that the depressurized zone is not a disturbed rock zone; the data from the depressurized zones do not support the hypothesis that the permeability, and the interconnected porosity, are greatly different in the depressurized zones from their far fleld values.

The latter classifications of test zones are subjective and will be examined in more detail as the Fluid Flow and Transport Department improves interpretation techniques and understanding of the rock matrix.

For the tests in Table 3, other than the Room $Q$ tests, the disturbed rock zone, if in fact it has a clear boundary and if it has a significant extent, was hypothesized to extend about one meter from the excavation into the formation. The boundary of the depressurized zone in the Marker Beds was hypothesized to be approximately 10 meters from the excavation. These hypotheses formed the basis for the geometrical treatment of the excavation suggested in Figure 1. Detailed repository depressurization calculations are planned for FY93.

The probability distributions recommended for the PA calculations were formulated so as to reflect the true range of scientific uncertainty in the parameter values supplied, including uncertainty due to measurement error and uncertainty due to interpretation ambiguities. As mentioned above, an order of magnitude uncertainty in the interpreted value of permeability was used as a rule of thumb for creating recommended probability distributions.

Al1. measurements of permeability were given equal weight, except those values derived from brine inflow measurements in 36" diameter holes in Room D. Those tests were considered flawed and deleted from the 1 ist because of the uncertain history of the excavation surrounding the test zone (Finley, 1992).

The hypothesis that permeabilities in the salado Formation are heterogeneous is given much weight in the Fluid Flow and Transport Department. The use of a single uniform value for all halite and argillaceous halite regions, and a different uniform value for all marker beds implies that the permeability values used in the PA calculaticns should be "effective" values that are rigorously derived frum our measurements. A systematic approach for defining such an "effective" value has not yet been outlined, but will be investigated in FY93. This aspect of formulating the distribution was ignored for these recommendations.

Given the assumptions and difficulties outlined above, differential probability distributions were formed by marking the locations 
along a permeability axis of the results of the tests in Table 3 . The number of tests in each $\log _{10}$ interval were used to indicate the relative probability that the true value lay in that interval. Cumulative probability distributions listed in Table 1 can be formulated from the differential probability distributions in Figures 2-8. Test results that were "Too low to measure" were assigned an equal probability of lying between a true 0 value and $1.0 \times 10^{-24} \mathrm{~m}^{2}$ Thus, the abscissa of Figure 2 is logarithmic between $10^{-24}$ and $10^{-21}$ and 1 inear between 0 and $10^{-24}$.

\section{Rationale for Formulating Pore Pressure Distributions}

The measurement of test-zone pore pressure is straightforward and is only accomplished in the Permeability Testing program and the Room $Q$ permeability tests. If, during a pressure build-up test or pulse-withdrawal test, the pressure reaches a steady state pressure, that pressure is interpreted as the formation pore pressure at the location of the test zone. If a steady-state pressure is not reached before the test is terminated, some technique must be used to extrapolate the formation pore pressure from the shape of the pressure-vs-time curve.

For the tests listed in Table 3, all pressures 1 isted are measured or estimated values of formation pore pressure. The far field formation pore pressures measured in the anhydrite layers yield a fairly consistent measurement of $12.5+-0.1 \mathrm{MPa}$. It is not understood why the pore pressure measured in the single halite far field test is significantly lower than those reached in the anhydrite far field. Possibilities include: (a) The regions in the halite that have non-zero permeability are not interconnected with higher pressure regions such as the anhydrite layers; (b) the regions in the halite that have non-zero permeability have not reached pressure equilibrium with the anhydrite layers; or (c) pore dilation (and accompanying depressurization) in response to excavation and/or drilling affects halite to a greater distance than anhydrite.

Based on current measurements, it cannot be ruled out that substantial regions of the salado Formation will be at significantly lower initial pore pressure than the anhydrite layers. Thus it was recommended that the performance assessment calculations include this possibility in the RCRA calculations.

Since the effect of excavation on the formation is still poorly understood, from a hydrological viewpoint, it is uncertain that tests belleved to be in the far field are indeed in the far field. It was recommended that the halite pore pressure reflect the single value measured, $9.5 \mathrm{MPa}$, with an uncertainty of $0.5 \mathrm{MPa}$ and the anhydrite pore pressure reflect the average value measured, 12.5 $\mathrm{MPa}$, also with an uncertainty of $0.5 \mathrm{MPa}$. It is recognized that this recommendation is not consistent with the equilibrium, continuum assumptions implicit in the PA and the 6119 repository scale modeling. (The assumption of formation hydraulic equilibrium 
can be tested using existing models and assumed values of halite and anhydrite permeability. Such a calculation may be performed by Department 6119 in the future.)

In order to reproduce some of the effects of depressurization of the salado Formation that would have occurred during the disposal phase of the repository, several additional recommendations were made concerning the initial conditions for the PA calculations: All disturbed zones, except for MB 138, should be fully saturated but at zero initial pore pressure. Because of its distance from the excavation MB 138 could remain slightly pressurized at the start of the disposal phase. Thus pore pressures in MB 138 should be sampled from an even probability distribution from 0 to $4 \mathrm{MPa}$. In the "depressurized regions" of both hallte and anhydrite the pressures should vary smoothly between the values of the surrounding formations. For example, the pressure below MB 139 should rise smoothly from 0 in the disturbed zone to the value assumed for the far field at distances of 11 or more meters from MB 139. Specific recommendations for initial pore pressures are included in Table 3 for each of the zones described in Figure 1.

\section{Afterthoughts and Comments on the Effect of Data Recommendations on RCRA Caloulations.}

Communications with the PA Department subsequent to making the recommendations outlined above have revealed that some of the assumptions outlined above concerning the PA model were not correct. An important aspect of the current PA model for the Salado Formation is its inability to simulate pressure-induced fracturing in the anhydrite layers, a phenomenon that has been experimentally demonstrated at the WIPP. The phenomenon may enhance the migration of gas into the formation as the gas pressure in the repository builds up. Thus it is possible that the current PA model underpredicts lateral gas migration.

Finally, the recommendations of the Fluid Flow and Transport Department were not fully implemented in the RCRA compliance calculations, because of insufficient time to eliminate the inconsistencies between the PA modeling approach and the Department 6119 recommendations. 
References:

Beauheim, R. L., G. J. Saulnier, Jr. and John D. Avis. 1990. Interpretation of Brine-permeability Tests of the salado Formation at the waste Isolation pllot plant site: First Interim Report. SAND90-0083. Albuquerque, NM: Sandia National Laboratories.

Beauheim, R. L., T. F. Dale, M. D. Fort, R. M. Roberts and W. A stensrud. 1992. Hydraulio Testing of 8alado Formation Evaporites at the waste Isolation pilot plant site: Becond Interpretive Report. SAND92-0533. Albuquerque, NM: Sandia National Laboratories.

Gelbard, F. 1992. A Two-Dimensional Model for Brine Flow to a Borehole in a Disturbed Rook zone. SAND92-1303. Albuquerque, NM: Sandia National Laboratorles.

MCTlgue, D. F. 1992. Permeability and Hydraulio Diffusivity of WIPP Repository salt Inferred from small-soale Brine Inflow Experiments. SAND92- . Albuquerque, NM: Sandia National Laboratories. 
Table 1. Recommended Cumulative probablitty Distributions for formation permeability $\left(\mathrm{m}^{2}\right)$, derived from

$$
\text { Figures 2-8. }
$$

Halite Far Field: Zone A

\begin{tabular}{|l|l|} 
Permeability $\left(\mathrm{m}^{2}\right)$ & Cumulative probability \\
\hline 0.0 & 0.00 \\
$1.0 \times 10.24$ & 0.57 \\
$1.0 \times 10.23$ & 0.71 \\
$1.0 \times 10.22$ & 0.86 \\
$1.0 \times 10.21$ & 1.00 \\
\hline
\end{tabular}

Halite Depressurized Zone: Zones B and C

Permeability $\left(\mathrm{m}^{2}\right) \quad$ Cumulative probability

\begin{tabular}{|l|l|}
\hline $1.0 \times 10.22$ & 0.00 \\
$1.0 \times 10.21$ & 0.44 \\
$1.0 \times 10.20$ & 0.94 \\
$1.0 \times 10.19$ & 1.00 \\
\hline
\end{tabular}

Halite Disturbed Zone: zones $D$ and $E$

\begin{tabular}{|l|l|} 
Permeability $\left(\mathrm{m}^{2}\right)$ & \multicolumn{1}{c}{ Cumulative probability } \\
\hline $1.0 \times 10.18$ & 0.00 \\
$1.0 \times 10^{-13}$ & 1.00 \\
\hline
\end{tabular}


Table 1. (Cont Inued)

Anhydrite Far Fleld: zone F

\begin{tabular}{|l|l|} 
Permeability $\left(\mathrm{m}^{2}\right)$ & \multicolumn{1}{l}{ Cumulative probab1lity } \\
\hline $1.0 \times 10.20$ & 0.00 \\
$1.0 \times 10.19$ & 1.00 \\
\hline
\end{tabular}

Anhydrite Depressurized zone: zones $G$ and $H$

\begin{tabular}{|l|l|} 
Permeability $\left(\mathrm{m}^{2}\right)$ & Cumulative probab111ty \\
\hline $1.0 \times 10.21$ & 0.00 \\
$1.0 \times 10.20$ & 0.08 \\
$1.0 \times 10.19$ & 0.58 \\
$1.0 \times 10.18$ & 0.83 \\
$1.0 \times 10.17$ & 0.92 \\
$1.0 \times 10.16$ & 1.00 \\
\hline
\end{tabular}

Anhydrite Disturbed Zone: Zone $\mathrm{J}$

\begin{tabular}{|l|l|} 
Permeability $\left(\mathrm{m}^{2}\right)$ & Cumulative probability \\
\hline $1.0 \times 1.0 .18$ & 0.00 \\
$1.0 \times 10.17$ & 0.12 \\
$1.0 \times 10.16$ & 0.25 \\
$1.0 \times 10.15$ & 0.37 \\
$1.0 \times 10.14$ & 0.75 \\
$1.0 \times 10.13$ & 0.87 \\
$1.0 \times 10.12$ & 1.00 \\
\hline
\end{tabular}

Anhydrite Disturbed zone: zone I

\begin{tabular}{|l|l|} 
Permeability $\left(\mathrm{m}^{2}\right)$ & \multicolumn{1}{c}{ Cumulative probability } \\
\hline $1.0 \times 10.19$ & 0.00 \\
$1.0 \times 10.18$ & 1.00 \\
\hline
\end{tabular}


Table 2. Parameter Estimates from Borehole Experiments. This from information in Table 5 of an early draft of McTigue, 1992. The difference between the values from the early draft (this table) and the table in McTigue, 2992 is the use of a literature value and a WIPp-specific measured value, respectively, for brine compressibility in the data interpretation.

\begin{tabular}{|c|c|c|c|c|c|}
\hline $\begin{array}{l}\text { Horchole } \\
\text { H }\end{array}$ & Rock Type & $\begin{array}{l}\text { Permeability } \\
\text { (d) } P_{0=10 \mathrm{MPa}} \\
\left(\mathrm{m}^{2}\right)\end{array}$ & $\begin{array}{l}\text { Permeability } \\
\left(\text { (a) } P_{0}=5 \mathrm{MPa}\right. \\
\left(\mathrm{m}^{2}\right) \\
\end{array}$ & $\begin{array}{l}\text { Permeability } \\
\left(\omega P_{0}=01 M P_{a}\right. \\
\left(m^{2}\right)\end{array}$ & $\begin{array}{l}\text { Diffusivity } \\
\text { (m2/sec) }\end{array}$ \\
\hline DBTHO & Halite & $2.9 \mathrm{E}-224.18 \mathrm{E}-22$ & $5.8 \mathrm{E} \cdot 22 \mathrm{t} .36 \mathrm{E} \cdot 22$ & $2.9 \mathrm{E} \cdot 21 \pm .18 \mathrm{E} \cdot 21$ & $4.7 \mathrm{E}-11 \pm .78 \mathrm{E}-11$ \\
\hline DHTI & Halite & $1.11 .211 .09 \mathrm{E} \cdot 21$ & $2.3 E \cdot 21 \pm .18 E-21$ & $1.1 \mathrm{E} .20 \mathrm{t} 09 \mathrm{E} \cdot 20$ & $3.5 \mathrm{E} \cdot 9 \pm .63 \mathrm{E} .9$ \\
\hline UnT12 & Halite & $6.4 \mathrm{E}-22+72 \mathrm{E}-22$ & $1.3 \mathrm{E} \cdot 21 \mathrm{t} .14 \mathrm{E} \cdot 21$ & $6.41: 211.72 \mathrm{E} \cdot 21$ & $10 \mathrm{E}-8 \pm .65 \mathrm{E}-8$ \\
\hline DHTI3 & Ilalite & $1.7 \mathrm{E}=221.26 \mathrm{E}-22$ & $3.4 \mathrm{E} \cdot 221.32 \mathrm{E} \cdot 22$ & $1.71:-21 \pm .26 \mathrm{E} \cdot 21$ & $5.9 \mathrm{E}-11 \pm .2 .3 \mathrm{E}-11$ \\
\hline DIITIAA & Ilalite & $7.81 \div 221.2 .41 .22$ & $1.6 \mathrm{E} .21 \mathrm{t} .48 \mathrm{E}-21$ & $7.8 \mathrm{E} \cdot 21 \pm .2 .4 \mathrm{E} \cdot 21$ & $2.8 \mathrm{E} \cdot 8 \pm 4.6 \mathrm{E} \cdot 8$ \\
\hline DBTIAB & Ilalite & $2.2 \mathrm{E}+21+28 \mathrm{E} .21$ & $4.5 \mathrm{E} 21+.56 \mathrm{E} \cdot 21$ & $2.2 \mathrm{E}-21 \pm .28 \mathrm{E}-21$ & $4.3 E-8 \pm 33 \mathrm{E} \cdot 8$ \\
\hline DHTISA & Halite & $3.2 \mathrm{E} \cdot 22 \mathrm{.} .55 \mathrm{E}-22$ & $6.4 \mathrm{E} \cdot 22 \pm 1.1 \mathrm{E} \cdot 22$ & $3.2 \mathrm{E} \cdot 21 \pm .55 \mathrm{I} .-21$ & $1.8 \mathrm{E} \cdot 101.86 \mathrm{E} \cdot 10$ \\
\hline DHTISB & Halite & $1.8 \mathrm{E} \cdot 221.59 \mathrm{E} \cdot 22$ & $36 \mathrm{E} \times 22 \pm 1.1 \mathrm{E} \cdot 22$ & $1.8 \mathrm{E} \cdot 21 \pm .59 \mathrm{E} \cdot 21$ & $1.3 \mathrm{E} \cdot 10+1.2 \mathrm{E} \cdot 10$ \\
\hline LABOI & Iladite & $.676 .221 .43 E 22$ & $1.3 \mathrm{E} \cdot 221.86 \mathrm{E} \cdot 22$ & $.67 \mathrm{E} \cdot 21 \pm .43 \mathrm{E} \cdot 21$ & $5.8 \mathrm{E} \cdot 11 \pm 9.1 \mathrm{E} \cdot 11$ \\
\hline DNT"3IA & Hulite & $9.01: 22+241: 22$ & $1.8 \mathrm{E} 21 \pm .48 \mathrm{E} .21$ & $9.0 \mathrm{E}-21 \pm .2 .4 \mathrm{E} \cdot 21$ & $1.27 \mathrm{E} \cdot 10 \pm .22 \mathrm{E} \cdot 11$ \\
\hline QPBO1 *1 & Anliydrile & $4.8 E-2.1+3 E .21$ & $9.6 \mathrm{E} \cdot 21+06 \mathrm{E} 21$ & $4.8 \mathrm{E} \cdot 20 \pm .3 \mathrm{E} \cdot 20$ & $1.1 \mathrm{E} \cdot 8 \pm .34 \mathrm{E}-8$ \\
\hline $\mathrm{QPBO}+1$ & Anliydrite & $8.2 \mathrm{E}-201.03 \mathrm{E} .20$ & $1.6 \mathrm{E}-19 t .006 \mathrm{E}-19$ & $8.2 \mathrm{E}-19 \pm .03 \mathrm{E}-19$ & $1.2 \mathrm{E} \cdot 9 \pm .014 \mathrm{E} \cdot 9$ \\
\hline QPHO3 * & Anliydrite & a.81:2111.51:21 & $9.61 \times 21 \pm .3121$ & $4.8 \mathrm{E} \cdot 20+1.5 \mathrm{E} \cdot 20$ & $6.4 \mathrm{E} .7 \pm 18.8 \mathrm{E} .7^{\circ}$ \\
\hline
\end{tabular}

* The lower limit of these uncertainty bounds should be assumed to be zero.

- I for all of these txorehole tests, the leng:th of the productive unit was assumed to be equal to the avenge thickness of Marker Bed 139 (3.fecl). 


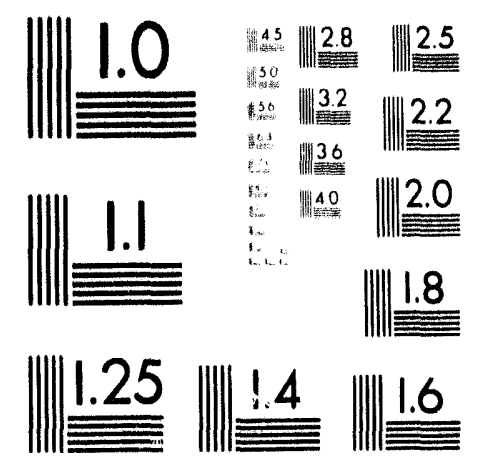



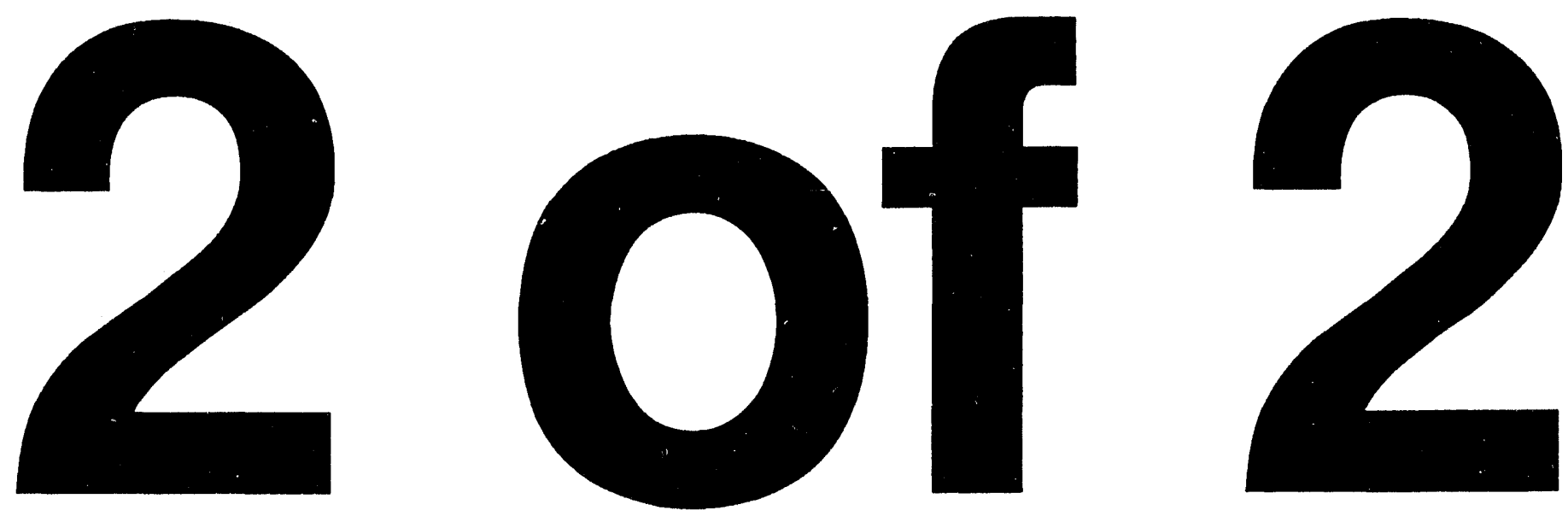
Table 3: Compilation of Interpreted Values of Permeability, $1 / 5 / 92$. Zones are referenced to Figure 1 .

\section{Zone Test Measured Permeability Pressure(MPA)}

\section{A. HALITE FAR FIELD}

$\begin{array}{ll}\text { QPP12 pre-mineby } \\ \\ \text { C2HO3 } & 6.8 \times 10^{-22} \mathrm{~m}^{2} \\ \text { SCP01 GZ } & \text { Too low to measure } \\ \text { QPP05 } & \text { Too low to measure } \\ \text { QPP02 } & \text { Too low to measure }\end{array}$

9.5

not measureable

not measureable

not measureable

not measureable

B. HALITE DEPRESSURIZED ZONE

$\begin{array}{lcc}\text { S1P72-A-GZ } & \begin{array}{c}8.6 \times 10^{-22} \mathrm{~m}^{2} \\ \text { QPP21 post } \\ \text { mineby } \\ 1.9 \times 10^{-22} \mathrm{~m}^{2}\end{array} \\ \text { C2H01-B } & 5.3 \times 10^{-21} \mathrm{~m}^{2} & 5.1 \\ \text { C2H01-B-GZ } & 1.9 \times 10^{-21} \mathrm{~m}^{2} & 4.8 \\ \text { L4P51-A } & 6.1 \times 10^{-21} \mathrm{~m}^{2} & 3.1 \\ \text { S0P01 } & 8.3 \times 10^{-21} \mathrm{~m}^{2} & 2.1 \\ \text { S1P71-A } & 6.1 \times 10^{-20} \mathrm{~m}^{2} & 4.4 \\ \text { QPP15 } & 2.2 \times 10^{-21} \mathrm{~m}^{2} & 2.9 \\ \text { DBT10 } & 5.8 \times 10^{-22} \mathrm{~m}^{2} & 3.1 \\ \text { DBT11 } & 2.3 \times 10-21 \mathrm{~m}^{2} & 5.0 \text { assumed } \\ \text { DBT12 } & 1.3 \times 10^{-21} \mathrm{~m}^{2} & 5.0 \text { assumed } \\ \text { DBT13 } & 3.4 \times 10^{-22} \mathrm{~m}^{2} & 5.0 \text { assumed } \\ \text { DBT14A/B } & 3.1 \times 10^{-21} \mathrm{~m}^{2} & 5.0 \text { assumed } \\ \text { DBT15A/B } & 5.0 \times 10^{-22} \mathrm{~m}^{2} & 5.0 \text { assumed } \\ \text { L4B01 } & 1.3 \times 10-22 \mathrm{~m}^{2} & 5.0 \text { assumed } \\ \text { DBT31A } & \text { not used } & 5.0 \text { assumed } \\ \text { QPP12 } & 4.4 \times 10^{-22} \mathrm{~m}^{2} & \end{array}$

\section{HALITE DEPRESSURED ZONE}

Same as region B for permeability; linearly increase pressure from region $\mathrm{E}$ to Region A pressure.

\section{HALITE DISTURBED ROCK ZONE}

$\begin{array}{lll}\text { C2H01-A } & 2.7 \times 10^{-18} \mathrm{~m}^{2} & 0.5 \\ \text { C2H01-A-GZ } & \text { unmeasurable } & 0.0 \\ \text { S1P73-B-GZ } & \text { unmeasureable } & 2.5\end{array}$

\section{E. HALITE DISTURBED ROCK ZONE}

Same as region D for permeability; linearly increase pressure from region I pressure to region C pressure. 
Table 3: Compilation of Interpreted Values of Permeability, $1 / 5 / 92$. Zones are referenced to Figure 1.

\section{Zone Test Measured Permeability Pressure(MPA)}

\section{A. HALITE FAR FIELD}

QPP12 pre-mineby

$\begin{array}{lll} & 6.8 \times 10^{-22} \mathrm{~m}^{2} & 9.5 \\ \text { C2HO3 } & \text { ToO low to measure } & \text { not measureable } \\ \text { SCPO1 GZ } & \text { ToO low to measure } & \text { not measureable } \\ \text { QPPO5 } & \text { ToO low to measure } & \text { not measureable } \\ \text { QPPO2 } & \text { ToO low to measure } & \text { not measureable }\end{array}$

\section{B. HALITE DEPRESSURIZED ZONE}

\begin{tabular}{|c|c|c|c|}
\hline $\begin{array}{l}\text { S1P72-A-GZ } \\
\text { QPP21 post }\end{array}$ & $\begin{array}{lll}8.6 \times & 10^{-22} \mathrm{~m}^{2} \\
\text { mineby }\end{array}$ & 5.1 & \\
\hline & $1.9 \times 10^{-22} \mathrm{~m}^{2}$ & 4.8 & \\
\hline $\mathrm{C} 2 \mathrm{HO} 1-\mathrm{B}$ & $5.3 \times 10^{-21} \mathrm{~m}^{2}$ & 3.1 & \\
\hline $\mathrm{C} 2 \mathrm{HOI}-\mathrm{B}-\mathrm{GZ}$ & $1.9 \times 10^{-21} \mathrm{~m}^{2}$ & 4.1 & \\
\hline L4P51-A & $6.1 \times 10^{-21} \mathrm{~m}^{2}$ & 2.7 & \\
\hline SOPOI & $8.3 \times 10^{-21} \mathrm{~m}^{2}$ & 4.4 & \\
\hline S1P71-A & $6.1 \times 10^{-20} \mathrm{~m}^{2}$ & 2.9 & \\
\hline QPP15 & $2.2 \times 10^{-21} \mathrm{~m}^{2}$ & 3.1 & \\
\hline DBT10 & $5.8 \times 10^{-22} \mathrm{~m}^{2}$ & 5.0 & assumed \\
\hline DBT11 & $2.3 \times 10-21 \mathrm{~m}^{2}$ & 5.0 & assumed \\
\hline DBT12 & $1.3 \times 10^{-21} \mathrm{~m}^{2}$ & 5.0 & assume \\
\hline DBT13 & $3.4 \times 10^{-22} \mathrm{~m}^{2}$ & 5.0 & assume \\
\hline $\mathrm{DBT} 14 \mathrm{~A} / \mathrm{B}$ & $3.1 \times 10^{-21} \mathrm{~m}^{2}$ & 5.0 & assume \\
\hline $\mathrm{DBT} 15 \mathrm{~A} / \mathrm{B}$ & $5.0 \times 10^{-22} \mathrm{~m}^{2}$ & 5.0 & assumed \\
\hline L4B01 & $1.3 \times 10-22 \mathrm{~m}^{2}$ & 5.0 & assume \\
\hline DBT $31 \mathrm{~A}$ & not used & & \\
\hline QPP12 & $4.4 \times 10^{-22} \mathrm{~m}^{2}$ & 9.4 & \\
\hline
\end{tabular}

\section{HALITE DEPRESSURED ZONE}

Same as region B for permeability; linearly increase pressure from region $E$ to Region A pressure.

\section{HALITE DISTURBED ROCR ZONE}

$\begin{array}{lll}\text { C2HO1-A } & 2.7 \times 10^{-18} \mathrm{~m}^{2} & 0.5 \\ \text { C2HO1-A-GZ } & \text { unmeasureable } & 0.0 \\ \text { S1P73-B-GZ } & \text { unmeasureable } & 2.5\end{array}$

\section{E. HALITE DISTURBED ROCR ZONE}

Same as region D for permeability; linearly increase pressure from region I pressure to region $C$ pressure. 
Table 3. (Coirinued)

F. ANHYDRITE FAR FIELD (greater than $10 \mathrm{~m}$ from excavation) SCPO1 MB 139 $3.0 \times 10^{-20} \mathrm{~m}^{2}$

QPP13 pre-mineby MB 139 $4.1 \times 10.20 \mathrm{~m}^{2}$

QPP03 pre mineby clay b

$$
4.4 \times 10^{-20} \mathrm{~m}^{2} \quad 12.6
$$

12.4

12.5

G. ANHYDRITE DEPRESSURIZED ZONE (less than 10 meters from excavation)

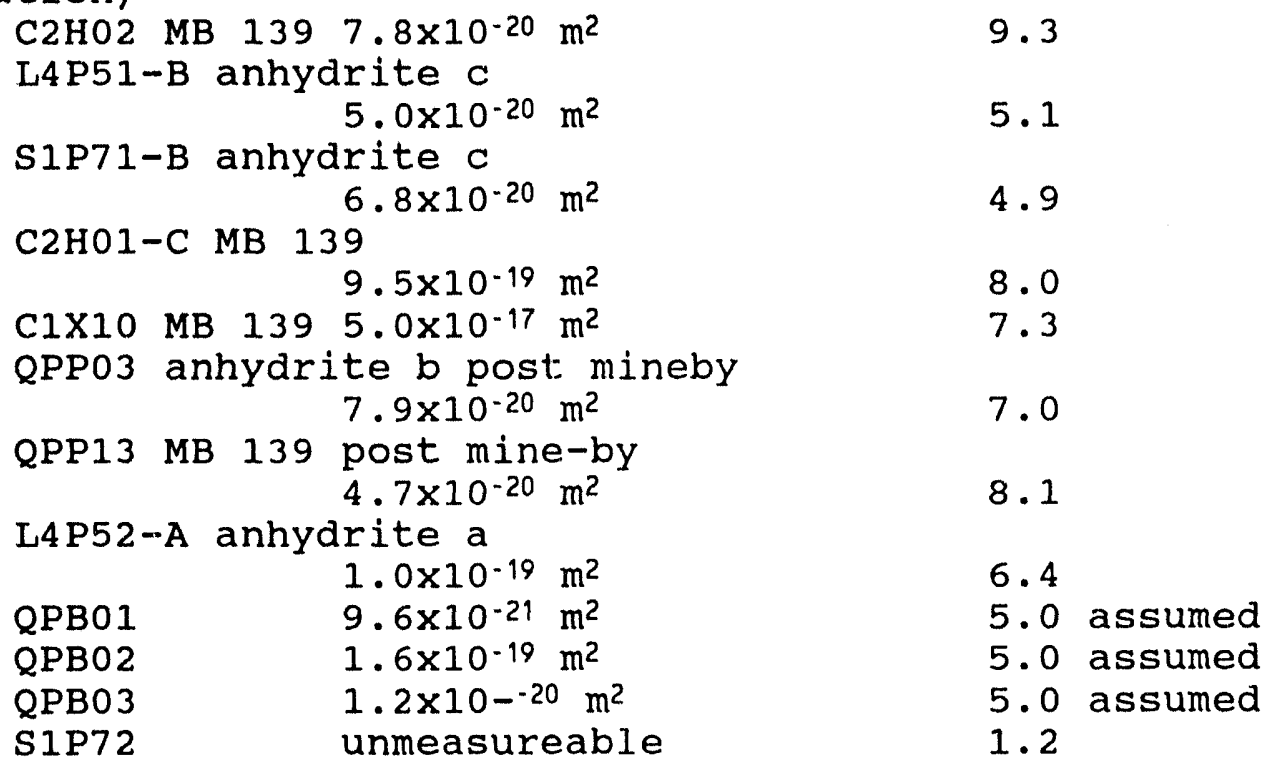

H. ANHYDRITE DEPRESSURIZED ZONE

Same permeability as region G; linearly increase pressure from region $I$ or $J$ pressure to region $F$ pressure.

I. ANHYDRITE DISTURBED ROCK ZONE (138)

S1P73-B MB 138

$2.9 \times 10^{-19} \mathrm{~m}^{2} \quad 4.5$

J. ANHYDRITE DISTURBED ROCK ZONE
SOPO1 GZ
$5.7 \times 10^{-18} \mathrm{~m}^{2}$
0.5
S1P73-A
too high to measure; estimated at $10.15 \mathrm{~m}^{2}$
0.0
S1P73-A-GZ too high to measure; estimated at $10^{-15} \mathrm{~m}^{2}$ 0.0
S1P71-A-GZ too high to measure; estimated at $10^{-14} \mathrm{~m}^{2}$ 0.0
L4P51-A-GZ too high to measure; estimated at $10^{-15} \mathrm{~m}^{2}$
Crawley
1.6 to $3.2 \times 10^{-13} \mathrm{~m}^{2}$
0.3
???

\section{A-15}


YET TO BE INTERPRETED

QPPO 1

QPPO 4

QPP11

QPP14

QPP2 2

QPP2 3

QPP2 4

QPP2 5

A-16 


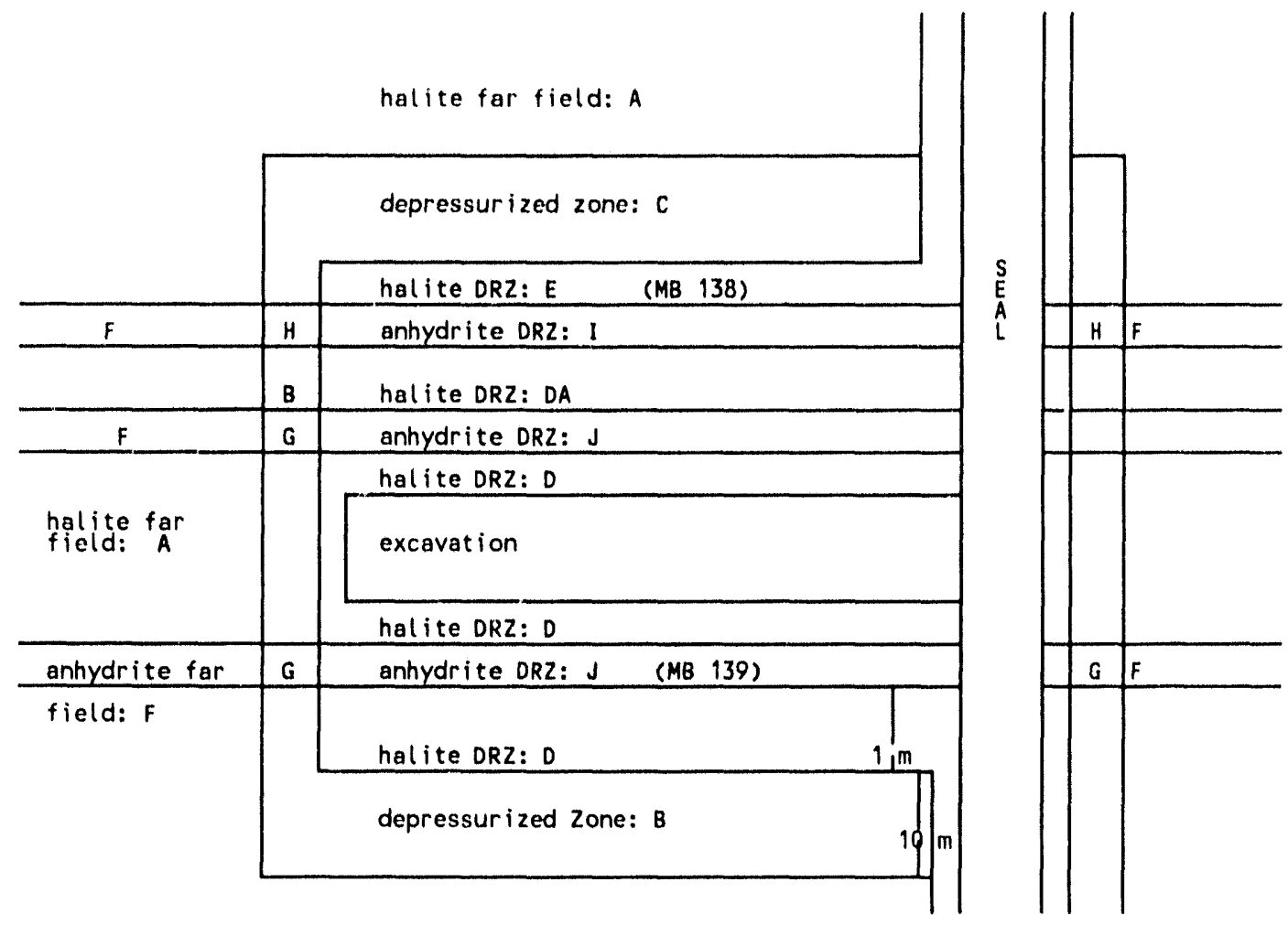

Figure 1: Schematic for assigning flow properties to Salado Formation (Not to Scale!!!!) 


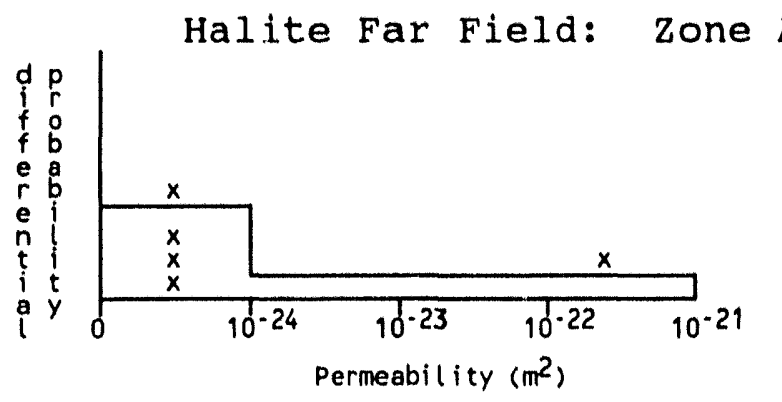

Figure 2 .

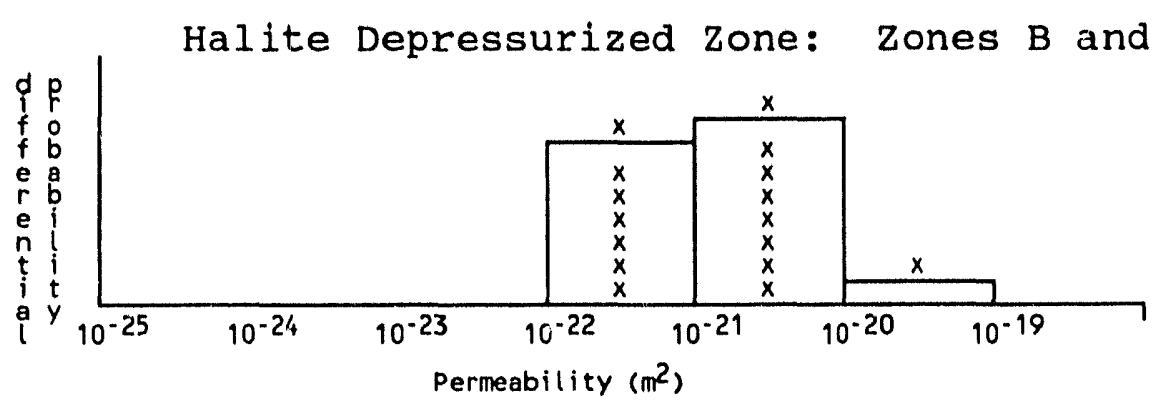

Figure 3 .

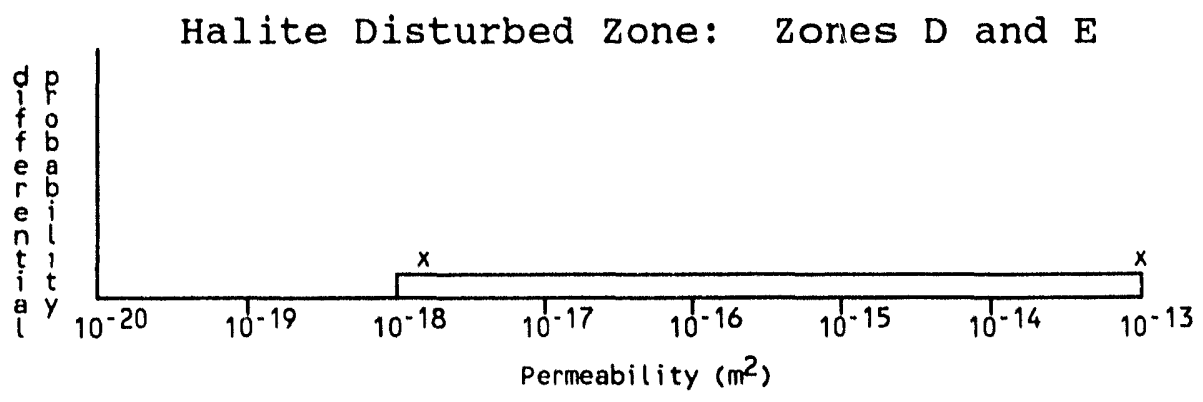

Figure 4 . 


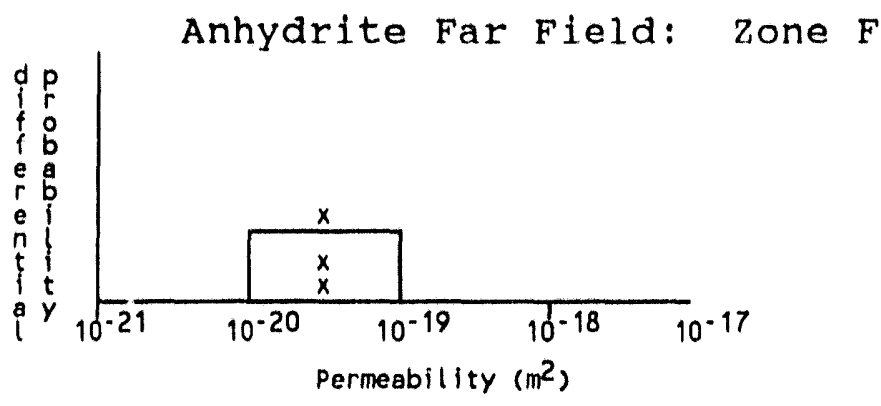

Figure 5 .

Anhydrite Depressurized Zone: Zones $\mathrm{G}$ and $\mathrm{H}$

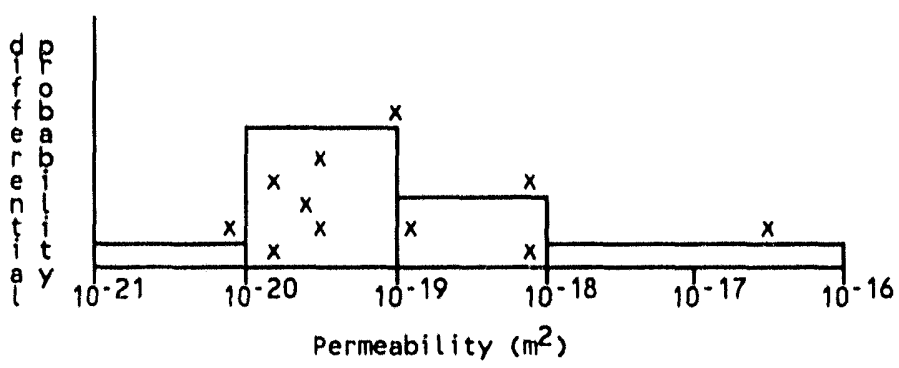

Figure 6 .

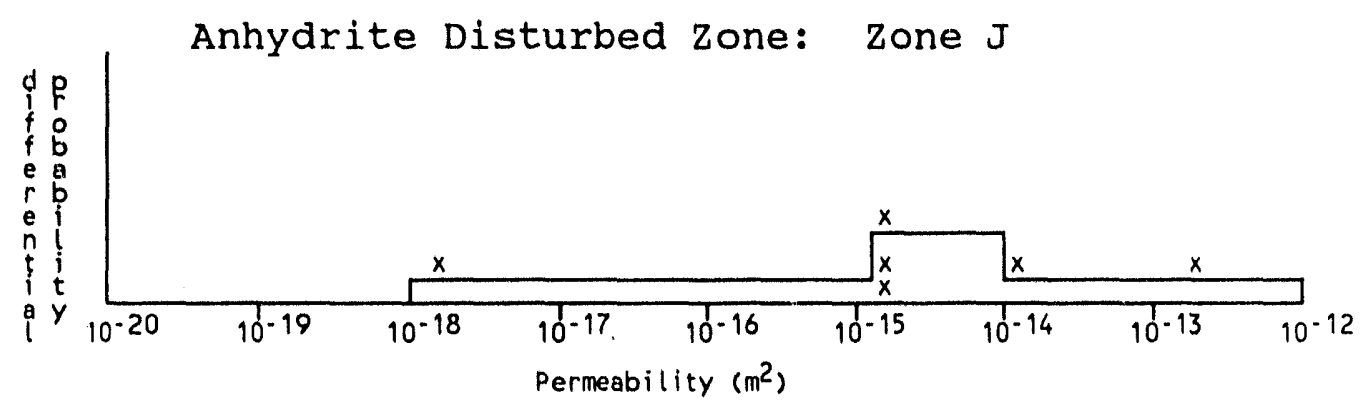

Figure 7 .

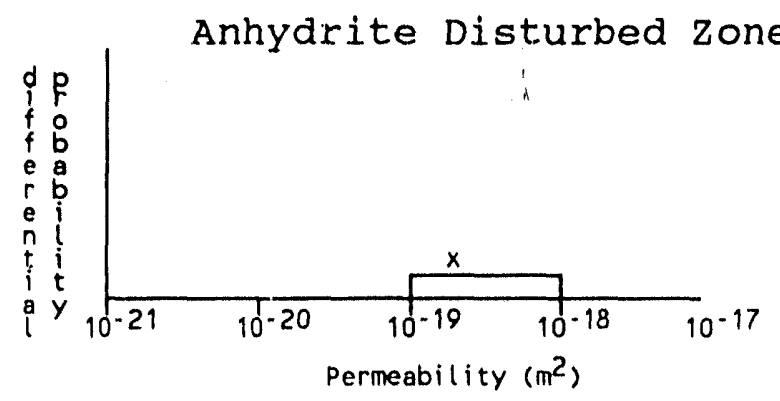

Figure 8 . 


\section{DISTRIBUTION}

\section{Federal Agencies}

US Department of Energy (6)

Office of Civilian Radioactive Waste Management

Attn: Deputy Director, RW-2

Associate Director, RW-10/50

Office of Program and

Resources Management

Office of Contract Business

Management

Director, Analysis and

Verification Division, RW-22

Associate Director, RW-30

Office of Systems and

Compliance

Associate Director, RW-40

Office of Storage and

Transportation

Director, RW-4/5

Office of Strategic Planning

and International Programs

Office of External Relations

Forrestal Building

Washington, DC 20585

US Department of Energy

Albuquerque Operations office

Attn: National Atomic Museum Library PO Box 5400

Albuquerque, NM 87185-5400

US Department of Energy (4)

WIPP Project Integration office

Attn: W.J. Arthur III

L.W. Gage

P.J. Higgins

D.A. Olona

PO Box 5400

Albuquerque, NM 87115-5400

US Department of Energy (3)

WIPP Project Integration Satellite

office

Attn:

R. Batra

R. Becker

B. B1 iss

Po Box 3090, Mail Stop 525

Carlsbad, NM 88221-3090

US Department of Energy (3)

WIPP Project Site office (Carlsbad)

Attn: V. Daub

$\mathrm{J}$. Lippis

J.A. Mewhinney

PO Box 3090

Car1sbad, NM 88221-3090
US Department of Energy

Research \& Waste Management Division Attn: Director

PO Box E.

Oak Ridge, TN 37831

US Department of Energy

Attn: E. Young

Room E-178

GAO/RCED/GTN

Washington, DC 20545

US Department of Energy

Office of Environmental Restoration and Waste Management

Attn: J. Lytle, EM-30, Trevion 11

Washington, DC 20585-0002

US Department of Energy (3)

Office of Environmental Restoration and Waste Management

Attn: M. Frei, EM-34, Trevion II

Washington, DC 20585-0002

US Department of Energy

Office of Environmental Restoration and Waste Management

Attn: S. Schneider, EM-342, Trevion II

Washington, DC 20585-0002

US Department of Energy (2)

Office of Environinent, Safety and Health

Attn: C. Borgstrom, EH -25

R, Pelletier, EH-231

Washington, DC 20585

US Department of Energy (2)

Idaho Operations office

Fuel Processing and Waste

Management Division

785 DOE Place

Idaho Falls, ID 83402

US Environmental Protection Agency (2)

Radiation Protection Programs

Attn: M. Oge

ANR -460

Washington, DC 20460 
US Geological Survey (2)

Water Resources Division

Attn: R. Livingston

4501. Indian School NE

Sulte 200

Albuquerque, NM 87110

US Nuclear Regulatory Commission Division of Waste Management

Attn: H. Marson

Mail Stop 4-H-3

Washington, DC 20555

\section{Boards}

Defense Nuclear Facilities Safety

Board

Attn: D. Winters

625 Indlana Ave. NW, Sulte 700

Washington, DC 20004

Nuclear Waste Technical Review

Board (2)

Attn: Chairman

$$
\text { S.J.S. Parry }
$$

1100 Wilson Blvd. Suite 910

Arlington, VA 22209-2297

Advisory Committee on Nuclear

Waste

Nuclear Regulatory Commission

Attn: R. Major

7920 Norfolk Ave.

Bethesda, MD 20814

\section{State Agencies}

Environmental Evaluation Group (3)

Attn: Library

7007 Wyoming NE

suite F-2

Albuquerque, NM 87109

NM Bureau of Mines and Mineral

Resources

Socorro, NM 87801

NM Energy, Minerals, and Natural Resources Department

Attn: Library

2040 S. Pacheco

Santa Fe, NM 87505

NM Environinent Department (3)

Secretary of the Environment

Attn: J. Espinosa

1190 St. Francis Drive

Santa Fe, NM 87503-0968
NM Environment Department

WIPP Project Site

Attn: P. McCasland

PO Box 3090

Carlsbad, NM 88221

\section{Laboratories/Corporations}

Battelle Pacific Northwest

Laboratories

Attn: R.E. Westerman, MSIN P8-44

Battelle Blvd.

Richland, WA 99352

INTERA InC.

Attn: J.F. Pickens

6850 Austin Center Blvd.

Suite 300

Austin, TX 78731

INTERA Inc.

Attn: W. Stensrud

PO Box 2123

Carlsbad, NM 88221

IT Corporation

Attn: R.F. McKinney

Regional office

5301 Central NE, Suite 700

Albuquerque, NM 87108

Los Alamos National Laboratory

Attn: B. Erdal, CNC-11

PO Box 1663

Los Alamos, NM 87544

RE/SPEC, Inc .

Attn: W. Coons

4775 Indian School NE

Suite 300

Albuquerque, NM 87110-3927

RE/SPEC, Inc, (2)

Attn: N.S. Brodsky

PO Box 725

J.L. Ratigan

Rapid City, SD 57709

Rock Physics Associates

Attn: J.D. We11s

4320 Stevens Creek Blvd. Ste. 282

San Jose, CA 95129

Southwest Research Institute (2)

Center for Nuclear Waste

Regulatory Analysis

Attn: P.K. Nair

6220 Culebra Road

San Antonio, TX 78228-0510 
SAIC

Attn: D.C. Royer

101 Convention Center Dr.

Las Vegas, NV 89109

SAIC

Attn: H.R. Pratt

10260 Campus Point Dr.

San Diego, CA 92121

SAIC (2)

Attn: M. Davis

J. Tollison

2109 Alr Park Rd. SE

Albuquerque, NM 87106

Tech Reps Inc. (4)

Attn: J. Chapman

C. Crawford

V. G1111land

T. Peterson

5000 Marble NE, Sulte 222

Albuquerque, NM 87110

TRW Environmental Safety Systems Attn: L. W11dman

2650 Park Tower Dr., Suite 1300

Vienna, VA 22180-7306

Westinghouse Electric Corporation (5)

Attn: Library

C. $\operatorname{Cox}$

L. Fitch

B. A. Howard

R. Kehrman

PO Box 2078

Carlsbad, NM 88221

Westinghouse-Savannah River

Technology Center (4)

Attn: N. Bibler

J.R. Harbour

M.J. Plodinec

G.G. Wicks

Aiken, SC 29802

\section{National Academy of Sciences, WIPP Panel}

Howard Adler

Oak Ridge Associated Universities

Medical Sciences Division

PO Box 117

Oak Ridge, TN 37831-0117

Ina Alterinan

Board on Radioactive

Waste Management, GF456

2101 Constitution Ave.

Washington, DC 20418
Fred $M$. Errisberger

250 Old MIll Road

Pltsburgh, PA 15238

John D. Bradehoeft

Western Reglon Hydrologist

Water Resources DIVIsion

US Geologlcal Survey (M/S 439)

345 Middlefleld Road

Menlo Park, CA 94025

Rodney C. Ewing

Department of Geology

University of New Mexico

Albuquerque, NM 87131

Charles Falrhurst, Chalrman

Department of $\mathrm{Cl}$. 11 and

Mineral Engineering

University of Minnesota

500 Pillsbury Dr, SE

MLnneapol1s, MN 55455.0220

B. John Garrick

PLG Incorporated

4590 MacArthur Blvd., Sulte 400

Newport Beach, CA 92660-2027

Leonard $F$. Konikow

US Geological Survey

431 National Center

Reston, VA 22092

Peter B. Myers

National Academy of Sciences

Board on Radioactive

Waste Management

2101 Constitution Ave.

Washington, DC 20418

Jeremiah O'Driscoll

Jody Incorporated

505 Valley Hill Drive

Atlanta, GA 30350

Christopher G. Whipple

Clement International

160 Spear St., Suite 1380

San Francisco, CA 94105

\section{Individuals}

P. Drez

8816 Cherry H111s RU. NE

Albuquerque, NM 87111 


\author{
D.W. Powers \\ Star Route Hox 8 / \\ Antlony, TX 19821

\section{Univerelties} \\ Unlveralty of Now Moxico \\ Grology Department \\ Attn: Library \\ Albuquerqua, NM 81131 \\ University of Washlugton \\ College of Ocenin \\ and Flahery Siloncos \\ Attu: G.R.lleath \\ 583 Henderson $1 / n \mid 1$ \\ Seattlo, WA 98195
}

\section{Llbraries}

Thomas Brannlgan Library

Attn: D. Dresp

$106 \mathrm{~W}$. Hadley St.

Las Cruces, NM 88001

Government Publlcatlons Department

ZImmerman Library

University of Now Moxico

Albuquerque, NM $8 / 131$

Hobbs Publle Llbrary

Attn: M. Lewls

$509 \mathrm{~N}$. Ship St.

Hobbs, NM 88248

New Mexico Junior College

Panne ll Libiary

Attn: R. Hill

Lovington Highway

Hobbs, NM 88240

New Mexico State Lithrary

Attn: N. MeCallan

325 Don Gaspar

Santa Fe, NM 87503

New Mexico Tech

Martin Speere Memorial Library

Campus Street

Socorro, NM 87810
Whel publir Heading Koom

Carlshad Roblle library

Atu: Director

$101 \mathrm{~s}$. Llalapunno st

Carlabal, NM H4290

\section{Forelon Addreseces}

studlecentrum Vour ketrmetelo

conte D'Pinergle Nuclealro

Attin: A. Bontie

SCK/CEN Honretang 200

B. 2,1001901 , HE:COILM

Atomle Herey of Canalla, Ind il)

Wiltentiell Roneatch Fintab.

Attil: B Coodwitl

M. Strvents

D. Wunlika

Plnowa, Manlloba, iANADA Rof 110

Francola chonovlor (2)

ANDKA

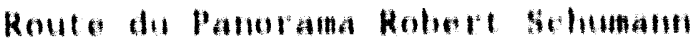

B. $P$, is

92266 Fontonay alts Rosos, Codos

FRANCF

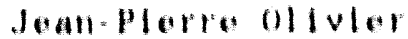

OfCD Nueloal binergy Agowicy

DI and Wante Matlagoment

38. Boulovalid Sueliet

$15016 \mathrm{PaI}^{\mathrm{L}} \mathrm{s}, \mathrm{FRNNCF}$

Claude Sombrot

Contre D'Btudes Nuclualros

Do la Valloo Klona

CEN/VAIRIIO

S.D.H.A. B.P. 1/1

30205 Bagnols-Sur-Cono, PRANCE

Gosellschate fur Reaktotalehothelt

(GRS) (2)

Attil: B. Baltos

W. Mullor

Schwortnorgasse 1

D. 5000 Cologno, GERMANY

Bundesanstalt fur Goowl soonschafion und Rohst of fe

Attn: $M$. Langer

Postfach $\$ 10$ 15;

3000 Hanover $\$ 1$, GBRMANY 
Bundesmintster fum fur Forschung und Technologie

Postach 200706

5300 Bonn 2, GERMANY

Institut fur Tieflagerung (2)

Attn: K. Kuhn

Theodor-Heuss-Strasse 4

D. 3300 Braunschwe $1 g$, GERMANY

Physlkalisch-Technlsche Bundesanstalt

Attn: P. Brenneke

Postach 3345

D. 3300 Braunschwe 18 , GERMANY

Shingo Tashiro

Japan Atomic Energy Research Inst.

Toka1-Mura, Ibarak1-Ken, 319-11

IAPAN

Netherlands Energy Research

Foundation ECN

Actn: L.H. Vons

3 Westerduinweg

PO Box 1

1755 ZG Petten, THE NETHERLANDS

Svensk Karnbransleforsorjning $A B$

Attn: F. Karlsson

Profect KBS

Karnbrans lesake rhet

Bo: 5864

10248 stockholm, SWEDEN

Nationale Genossenschaft für die Lagerung radloaktiver Abfälle (2)

Attn: S. Vomvoris

P. Zuidema

Hardstrasse 73

CH. 5430 Wettingen, SWITZERLAND

AEA Technology

Attn: J.H. Rees

D5W/29 Culham Laboratory

Abington, Oxfordshire OX14 3DB

UNITED KINGDOM

AEA Technology

Attn: W.R. Rodwell 1

$044 / A 31$ Winfrith Technical Centre

Dorchester, Dorset DT2 8DH

UNITED KINGDOM
AEA Technology

Attn: J.E. Tinson

B4244 Harwe11 Laboratory

Didcot, Oxfordshire OX11 ORA

UNITED KINGDOM

D.R. Knowles

British Nuclear Fuels, plc

Risley, Warrington, Cheshire WA3 6AS

1002607 UNITED KINGDOM

\section{Internal}

1502

J.C. Cummings

6000 D.L. Hartley

6115 R.L. Beauheim

6115 P.B. Davies

6116 D.J. Borns

6117 D.J. Holcomb

6117 D.H. Zeuch

6119 E.D. Gorham

6119 S.M. Howarth (15)

6119 Staff (14)

6121 J.R. Tillerson

6121 Staff (7)

6300 D.E. E11is

6302

6303

6303

6305

6305

6306

6342

6342

6343

6343

6345

6345

6347

6348

6348

6351

6352

6352

6352

7141 .

7151

$7613-2$

L.E. Shephard

S.Y. Pickering

W.D. Weart

S.A. Goldstein

A.R. Lappin

A.L. Stevens

D. R. Anderson

Staff (20)

$\mathrm{V}$. Harper-Slaboszewicz

Staff (2)

R.C. Lincoln

Staff (9)

D.R. Schafer

J.T. Holmes

Staff (4)

R.E. Thompson

D.P. Garber

S.E. Sharpton

WIPP Central Files (10)

Technical Library (5)

Technical Publications

Document Processing for

DOE/OSTI (10)

8523-2 Central Technical Files 

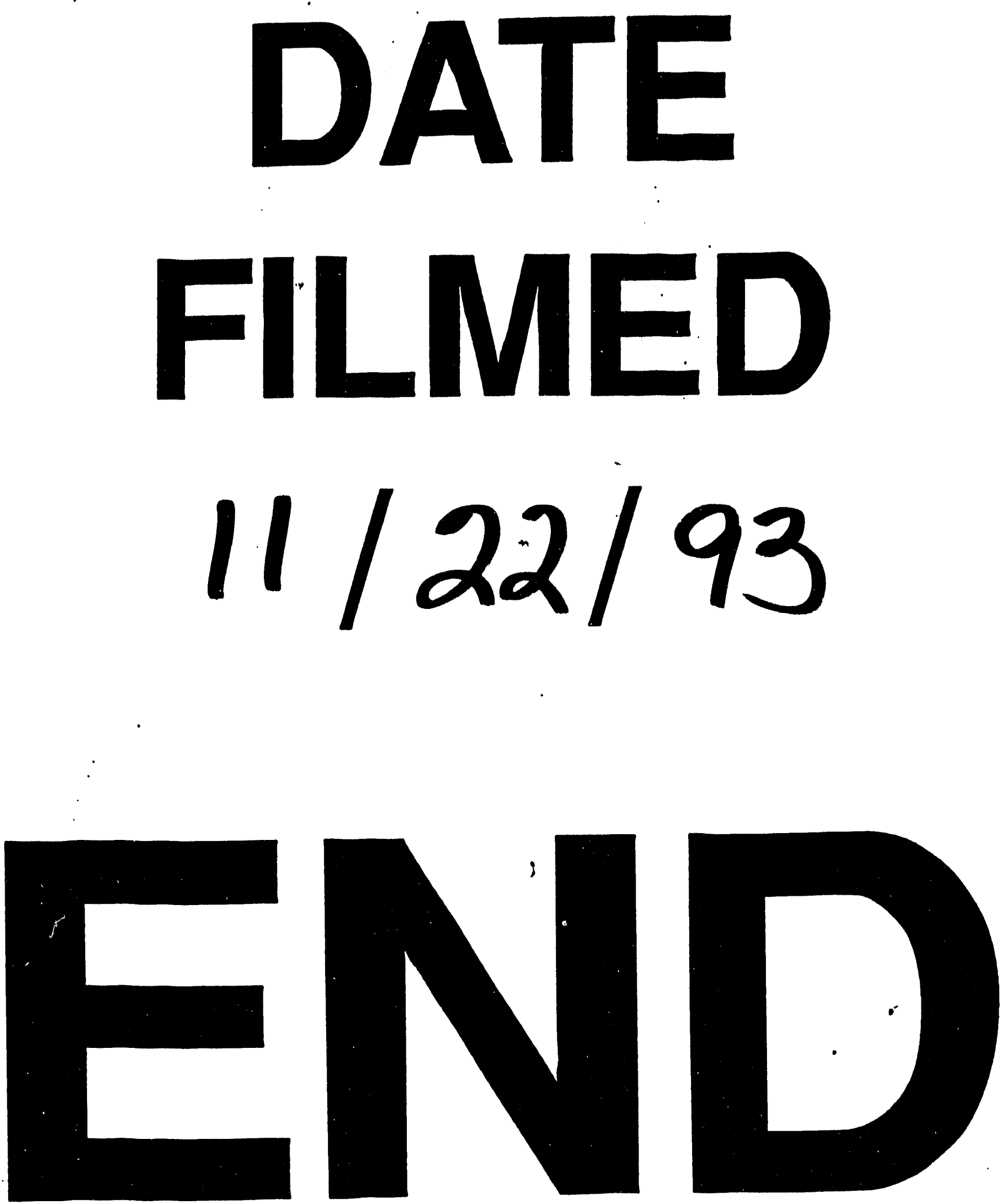


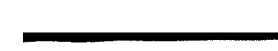

